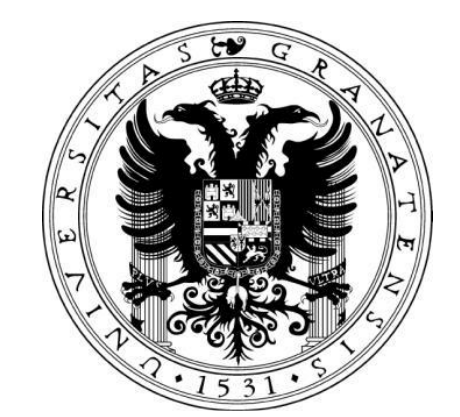

Universidad de Granada

\title{
ETNOMATEMÁTICA Y MULTICULTURALIDAD EN LA EDUCACIÓN BÁSICA EN CHILE. EL CASO DE LA ARITMÉTICA MAPUCHE
}

\author{
SONIA SALAS SALINAS
}

Tesis Fin de Máster

Programa de Máster en Didáctica de la Matemática

Departamento de Didáctica de la Matemática

Universidad de Granada

Granada, Septiembre 2014 


\section{ETNOMATEMÁTICA Y MULTICULTURALIDAD EN LA EDUCACIÓN BÁSICA EN CHILE. EL CASO DE LA ARITMÉTICA MAPUCHE}

Trabajo de fin de máster realizado bajo la dirección del doctor D. Juan Díaz Godino que presenta Sonia Salas Salinas para su evaluación por el Departamento de Didáctica de la Matemática de la Universidad de Granada.

Fdo.: Sonia Salas Salinas

$\mathrm{V}^{\mathrm{o}} \mathrm{B}^{\mathrm{o}}$

Juan D. Godino 


\section{RECONOCIMIENTOS:}

Esta investigación ha sido realizada en el Departamento de Didáctica de la Matemática de la Universidad de Granada, en el marco del proyecto de investigación EDU201231869, (Ministerio de Economía y Competitividad, España), y del Programa de Capital Humano Avanzado de la Comisión Nacional Científica y Tecnológica (CONICYT) de Chile, dentro del Grupo de Investigación FQM-126, Teoría de la Educación Matemática y Educación Estadística (Junta de Andalucía). 


\section{RESUMEN}

El escenario de la interculturalidad y la educación matemática ha tomado relevancia en los últimos años, especialmente en América, con las aportaciones de algunas investigaciones desde la Didáctica de la Matemática que están contribuyendo a la reflexión en esta materia. En este contexto, nuestro trabajo pretende explorar la articulación de la etnomatemática de uno de nuestros pueblos originarios, pueblo Mapuche, y la matemática escolar en el actual modelo de la Educación Intercultural Bilingüe (EIB) en Chile.

Muestro marco teórico y metodológico, basado en los enfoques de la Matemática Crítica y la Etnomatemáticas, nos ha permitido abordar la problemática a que se enfrentan los estudiantes mapuches al ingresar a la escuela formal en Chile. Para ello nos hemos propuesto una indagación histórica de la evolución socio-política de la educación en Chile, a fin de contextualizar el escenario en que han ido ocurriendo los hechos y cómo hemos llegado al actual modelo educativo, en que se incorpora el programa de EIB (ver anexo 1). Paralelamente, realizamos una revisión de la bibliografía específica sobre el conocimiento de la cultura mapuche, siendo nuestro foco de atención el conocimiento matemático y su contextualización en los programas de Lengua Mapunzugun (lengua mapuche), en el currículo de matemática en las últimas dos décadas y las Orientaciones Curriculares en matemáticas para la EIB. Lograr sistematizar la información sobre la aritmética mapuche es vital, para su posterior comprensión, descripción e interpretación; para luego identificar posibles ventajas o dificultades de aprendizaje en los estudiantes mapuche en los primeros años de escolarización. Al tomar conciencia de las limitaciones de este estudio, recurrimos a dos casos-típicos para establecer un primer contacto con las actuaciones matemáticas de los estudiantes mapuches en dos escuelas municipalizadas. Sin tener éste un carácter formal y sistémico, pero si con la finalidad de evidenciar la necesidad de investigación rigurosa y sistemática en esta materia, procurando identificar posibles líneas de investigación en Didáctica de la Matemática que aporte conocimiento científico sobre el complejo escenario del aula de matemática en la Educación Intecultural Bilingüe. 
"YÑEY NO RUME KIMLAY CHEU AMUTUAL KIMNOLU CHEU NII KUPALME". "Nadie puede saber dónde ir, si no sabe de dónde viene" PIUKEYEN NUUKE MAPU

A mis grandes amores. Mis hijas Isabeau e Ischka. Mi nieto adorado, Baltazar.

Gracias profesor Dr. Juan D. Godino por guiar mi esencia y creatividad profesional, permitiéndome aprender de su sapiencia y calidad humana. 


\section{ÍNDICE}

1. PROBLEMA DE INVESTIGACIÓN Página

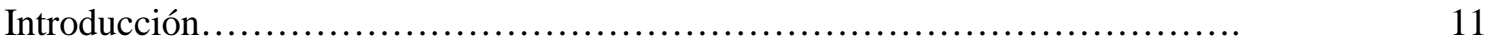

1.1. Contexto: Educación Intercultural Bilingüe y el pueblo mapuche................ 12

1.2. Área problemática: Etnomatemática y multiculturalidad................. 17

1.3. Problema y preguntas de investigación ................................ 19

1.4. Objetivos de investigación........................................ 21

1.5. Justificación y motivación................................................... 21

2. FUNDAMENTACIÓN TEÓRICA Y METODOLÓGICA

2.1. Enfoque Teórico.................................................. 23

2.1.1. Matemática Crítica y Etnomatemática............................ 24

2.1.2. Cultura Mapuche........................................... 28

2.2. Metodología................................................... 31

3. ETNOMATEMÁTICA EN EL CURRÍCULO ESCOLAR CHILENO 33

3.1. Programa de estudio Lengua Mapuzugun............................. 33

3.2. Orientaciones curriculares en matemáticas para contextos interculturales 37

4. EL CASO DE LA ARITMÉTICA MAPUCHE............................... 45

4.1. Características del Rakin, matemática mapuche........................ 45

4.2. Análisis morfo-matemático..................................... 50

4.3. Operaciones aritméticas en la cultura mapuche........................ 55

4.4. Estudio comparativo de la aritmética mapuche con la aritmética escolar 57

4. 5 Potenciales ventajas o dificultades de aprendizaje del alumno mapuche 60

5. SÍNTESIS Y CONCLUSIONES.................................... 70

5.1. Limitaciones..................................................... 72

5.2. Cuestiones abiertas............................................ 73

REFERENCIAS ......................................................

Lista de Tablas y Figuras..............................................

ANEXOS

1. Evolución de la Educación en Chile desde la segunda mitad del Siglo XX

2. Programa de estudios de Lengua Mapuzugun. $1^{\circ}$ a $4^{\circ}$ año Básico"

3. Orientaciones para contextualizar la educación matemáticas en la EIB

4. Actividad de conteo $2^{\circ}$ Básico (casos-tipos)

5. Encuesta profesores de estudiantes mapuches 


\section{PROBLEMA DE INVESTIGACIÓN}

\section{Introducción}

Los nuevos principios orientadores en materia de educación del Gobierno de Chile, a partir del regreso de la democracia en 1990 (ver anexo 1) se focalizan, entre otros, en los siguientes aspectos: la preocupación por la calidad de la educación; equidad en la distribución del saber, superando las desigualdades sociales y étnicas; la promoción de la creatividad y el acceso masivo a los bienes culturales (Ministerio de Educación y OEI, 1993). En concordancia con otros países del mundo y especialmente de Latinoamérica, se inicia un proceso de reconocimiento y valoración de la diversidad cultural, lingüística y social que poseen nuestros pueblos originarios, comprendiendo que esta riqueza cultural y las lenguas de éstos conforman el soporte de la construcción de la identidad nacional de cara al fenómeno de la globalización.

El actual marco curricular de la educación general básica en Chile ha introducido la Educación Intercultural Bilingüe (EIB) en los primeros niveles de ésta, lo que ha permitido incorporar las Bases Curriculares y los respectivos Programas de Estudio del Sector de Lengua Indígena (SLI). El programa de Educación Intercultural Bilingüe, se está implementando gradualmente desde el año 2010, en las zonas con alta densidad poblacional indígena. Al igual que en otros países donde se implementa una educación intercultural, nuestro país promueve con este programa el estudio y la preservación de la lengua indígena como primera lengua, junto al castellano.

Desde la Didáctica de la Matemática, existen estudios que han permitido poner de manifiesto la necesidad de incorporar la etnomatemática de la cultura ${ }^{1}$ local en los currículos de matemáticas para re-descubrir y valorar los distintos conocimientos matemáticos que utilizaban o utilizan sus culturas originarias. En Chile existe muy poca investigación al respecto, por ello nuestra primera intención es explorar el conocimiento matemático de uno de nuestros pueblos originario, el pueblo Mapuche. Esto nos permitirá proyectar nuestro trabajo hacia el análisis de la relación entre la matemática mapuche y la matemática escolar que se imparte en todo el territorio nacional. Para ello, no apoyaremos en investigaciones sobre la gramática de los pueblos precolombinos, que han descrito desde la lingüística los numerales en lengua

\footnotetext{
1 Aspectos semióticos, de simbolización, expresión y comunicación. Aspectos socio-políticos, de organización y de las relaciones sociales y de poder. Aspectos cognitivos, de modos de conocer, ligados al entorno. Aspectos tecnológicos, de productos o artefactos, creados con fines de dominio de la naturaleza, o para facilitar el trabajo, o posibilitar el ocio (Oliveras, 1996)
} 
mapunzugun (lengua del pueblo mapuche). El actual marco de la EIB está abriendo posibilidades de investigar y profundizar sobre el conocimiento de las culturas de los pueblos originarios, entre ellos el conocimiento matemático. Conocer el estado actual de la cuestión, nos permitirá aportar una descripción morfo-matemática de los números mapuches y un análisis socio-crítico del escenario en que debiera confluir la interacción dialógica entre etnomatemática mapuche y la matemática escolar. En un análisis a priori, a la luz de los antecedentes recabados y la experiencia docente en las aulas de matemáticas de la educación pública de la tesista, señalamos potenciales conflictos que pueden o no influir en los aprendizajes de los estudiantes mapuches en los primeros años de escolarización. Sin embargo, aún cuando las motivaciones socioculturales e instruccionales de abordar esta problemáticas pueden ser válidas, estamos conscientes de las limitaciones de este estudio el que nos puede permitir o no, conocer las potencialidades o limitaciones de este conocimiento matemático y su real posibilidad de incorporación en el quehacer escolar matemático en el marco de la EIB.

\subsection{Contexto: Educación Intercultural Bilingüe y el pueblo mapuche}

Diversos organismos internacionales e investigaciones, promueven la pervivencia de las diferentes culturas en el mundo como patrimonio de la humanidad. Atendiendo a que la diversidad cultural es una manifestación empírica de la construcción del conocimiento y desarrollo de la humanidad. Asumiendo que la lengua es un bien esencial de la actividad humana y su desarrollo supone la existencia activa de un grupo humano que la comparte.

Las investigaciones realizadas en las últimas décadas por la ONU y sus distintas agencias como UNICEF, UNESCO, OIT, entre otras, han contribuido a la implementación de la Educación Intercultural Bilingüe (EIB) en nuestro país. Éstas y otras investigaciones en educación y cultura, han dejado en evidencia que Latinoamérica es un continente con una riqueza cultural muy importante, posee numerosos pueblos indígenas que conforman esta diversidad cultural, lingüística y social. Esta diversidad cultural y la lengua de sus pueblos originarios conforman el soporte de la construcción identitaria ${ }^{2}$ de cada nación, frente al fenómeno de

\footnotetext{
${ }^{2}$ Imagen de uno mismo, legítima y positiva que fortalecen aspectos más profundos y más íntimos de la relación del hombre (individuo, persona) con el mundo y con los otros, pero también consigo mismo, en términos de Quintriqueo, S. y McGinity, M. (2009)..
} 
globalización; por ello la importancia de la "Educación Intercultural" en nuestro continente.

Los aspectos linguíísticos en nuestro territorio, también han cambiado a través de la historia, luego del largo proceso de conquista y colonización, y posteriormente, el largo proceso de consolidación como nación. En este camino que lleva más de 400 años, los pueblos originarios han ido desapareciendo y perdiendo su figura como ciudadano originario de estas tierras, al igual que sus lenguas originarias en los tramos de edad más jóvenes, siendo sólo los adultos mayores los que declaran dominar su lengua materna (Treviño, Donoso, Aguirre, Fraser, Godoy, Inostroza y Castro, 2013). Lo planteado por Treviño y colaboradores demuestra de alguna forma que las actuales políticas en materia de EIB no logran la pervivencia de la lengua, ya que los antecedentes entregado en el año 2000 por Durán y Hernández (en Corporación Nacional de Desarrollo Indígena, 2005) planteaba que la situación sociolingüística de la población mapuche era heterogénea, dado que algunas comunidades conservaban parcialmente su lengua y en otras comunidades ésta tenía bastante vitalidad y era usada por niños, jóvenes y adultos. Actualmente se reconoce como lengua oficial el español y por ello su enseñanza en todos los niveles educativos en el territorio nacional. Sin embrago, existen otras lenguas, que aún son habladas por los grupos étnicos que asentados a los largo de todo el país, tratan de mantener viva su lengua, costumbres y tradiciones, entre ellos se identificaban los grupos étnicos: aymara, aymara-quechua y en cunsa o atacameño, que habitan en la zona noreste; el mapuche, el qawásqar o alacalufe, el yagán o yamana, distribuidos en la zona sur y austral del país; y el pascuense, que habita la Isla de Pascua y que aún conservan su lengua nativa, pero la mayoría de los pascuenses son bilingües. Respecto a la lengua: zona norte, lengua vernácula, los aymara, lengua aymara; zona sur, mapuzugun; austral, lengua yagán; los pascuense, el rapa-nui. La mayor cantidad de habitantes lo tiene el pueblo mapuche y por ello la importancia de la enseñanza del mapuzugun. El rapa-nui se enseña en Isla de Pascua y las otras lenguas no han sido enseñadas hasta hoy en que se aprueban y elaboran los programas de lengua indígena.

Nuestro interés es el pueblo mapuche y hemos mirado la historia para contextualizar los hechos ocurridos hasta hoy. Es así como es posible encontrar desde 1925, documentos que plantean demandas del pueblo mapuche al Estado de Chile, por una educación en su lengua y a partir de su cultura; en 1935 la Junta General de Caciques del 
Butahuillimapu ${ }^{3}$ (Jefes Políticos Mapuches de las Grandes Tierras del Sur de Chile), pidieron al gobierno de la época "colegios propios al interior de sus comunidades, nombrar una comisión que estudie el idioma mapuche, textos de enseñanza que se distribuyeran en forma gratuita en los colegios fiscales para que mapuches y mestizos chilenos se posesionen del idioma nativo de los padres de la raza chilena de este país...." (Ministerio de Educación, 2005). Sin embargo, no es hasta que Chile regresa al sistema democrático, que estas demandas de los pueblos originarios, hechas a través de la historia de nuestro país, fueron acuñadas, escuchadas y se inicia un proceso real de dar respuestas a dichas demandas desde las esferas gubernamentales.

Con el regreso de la democracia en 1990, se inicia el reconocimiento de las raíces étnicas de nuestra nación y con la Ley $\mathrm{N}^{\mathrm{o}} 19.253$ (Ministerio de Planificación y Cooperación, 1993) se reconoce nueve pueblos indígenas: Mapuche, Aymara, Rapa Nui o Pascuense, Atacameño o Likan Antai, Diaguitas, Quechua, Colla, Kawáshkar o Alacalufe y Yámana o yagán. De esta forma se emprende un proyecto para la valoración de su existencia y el reconocimiento a su integridad y desarrollo, de acuerdo a sus costumbres, valores y cosmovisión. La Ley General de Educación (Ministerio de Educación, 2009), representa el actual marco institucional para la educación obligatoria y su principio orientador enmarca a la educación....

(...) "en el respeto y valoración de los derechos humanos y de las libertades fundamentales, de la diversidad multicultural y de la paz y de nuestra identidad nacional”... (Art. 2)

Al mismo tiempo que la LGE el año 2009 se dicta el Decreto Supremo N $^{\mathbf{0}} 280$ (Ministerio de Educación, 2009) que incorpora un nuevo sector (asignatura) de aprendizaje para la educación general básica, el Sector de Lengua Indígena (SLI), estableciendo así un Programa de Educación Intercultural Bilingüe (EIB). Este decreto se traduce en las actuales Bases Curriculares específicas de cuatro lenguas indígenas: Aymara, Mapuzugun, Quechua y Rapa Nui, para un nuevo modelo de formación bilingüe. Este nuevo marco legal establece: "el uso y conservación de los idiomas indígenas, junto al español en las áreas de mayor densidad indígena" (Ministerio de Educación, 2009).

No obstante, a pesar de la reciente puesta en marcha de la EIB, el pueblo mapuche continúa organizado para levantar demandas al estado chileno, que den cuenta real de su

\footnotetext{
3 "Gran territorio del sur", llamado así por los Mapuche-Huilliche. Este territorio se extendía desde el río Toltén hasta la isla de Chiloé.
} 
cultura. Para el pueblo mapuche, este programa es uno más de los llevados a cabo por la institucionalidad y no representa sus verdaderas aspiraciones. Varias investigaciones desde la sociología, la antropología y las ciencias de la educación dan cuenta del complejo escenario de los procesos educativos en el actual modelo, que si bien en su discurso pretende valorizar nuestras raíces culturales, en su aplicabilidad no es más que otro modelo de aculturación del pueblo mapuche. Rother (2005) en su investigación sobre el conflicto intercultural y la educación en Chile, en cuanto a los desafíos y problemas que presenta el actual modelo de la EIB para el pueblo mapuche, nos plantea que muchos de los profesores mapuches, formados en el modelo educacional común a todo el país, sienten que fueron desarraigados de su cultura, como lo expone en su trabajo.....

(...)"yo creo que el daño cultural, en el desarrollo de la identidad propia de uno, sentirse bien quién eres y cómo eres, creo que nos hicieron mucho daño, mucho. Mucho, mucho porque siendo un internado, un hogar con cien por ciento de niños mapuches nunca jamás se escuchó una afirmación siquiera que nos diga: Tú eres mapuche, tu cultura tiene cosas maravillosas, tú tienes una lengua que tienes que cultivar y hablar... Nunca jamás. Sino fue el contrario, creo que la estrategia fue desarraigarnos totalmente de la cultura.... Era un sistema tan rígido pero ordenado y sumamente estricto, poco menos como un recinto militar”.... (Don Eduardo, actualmente Director de una escuela mapuche en Piedra Alta, Lago Budí, Novena Región). (Rother, 2005, p. 76)

Estas declaraciones debe motivar la reflexión de las instituciones e investigadores, como reflexiona el pueblo mapuches sobre su propia educación y cultura, lo que los lleva a plantearse y plantear a las autoridades la necesidad de crear una propia EIB y lo plantean aludiendo a que hoy en Chile existen instituciones educativas que elaboran sus propios programas de estudios (Instituciones alemanas, italianas, inglesas y otras), a través de los cuales transmiten sus valores, creencias y cosmovisión. De acuerdo a los antecedentes de la evolución histórica de nuestra educación (ver anexo 1), el pueblo mapuche está en su legítimo derecho de exigir crear su propia EIB, por cuanto la actual LGE ha perpetuado la "libertad de enseñanza" promovida y establecida por la dictadura militar, es decir pueden elaborar sus propios programas de educación intercultural para su pueblo y para todo aquel que quiera educar a sus hijos en nuestra cultura.

Los estudios que analizan la implementación del programa de EIB en Chile, han dejado en evidencia la complejidad de éste, por cuanto su concepción a nivel estatal deja 
entrever su concepción socio-política y se refleja en que es un programa sólo para la población indígena; es decir es una política dentro del Sistema Nacional de Educación y no incluye a toda la población estudiantil, por cuanto mantiene su carácter de segregación étnica. Por otra parte, plantea que el lenguaje indígena, en este caso el mapunzugun, está en primer plano porque su presencia en la tarea escolar busca disminuir las dificultades de aprendizaje en los niños mapuches y promover el bilingüismo como parte del desarrollo del pensamiento, sin embargo no se existe una política sobre procurar los medios (humanos, materiales y didácticos) necesarios para ello. En la práctica la EIB no conduce a un dialogo entre el Estado, la mayoría de la sociedad chilena y los mapuches (Rother, 2005), es decir el conocimiento ancestral del pueblo mapuche no es valorado como recurso en favor del aprendizaje de todos los ciudadanos y que potencie el desarrollo armónico de nuestra nación. El que las políticas educativas mantengan este carácter de segregación cultural-étnica promueve la idea de una sociedad unicultural, en la que todos debemos aprender y adquirir la cultura dominante.

El actual marco curricular para la educación obligatoria reconoce y valora el lenguaje indígena, esencialmente, porque a través de éste la sociedad chilena podrá comprender y valorar su cultura; aprendiendo aspectos fundamentales como la circularidad del tiempo, la relación parte a todo con la naturaleza, la posición y definición de la persona en relación con su entorno, la armonía y otros conocimientos de las culturas originarias. De alguna forma, la intención de estas nuevas medidas aportan al rescate de nuestra cultura, luego del exterminio sistemático y de la aculturación a la que fueron y son sometidos (Belloli, 2009) nuestros pueblos originarios. Este sector de aprendizaje entra en vigencia gradualmente a partir del año 2010 en el primer año de educación básica, de manera obligatoria en aquellos establecimientos con una matrícula indígena igual o superior al $50 \%$ y a partir del año 2014 en los establecimientos con una matrícula igual o superior al 20\% (Ministerio de Educación, 2009). Según la base de datos del Ministerio de Educación, en la actualidad, el 70\% de los establecimientos del país poseen matrícula indígena (más detalles ver anexo 1) y no puede ser desconocida; por ello en el marco del programa de la EIB, el gobierno propone avanzar en el respeto y valoración de la diversidad, convirtiendo a la escuela en un espacio educativo que asegure a los niños y niñas, el acceso al conocimiento transmitido por su pueblo de origen; invite a los estudiantes a ser actores de su propio proceso educativo, toda vez que su cultura y lengua son el punto de partida para el desarrollo de competencias (habilidades, 
conocimientos y actitudes); y propicie que la lengua originaria sea un elemento de inicio de una conversación sobre interculturalidad.

Los procesos de aculturación en América han subvalorado el "mundo cultural matemático" (Bishop 1999), de estos pueblos. La educación monocultural ha sido el actual método de colonización y formación de los estados (Quilaqueo y Quintriqueo, 2010), lo que ha significado una disminución o exclusión del conocimiento y cosmovisión de los mapuches en la educación escolar (Quintriqueo y Maheux, 2004). La intención de un discurso multicultural e intercultural no ha detenido la aculturación, ya que en la actualidad tenemos en nuestras aulas muchos casos de autonegación de la identidad mapuche en jóvenes mapuches para poder integrarse a la sociedad chilena (Quintriqueo y McGinity, 2009). Esto ha significado sin lugar a dudas una pérdida del conocimiento ancestral de su cultura de origen en pro de la adopción de la cultura dominante. En este sentido, podemos decir que la enculturación matemática en su nivel formal (Bishop. 1999) y los valores que transmite, afecta la consolidación identitaria del individuo en sociedad.

En este escenario complejo para la educación intercultural, nuestra investigación, pretende poner de manifiesto la problemática de la educación matemática en un país multicultural, siendo los estudiantes el centro de atención, por cuanto se enfrentan al aprendizaje de la matemática escolar con un acerbo cultural distintos y ajeno a la cultura matemática (Bishop, 1999). La implementación de la EIB requiere de una constante investigación de acuerdo al conocimiento de nuestros pueblos originarios y en distintas área, entre ellas la Didáctica de la Matemática que aborde el conocimiento matemático y su posible articulación con la matemática escolar. El conocimiento matemático de los pueblos originarios aún se mantiene segregado y éste podría contribuir al encuentro dialógico con el conocimiento matemático escolar, por ser parte del conocimiento previo con que llega el estudiante a la escuela.

\section{2. Área problemática: Etnomatemática y multiculturalidad}

Los nuevos conflictos que surgen en la formación de los ciudadanos chilenos a partir de la implementación de la EIB, han sido abordados por investigadores como Gajardo (2012), Quintriqueo y Maheux (2004), Quilaqueo y Quintriqueo (2010), Treviño, et al., (2013), Rother (2005), Quintriqueo y McGinity (2009), entre otros. Éstos han puesto en la discusión cuestiones como: la elaboración de programas propios en las comunidades 
indígenas, tener un currículo intercultural a nivel país, tomar las medidas necesarias para la implementación de estos programas (Profesores, materiales, formación didáctica, etc.), abordar los distintos conocimientos de los pueblos originarios, entre ellos el conocimiento matemático, a fin de aportar a la disminución de los problemas de aprendizaje de los estudiantes mapuches, los que se reflejan en los resultados obtenidos en las evaluaciones nacionales estandarizadas. Los bajos rendimientos en matemáticas en las evaluaciones nacionales estandarizadas (ver anexo 1: tablas 1.1, 1.2, 1.3, 1.4, 1.6, 1.7) del actual modelo educativo, deja en evidencia la discriminación social existente en relación a la calidad de la educación. Los niveles de aprendizajes son notoriamente bajos y se distribuyen de manera socialmente discriminatoria; esto es, en sectores de ingreso medios-bajos los estudiantes, atendidos por las escuelas y liceos municipales, aprenden notablemente menos que los estudiantes de los sectores medio-altos o altos que asisten a escuelas y liceos particulares (ver anexo 1).

Los años de experiencia profesional me ha permitido vivir varias reformas educativas en Chile y he visto los constantes cambios de los programas de estudios en matemáticas para todos los niveles de la educación obligatoria en las últimas tres décadas. Uno de ellos, que he acuñado desde el año 2009, en que la actual LGE introduce nuevos cambios, se relaciona con este estudio y toma mayor relevancia a partir de la incorporación, al currículo nacional, del Programa de EIB. En el Programa de Estudios de $7^{\circ}$ año básico del año 2000, vigente hasta el año 2009, éste incorporaba una unidad didáctica denominada "Sistemas numéricos en la historia y actuales" (Ministerio de Educación, 2002), en el cual se introducía el estudio del sistema de numeración del pueblo mapuche, como elemento de comparación y comprensión del sistema de numeración decimal posicional y sus características. Mi experiencia profesional con esta unidad didáctica, de las cuales guardo algunos registros fotográficos, me otorgaba la oportunidad de dar a conocer a todos los actores de la comunidad educativa del establecimiento la etnomatemática del pueblo mapuche, logrando con ello poner de manifiesto la existencia de distintas formas de hacer matemáticas. En el proceso de trabajo escolar los estudiantes de origen mapuche asumían un rol primordial, lo que reforzaba su autoconcepto y actitud identitaria con su cultura de origen. En el desarrollo del proyecto de curso (metodología de trabajo de la unidad), los estudiantes de $7^{\circ}$ año, se apropiaran de las cualidades del sistema de numeración mapuche y lo relacionaran con el conocimiento que ellos tenían de la matemática escolar y que venían estudiando por siete años, luego compartían este conocimiento con el resto de la comunidad de la 
escuela, explicando las propiedades y principios matemáticos que subyacen en la aritmética mapuche, mediante presentaciones públicas con material concreto y simbólico elaborado por ellos mismos. El año 2009 se retira esta unidad didáctica del Programa de Matemáticas de $7^{\circ}$ año y no se incorpora en ningún otro nivel de la educación básica. El mismo año en que se inicia la implementación de la EIB en la educación básica, se priva a los estudiantes del estudio de la aritmética mapuche en sus aspectos elementales, lo que no facilita el encuentro dialógico entre la cultura matemática de origen del estudiante y la cultura matemática escolar.

Atendiendo a los Derechos Humanos, los Convenio de la OIT y los Derechos del Niño, los cuales establecen el respeto por el desarrollo autónomo de las minorías étnicas en el mundo y promueven la preservación de su patrimonio cultural en armonía con las naciones independientes a las que pertenecen y principalmente el cultivo de las lenguas originarias, desde un enfoque post-moderno (Hirmas, Hevia, Treviño y Marambio 2005), que tiene como fin la valoración y trato igualitario de las distintas culturas sin sobreponer un conocimiento sobre otro; en este estudio estamos interesados en la etnomatemática del pueblo mapuche y su relación dialógica con la matemática escolar. Nuestro propósito es aportar una visión crítica de la enseñanza de la matemática escolar en un contexto intercultural, asumiendo que las matemáticas, como ciencia es un producto de una comunidad científica que la comparte, sin embargo no podemos olvidar que éstas son un producto cultural surgido del desarrollo del conocimiento humano para satisfacer distintas necesidades sociales y culturales en un momento determinado de la historia (Georgorió, Prat y Santesteban, 2006).

\subsection{Problema y preguntas de investigación}

Los nuevos conflictos que se evidencian con la implementación de la EIB, la falta de investigación en Didáctica de la Matemática que aborde el conocimiento matemático del pueblo mapuche y su articulación con la matemática escolar, el retiro de la aritmética mapuche del currículo de matemática, el escaso conocimiento de la etnomatemática mapuche que poseen los distintos actores del proceso de enseñanza y aprendizaje de las matemáticas, el actual modelo monocultural del currículo de matemáticas, el no considerar el conocimiento matemático de origen del estudiante como conocimiento previo para el aprendizaje de la matemática escolar y otros aspectos que hemos descrito, nos han permitido iniciar en este estudio un largo camino para describir la matemática viva (Oliveras 2006) del pueblo mapuche. Este conocimiento 
mapuche llega con el estudiante a cerca del $70 \%$ de los establecimientos del nuestro país y con mayor presencia en las escuelas en que se implementa el programa EIB en la lengua mapunzugun (ver anexo 1) y el complejo escenario del proceso de enseñanza y aprendizaje de la matemática escolar en la educación básica en contexto mapuche. En este proceso de exploración, nos hemos planteado algunas cuestiones que requieren nuestra atención como investigadores:

1) Si las actividades didácticas propuestas por el programa de lengua mapuzugun, en el primer ciclo básico, utiliza los números en mapuzugun, ¿qué características morfomatemáticas tienen estos números mapuches?,

2) ¿Existe la aritmética mapuche? ¿Tiene cualidades que puedan ser relacionadas con la matemática escolar? ¿Qué dice al respecto las orientaciones curriculares en matemáticas para la EIB?

3) ¿En qué medida el uso de los números mapuches, puede significar una dificultad o ventaja para el aprendizaje de la matemática escolar?, ¿podemos identificar a priori algún conflicto semiótico en el aprendizaje?

4) ¿cómo afecta el proceso de aculturación matemática en la escuela al desarrollo identitario del estudiante mapuche?, ¿la autonegación identitaria afecta el aprendizaje de la matemática escolar?, ¿qué opinión tendrán los profesores de estudiantes mapuches sobre nuestras inquietudes investigativas?

A partir de estas interrogantes nos proponemos mirar con las lentes de la Etnomatemática los programas de lengua mapunzugun e identificar en ellos la etnomatemática mapuche, como parte de su tradición oral, para luego describir su estructura morfo-matemática. Consecuentemente con el panorama que nos proporcione la mirada anterior, y apoyados en la Matemática Crítica miraremos las orientaciones didácticas en el sector de aprendizaje de matemáticas para el contexto mapuche, describiendo la relación dialéctica entre la etnomatemática mapuche y la matemática escolar propuesto por éste para los primeros niveles de la educación básica en el marco de la EIB. Luego continuar con la exploración de las cualidades de la aritmética mapuche e indagar y describir posibles conflictos cognitivos en los estudiantes mapuches al enfrentar el estudio de la matemática escolar. Evidenciando la complejidad de este escenario y la necesidad de investigación sistemática en Didáctica de la matemática, para atender estas y otras cuestiones del proceso de enseñanza y aprendizaje de la matemática escolar para la EIB en Chile. 


\subsection{Objetivos de Investigación}

\section{Objetivos específicos}

1. Describir y analizar la estructura morfosintáctica y morfo-matematica de los números en palabras utilizados por el programa de estudio de lengua mapunzugun.

2. Describir y comprender las cualidades de la aritmética mapuche presente en las orientaciones didácticas del currículo de matemáticas para el estudio de la matemática escolar en la EIB.

3. Describir los objetos matemáticos intervinientes en los sistemas de prácticas de la aritmética mapuche y su posible articulación con la matemática escolar en los primeros niveles de educación básica.

4. Describir las ventajas y/o dificultades de aprendizaje de la matemática escolar al no considerar el conocimiento matemático de origen de los estudiantes mapuches en los primeros años de escolarización.

\section{Objetivo del Estudio:}

Describir y comprender el complejo escenario de enseñanza y aprendizaje de la matemática escolar en contexto mapuche en los primeros niveles de la educación básica, para evidenciar la existencia de la aritmética mapuche, sus cualidades y posible articulación con la matemática escolar e identificar ventajas o dificultades en su incorporación al aula.

\subsection{Justificación y motivación.}

La existencia de una matemática viva (Oliveras, 2006) del pueblo Mapuche, que llega al $70 \%$ de nuestras escuelas con los estudiantes como parte de su conocimiento previo y que sólo un 2,43\% del total de las escuelas del país, atiende esta diversidad (Ver anexo 1); ha sido suficiente motivación para iniciar este estudio. Nos interesa que nuestros estudiantes, independiente de su cultura de origen, no se vean enfrentados a su corta edad a una aculturación cognitiva que pueda mutilar su porvenir o generar la autonegación de su cultura de origen, como consecuencia del negativo autoconcepto y baja autoestima (Gajardo, 2012). El conocimiento previo al ingresar a la escuela es y debe ser el punto de partida para afianzar los nuevos conocimientos y el conocimiento matemático de origen "es" un conocimiento previo. Luego estamos convencidos que la interdisciplinariedad en la EIB puede favorecer el desarrollo identitario del estudiante mapuche y por consiguiente la identidad nacional, siendo la matemática escolar un 
motor de razonamiento que potencia el desarrollo de pensamiento y la actitud crítica frente a acontecer cotidiano.

Sin embargo, creemos que aun cuando todas nuestras escuelas no reúnan los requisitos para implementar el programa de EIB, cada una de ellas debe ser consciente de la cultura de origen de sus estudiantes y del conocimiento que llega con él a la escuela, como parte de su proceso de socialización primaria, y por tanto atender la diversidad sociocultural, dando espacio a lo planteado por Gimeneo Sacristán:

"La escuela debe ofrecer instrumentos críticos para entender las relaciones sociales, apoyar el modelo de "individuo en sociedad" y de "individuo en la cultura”, propiciando en su propio ambiente las relaciones más convenientes" (Gimeno, 2002: p.106)

Describir la aritmética del pueblo mapuche es un primer paso hacia su re-valoración y potencial utilización en la escuela para una mejor comprensión de la matemática escolar. Así se cumple con el propósito de desarrollar en los estudiantes el conocimiento y habilidades que le permitan interactuar con otras culturas, comprendiendo sus códigos, lenguaje simbólico, etc., sin perder las oportunidades de desarrollo continuo y en armonía con su propia cultura y conocimiento ancestral.

Conocer y comprender las relaciones entre etnomatemática y la matemática escolar, en el contexto mapuche nos proporcionará un escenario epistemológico dentro del conocimiento didáctico matemático que puede favorecer el desarrollo de estrategias metodológicas para la adecuada transposición didáctica del conocimiento matemático en los primeros niveles de la educación básica.

Dar a conocer la estructura morfo-matemática del sistema de numeración mapuche nos permite comprender los procesos complejos de aprendizaje a que se enfrentan los estudiantes mapuches en sus primeros años de escolarización y dejar en evidencia los conflictos semióticos que implican las habilidades de codificación y descodificación.

Desde una visión socio-antropológica, este estudio nos orienta sobre como la educación matemática adecuada en la educación obligatoria, puede ser una herramienta favorable para potenciar el pensamiento crítico de todo ciudadano y aportar al porvenir de nuestros estudiantes. Un matemática crítica, nos permite mirar la interculturalidad de una manera diferente: inclusiva, dialógica, sin sobreponer una cultura sobre otra, tomar de cada una aquello que es favorable para la formación integral del aprendiz, sin desraizarlo de su cultura para ser parte de otra cultura, entender que el conocimiento es un producto humano, que la ciencia y las distintas disciplinas son producto de una 
comunidad científica que las comparte, que es valioso ser y pensar distinto, que el respeto por la cultura del otro es un valor inconmensurable, que el entender y hacer matemática desde otro punto de vista no te hace inferior, que la matemática como disciplina científica ha sido desarrollada por una comunidad científica que la comparte pero no todos estamos obligados a compartir sus principios, valores e ideología, que todo ser humano nace "libre"....de y para...(pensar, actuar, decidir...) y muchas más cuestiones filosóficas en relación a los valores que se transmite en el nivel formal de la educación matemática. Contribuir al desarrollo identitario de nuestros estudiantes y de nuestra nación, es tarea del Sistema Educativo y la instrucción matemática crítica puede aportar a ello.

Por último el comprender y describir este escenario implica poner de manifiesto la necesidad de investigar de manera sistemática el conocimiento matemático del pueblo mapuche y su posible articulación dialógica con la matemática escolar, otorgando oportunidad de producir un conocimiento didáctico matemático (Godino, 2009) que luego esté al servicio de la institucionalidad y de otros actores (Moreno, 2004) participantes en el proceso de enseñanza y aprendizaje de las matemáticas para la educación básica, a fin de mediar entre el aprendizaje de la matemática escolar de los estudiantes mapuches y su conocimiento matemático de origen.

\section{FUNDAMENTACIÓN TEÓRICA Y METODOLÓGICA}

\subsection{Enfoque teórico}

En este proceso de formación continua como profesional, he tenido la oportunidad de conocer algunas líneas de investigación que de alguna forma han motivado este trabajo, me refiero a la Matemática Crítica, la Etnomatemática y el conocimiento didácticomatemático (CDM) del profesor de matemática, planteado por el Enfoque Ontosemiótico del Conocimiento y la instrucción Matemática (EOS). Este último me hace mucho sentido, ya que en nuestro país tenemos un Marco para la Buena Enseñanza (MBE), que nos orienta hacia una buena práctica en el aula, considerando algunas facetas del CDM del EOS como dominios a tener en cuenta en nuestra actuación.

Exponemos en este apartado los enfoques teóricos que han aportado a la definición de la problemática a abordar en este estudio y su justificación, a fin de articular un sustento teórico que no sólo aborde la matemática mapuche desde un punto de vista socioantropológico, sino también desde el punto de vista sistémico-ecológico. Con esta introducción se pretende describir la motivación por nutrir este estudio con los enfoques 
teóricos de la "Matemática Crítica" y la "Etnomatemática". La Cosmovisión de nuestro pueblo mapuche nos ha entregado elementos para el marco de referencia de este estudio, por lo que hemos considerado relevante describirla en este apartado.

\subsubsection{Matemática Crítica y Etnomatemática}

La actual sociedad crecientemente multicultural, producto de la globalización, genera un constante cuestionamiento de las políticas educacionales en el mundo y los aportes de diversas investigaciones han contribuido a ello desde distintos enfoque. Es así como la etnomatemática ha surgido para dar respuesta a una necesidad cultural dentro de la disciplina de las matemáticas. Hay quienes han profundizado en investigaciones etnomatemáticas apoyando a las diversas culturas autóctonas de distintas partes del mundo a redescubrir su historia y valorizar sus tradiciones y conocimiento, incluyendo en ello las diferentes maneras de contar, medir, ordenar, etc., es decir, diferentes maneras de hacer matemática (D'Ambrosio, 2000, p. 439). En la comunidad científica, se reconocen los aportes de connotados investigadores de la psicología de la educación, como Vigotsky quien ya en los años 50 nos hablaba del aprendizaje sociocultural del individuo. Han transcurridos varias décadas desde entonces, para ver cómo el mundo, consecuencia de la globalización, es un lugar multicultural donde cotidianamente aprendemos de la cultural del otro.

La Matemática Crítica y la Etnomatemática, han permitido interpretar una serie de cuestiones que no han andado bien en la enseñanza de la matemática luego de la occidentalización de la educación basada en la idea de la modernización (Vithal y Skovsmose, 1997). Cuestiones como la autoridad del profesor capaz de controlar y apaciguar la inquietud de los estudiantes, la resistencia de la matemática formal hacia la interdisciplinariedad (Skovsmose, 1999), la ausencia del componente socio-cultural dentro de la disciplina de las "Matemáticas", la ausencia del desarrollo del pensamiento crítico, entre otras.

Skovsmose (1999, p. 67) plantea (...)

"es importante hacer crítica a la educación si se quiere que ésta no degenere en una manera de socializar efectivamente a los estudiantes en una sociedad tecnológica y, al mismo tiempo, aniquilar la posibilidad de que desarrollen una actitud crítica hacia, justamente, esa misma sociedad”.

En la actualidad son varios los autores que se adhieren a la formación crítica de la ciudadanía y que han aportado a esta visión desde la formación matemática de los 
ciudadanos, entendiendo que el aprendizaje de la matemática potencia el desarrollo del pensamiento crítico y provee de herramientas cognitivas que permiten desarrollar una actitud crítica frente al acontecer cotidiano de una nación.

La etnomatemática nos permitirá mirar las cuestiones sociales y culturales en el conocimiento matemático del pueblo mapuche, mientras que la matemática crítica nos permite fundamentar los aspectos sociales y políticos. Visiones que permiten desarrollar una "alternativa" de educación matemática que exprese la conciencia social y la responsabilidad política (Vithal y Skovsmose, 1997). La etnomatemática nos orienta en la identificación de las competencias matemáticas arraigadas en una cultura, mientras que la matemática crítica ofrece un marco para la contextualización de "liberación" de la idea de modernización que abraza burocracia, capitalismo y opresión (Vithal y Skovsmose, 1997). Abrazamos la idea de liberación que plantea Skovsmose, (1999) cuando es referida a la idea de libertad para pensar, decidir, reflexionar, actuar y de pobreza, opresión, marginación, segregación. En la actualidad, distintas culturas que conviven en este mundo multicultural están en búsqueda de esa liberación y preservar su conocimiento y cosmovisión; sin embargo, están conscientes que es necesario aprender los marcos interpretativos de otras culturas para establecer relaciones dialécticas en igualdad de condiciones. Es importante señalar, que producto de la occidentalización del conocimiento matemático, éste domina los currículo en casi todo el mundo; entonces es imprescindible adoptar un visión socio-crítica de la educación matemática para no desraizar al aprendiz de su cultura para pertenecer a otra mediante la adquisición de un nuevo conocimiento matemático, como bien lo plantea Rother, (2005). En esta lógica se torna relevante uno de los supuestos de la etnomatemática, que plantea que el aprendizaje de la matemática puede ser mejorado si en el proceso de enseñanza y aprendizaje se construye el nuevo conocimiento a partir de la etnomatemática existente en la cultura de origen del estudiantes y con la cual está familiarizado.

Los cuestionamientos en materia de matemática y cultura datan de varias décadas atrás, como plantea Gerdes (1996), quien describe que en los años 50 algunos matemáticos, etnógrafos, psicólogos y educadores abordaban cuestiones de esta naturaleza y pueden considerarse como los precursores principales de la etnomatemática. Por otro lado la matemática crítica, también tiene sus orígenes en la educación crítica y la teoría crítica, representada por filósofos, sociólogos, matemáticos, físico de esa época, quienes inspiraron, en los años 70, las producciones que Skovsmose publicaría más tarde 
(Skovsmose, 1999). Es decir, desde hace bastante tiempo se viene cuestionando la naturaleza de las matemáticas desde distintos enfoques y por distintos investigadores. A partir de los años 70 se comienza a diversificar entre los matemáticos de la época la necesidad de investigar y reorientar el rol social de la educación matemática. En este contexto se acuña la etnomatemática que tiene su origen en la epistemología y la historia del conocimiento matemático.

Tampoco es nuevo el considerar los aprendizajes previos de los estudiantes a la hora de iniciarlos en un nuevo aprendizaje y más aún si recordamos que desde tiempos remotos hasta hoy fuera del entorno escolar la mayoría de los niños utilizan los números, cuentan, clasifican distintos objetos (color, tamaño, etc) y cuantifican situaciones de su entorno. Entonces no estamos lejos de comprender que es necesario respetar, valorar e incorporar los conocimientos matemáticos de la cultura de origen de los estudiantes al ingresar a la escuela. Una educación intercultural debiera considerar las prácticas y las percepciones (D’Ambrosio, 1999) de los estudiantes como una base en la cual afianzar el nuevo conocimiento, es decir considerar su historia individual y su cultura de origen. La etnomatemática es parte de la práctica cotidianas de los estudiantes dentro y fuera de la escuela, por ello reconocerla como una práctica válida refuerza la creatividad, los esfuerzos, el auto-respeto cultural (D’Ambrosio, 2000), en una sociedad multicultural.

La etnomatemática nos dice que hay distintas formas de hacer matemática, de acuerdo a la cultura en que se desarrolla, y la Matemática Crítica nos plantea que se debe desarrollar un pensamiento crítico para entender esas distintas formas de hacer matemáticas. Esto nos lleva a entender, por una parte, que hay diversidad de matemática y que éstas tienen un componente cultural y personal (Oliveras, 2006), social, político e ideológico. En este sentido, toma relevancia considerar la peculiaridades culturales de los estudiantes en el aula de matemáticas a fin de enfrentarlos a situaciones problemas que favorezcan la relación dialógica entre los distintos conocimientos matemáticos a poner en juego y los que se pretende alcanzar, como también instar el pensamiento crítico. Esta actitud hacia el aprendizaje intercultural, en que todos aprendemos del otro, favorece el afianzar el auto-concepto identitario y las propias raíces culturales.

Skovsmose (2012), nos plantea una visión interesante de "obstáculo" de aprendizaje, desde la matemática crítica, que se entrecruza con la visión de la etnomatemática, en cuanto a la "exclusión" que provoca un modelo de currículo monocultural e universal. Plantea que la noción clásica de obstáculo, podría ser un disfraz de exclusión. Skovsmose, para ilustrar su postulado de "política de obstáculo de aprendizaje" nos 
narra su investigación sobre los obstáculos de los niños negros en el pasado apartheid de Sudáfrica, concluyendo que los investigadores de la época interpretaron que los problemas de aprendizaje de los niños negros venían con ellos a la escuela, lo que no pasaba con los niños blancos. Es decir se instaló la política de establecer de antemano los obstáculos de aprendizaje de los niños negros por tanto la escuela les podía compensar tales deficiencias culturales. Para quienes trabajamos a diario con estudiantes diversos, este postulado es un llamado a la reflexión sobre la política del obstáculo de aprendizaje. El no considerar la cultura de origen de nuestros estudiantes al ingresar a la educación "formal”, puede ser asumido cómo una "política de obstáculo de aprendizaje"; el que puede sepultar su porvenir ${ }^{4}$ y arruinar el porvenir de un grupo de niños es un acto sociopolítico (Skovsmose, 2012).

Vithal y Skovsmose (1997) describen cuatro facetas o campos de estudio de la etnomatemática:

1) Historia de la matemática. Se critica la visión tradicional de la historia de la matemática por ignorar, devaluar, distorsionar o marginar las contribuciones de otras culturas no Europeas al cuerpo de conocimiento referido como matemáticas occidentales.

2) Antropología cultural matemática. Análisis de las matemáticas de culturas tradicionales, pueblos indígenas que pueden haber sido colonizados pero continúan con sus prácticas matemáticas originales. Se han explorado estas prácticas en relación a temas como sistemas numéricos, simbolismo y lenguaje gestual, juegos y rompecabezas, geometría, espacio, formas, patrones, simetría, arte y arquitectura, tiempo, dinero, redes, grafos, dibujos en la arena, relaciones de parentesco y artefactos.

3) Matemáticas en la vida cotidiana. Análisis de las matemáticas usadas por diferentes grupos en entornos de la vida diaria mostrando el conocimiento matemático que se genera en una amplia variedad de contextos, tanto por adultos como por niños.

4) Relaciones entre etnomatemática y educación matemática. Se estudian las conexiones (o falta de ellas) entre las matemáticas encontradas en los contextos de la vida diaria y los correspondientes al sistema de la escuela formal.

A partir de los cuatro puntos propuestos por Vithal y Skovsmose y con el transcurso de esta investigación, nos dimos cuenta que era necesario incorporar un quinto campo de estudio,

\footnotetext{
${ }^{4}$ Como percibe una persona las oportunidades que las situaciones sociales, políticas y culturales le proporcionan.
} 
5) Articulación de la etnomatemática y la matemática escolar. Que diese cuenta de la interacción de las relaciones entre la etnomatemática y la matemática escolar, no sólo para señalar sus semejanzas y diferencias o caracterizar la etnomatemática existente en una cultura; sino, además, para comprender dicho conocimiento a fin de proponer diseños didácticos que articulen adecuadamente ambos conocimientos matemáticos en el aula.

En esta investigación estamos interesados por dos de los aspectos mencionados por Vithal y Skovsmose, 2) Antropología cultural matemática, y 4) Relaciones entre etnomatemática y la enseñanza y aprendizaje de la matemática escolar, particularizados al caso del pueblo mapuche en Chile. Agregando nuestro quinto campo de estudio, que intentará poner de manifiesto la necesidad de articular la etnomatemática mapuche y la matemática escolar en la educación básica.

\subsubsection{Cultura Mapuche}

El pueblo Mapuche, es una de nuestras culturas milenarias del continente Americano, Abya-Yala ${ }^{5}$. Su cosmovisión y filosofía se basan en la "circularidad del universo", "la dualidad permanente", "la inmaterialidad no existe, todo es materia", "el mundo cíclico", "la Sabiduría innata del Che", "Tayi-Chegen, importancia del ser gente", "El Zuam $^{7}$ y otros conceptos del Che". Dos principios, fundamentales, sustentan el conocimiento mapuche (Consejo Nacional de la Cultura y las Artes, 2012), desde que nuestro pueblo tomó conciencia de su existencia, y es, "la lengua vernácula, el mapuzugun $^{8}$, a través del cual se ha expresado todo el descubrimiento hecho en los miles de años de observación; y los epew, metáforas de la observación permanente de la naturaleza, que se relatan en forma de cuentos y que las culturas dominantes han tratado de menospreciar llamándolas mitos. Hay estudios que calculan la aparición de la voz humana sobre los 30 mil años, el mapuzugun por lo menos tiene unos 12 mil años (Ñanculef 2005). La sabiduría del pueblo mapuche ha mantenido su conocimiento y ha sido capaz de ponerlo de manifiesto a pesar de los constantes intentos de aculturación a que se han visto sometidos por parte de las culturas dominantes.

\footnotetext{
5 Nombre dado al continente americano, su significado literal es "Tierra en plena madurez o tierra de sangre vital".

${ }^{6}$ Palaba en Mapuzugun que significa "gente". Mapuche significa "Gente de la Tierra"

${ }^{7}$ En mapuzugun se refiere a los lados de la Tierra. Meli Zuan "los cuatro lados de la tierra".

${ }^{8}$ La palabra original es Mapudungun, en que Mapu significa "tierra" y dungun "hablar o lenguaje", es decir, es el "hablar de la tierra". Su pronunciación suena parecido a una "d" y "z" o "th" en inglés, en thanks, por ello el cambio de grafema "D” por “Z”, quedando “mapuzugun” (ver CONADI, 2005)
} 
Su conocimiento de distintas ciencias como la matemática, filosofía, botánica, medicina, cosmología, astronomía, etc. (Ñanculef, 2005), se inscribe en su lengua vernácula, mapuzugun, el hablar de la tierra; por ello lo que expresan es todo aquello que el pueblo mapuche ha practicado a lo largo de su historia y lo que no ha conocido, simplemente, no está en lengua mapuche, como lo es caballo, vaca, etc..(Ñanculef, 2001). Según los Kimche y Machis, "sabios Mapuches", observando el cosmos han generando el Meli-Witxan-Mapu, "ciencia de la cosmología" Mapuche. Éste conocimiento les permitió establecer un calendario, "Rakin Txipantu" con el que han contado los ciclos de sucesos cósmicos y sus fenómenos, registrándolos en el kipu ${ }^{9}$ mapuche y en su Kimün ${ }^{10}$. Este registro lo han utilizado para predecir acontecimientos. De acuerdo al Rakin Txipantu, calendario mapuche, el año 2013, en que han pasado 472 años de la llegada de los españoles al Chile Mapuche en 1536 y 1541 según el calendario Gregoriano (Ñanculef, 2001), el pueblo Mapuche celebrará en el We Txipantu ${ }^{11}$ el fin del año 12.479, mari epu waragka meli pataka regle mari aylla. Otro aspecto importante a destacar es el Txafkintu, "intercambio", a cuya acción la cultura dominante le llamó "trueque", que significa intercambiar bienes y servicios, sin la mediación del dinero. Pero cuando se hace mención al trueque, se cree que éste se realizaba de manera proporcional a los bienes y servicios que se intercambian. En este sentido Juan Ñanculef Huaiquinao, Kimche (sabio mapuche), investigador e historiador mapuche nos explica que el intercambio entre los mapuches no tenía un sentido comercial ni económico. Se realizaba como una acción humana, un proceso social en que no sólo intercambiaban alimentos, también sus linajes, sus Kimün, tótem ${ }^{12}$; es decir después del primer intercambio ya se consideraban hermanos. Esta forma de intercambio con los españoles fue cambiando en el proceso de aculturación; en un principio se intercambiaban bienes que no guardaban relación proporcional de acuerdo al valor comercial que cada uno de ellos tenía y en el cual los mapuches estaban en desmedro y los wingka o winka ${ }^{13}$, como ellos le llamaban a la gente de otra sangre, se vieron beneficiados. Al transcurrir el tiempo de aculturación y adaptación del pueblo

\footnotetext{
${ }^{9}$ Artefacto mapuche de hilos horizontales tejidos y verticales sueltos, en las que registran a través de nudos.

${ }^{10}$ Conocimiento Mapuche

${ }^{11}$ Significa "regreso del sol". Inicio de un nuevo ciclo, en español es un nuevo año. Tiene el sentido de renovación del compromiso y las formas de como se relaciona el mapuche con la naturaleza.

${ }^{12}$ Era el animal, objeto o fenómeno de la naturaleza que representaba al grupo familiar o linaje.

13 Nombre para referirse a los invasores españoles, representaba el "nuevo inka", nuevo invasor. Actualmente lo utilizan para referirse a personas criollas o mestizas no mapuches.
} 
mapuche a esta nueva forma de organización socio-político, aprendieron de los winkas y comenzaron a valorar sus bienes para transarlos con los españoles. Es así como acordaron, que la moneda mapuche sería el animal, "Kullin", que se mantuvo por más de 300 años en la relación comercial con los españoles; desde esta nueva concepción tantos Chil-li (Llamas) o tantos Weke (Guanacos) podía costar un lote de género o un caballo o una vaca, es decir fue la base del intercambio de los mapuches con los winkas (Ñanculef, 2001).

En cuanto a la ciencia que nos ocupa en este estudio, el pueblo mapuche ha tenido un conocimiento pragmático del análisis de tiempo y espacio, para el cual su sistema numérico, simple, lógico y regular, les ha permitido contar y llevar registro de una serie de acontecimiento como: ciclos de la tierra, los fenómenos del universo y la naturaleza, años de las personas, establecer un calendario, cantidad de animales de cada familia, cantidad de terreno, integrantes de una familia, número de hijos, fecha de nacimiento, reparto de tierras, etc.. Para ello, han cultivado su propio conocimiento matemático que se basa en un sistema de numeración decimal regular no posicional, como podremos apreciar en el siguiente apartado. Aun cuando su sistema numérico decimal no es posicional, las características de su Rakin, les ha permitido históricamente describir los fenómenos observados para desarrollar su Kimün, conocimiento ancestral. Para el sabio mapuche, observar una noche estrellada era observar un cuaderno de cálculos (Ñanculef, 2005). El conocimiento matemático, era tan importante como el conocimiento cíclico y la conocida teoría de conjuntos, que es la base del análisis del Meli Witxan Mapu, los cuatro tirantes de la tierra, conocido como los cuatro puntos cardinales.

El Meli Witxan Mapu es el conocimiento científico Mapuche de la cosmología, de la teoría de conjuntos, del movimiento de los planetas, del sistema solar, y por cierto del calendario Mapuche, como lo es la "Cruz Andina”, de nuestros hermanos Aymará. (Ñanculef, 2005)

Las primeras caracterizaciones del Rakin, como sistema de contar, es con la llegada de los españoles en el siglo XVII; el aporte de Valdivia es una de las bases para comprender la existencia de un conocimiento matemático mapuche. Luego ha habido otros estudios, que basados en los aportes de Valdivia, han descrito dicho conocimiento matemático, sin llegar a establecer la existencia de un sistema de numeración. En el actual modelo de EIB, hay nuevos investigadores que se están dando a la tarea de investigar en esta materia, aún con muy poca publicación en revistas científicas. 


\subsection{Metodología}

Al plantear este estudio, con dimensiones socio-políticas, socio-culturales e instruccionales, en un escenario en que confluyen los enfoques teóricos de la matemática crítica y la etnomatemática, se tomó la decisión de realizar una propuesta de investigación con varias cuestiones que han ido emergiendo en el proceso, las que trataremos de incorporar de manera coherente.

Como investigación cualitativa exploratoria descriptiva, interpretativa, la que desde la epistemología se inscribe en el paradigma del "relativismo" (Oliveras, 1996), por lo que asumimos los postulados acerca del conocimiento en cuanto es relativo y se puede definir de acuerdo a criterios locales que se ubican en cada sistema socio-histórico o ecosistema intelectual y así cada sujeto conoce contextualizadamente en su propio ecosistema (Oliveras, 2006). Se optó luego de un trabajo exploratorio inicial por un diseño que se enfocara en un fenómeno central como concepto a desarrollar y otros fenómenos relevantes que se interrelacionan directamente con el fenómeno central y entre sí (Sampieri, Fernández y Baptista, 2010), como se muestra en la figura 2.1. En cuanto a la muestra de nuestro estudio, ésta se compone de documentos históricos de la época hispánica, documentos oficiales públicos, investigaciones, comunicaciones, publicaciones públicas y privadas y participantes claves. Es una muestra guiada que incorpora muestra de experto (Sampieri et al, 2010), en nuestro caso un Kimche ${ }^{14}$ investigador e historiador, funcionario de la Corporación Nacional de Desarrollo Indígena (CONADI). En el proceso se tuvo acceso a dos casos-tipo, de estudiantes mapuches de $2^{\circ}$ año básico y sus profesoras, de dos regiones de nuestro país (Araucanía y Valparaíso), por conveniencia se incorporaron, ya que nos aporta riqueza para la comprensión fenomenológica de nuestro estudio y dan cuenta de algunos supuestos de nuestro marco teórico. Nuestras unidades de estudio se centran en los significados, las prácticas y las relaciones de los elementos de nuestro diseño, las que componen el complejo entramado del estudio y que nos permitirán describir de mejor forma la problemática para su interpretación y proyección.

\footnotetext{
${ }^{14}$ Sabio Mapuche
} 


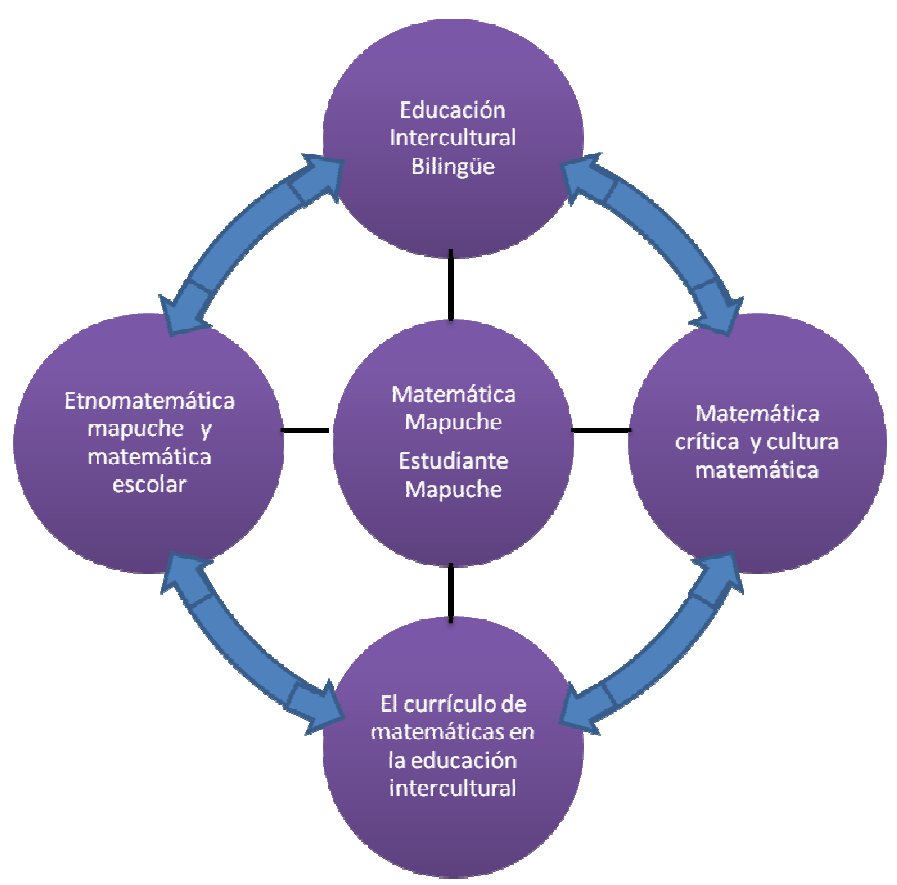

Figura 2.1. Configuración del estudio

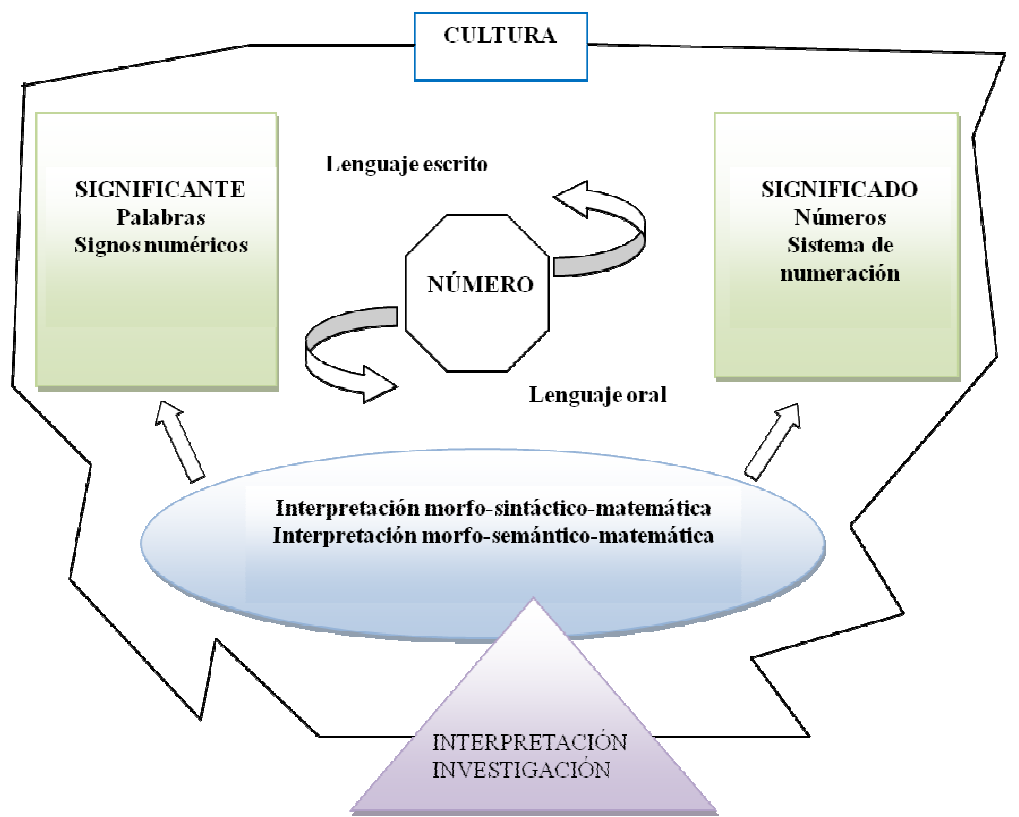

Figura 2.2. Esquema de interpretación morfo-matemática. De Bengoechea (2009).

La Figura 2.2 representa el esquema a seguir para la caracterización morfosintáctica y morfo-matemática del sistema de numeración oral mapuche (De Bengoechea, 2009). Este esquema planteado por De Bengoechea (2009) se fundamenta en un enfoque sociocultural del aprendizaje, el que aborda el significado y significante de las palabras numéricas y signos numéricos en un juego de lenguaje en el contexto cultural en que se plantea la investigación. Se abordan las palabras numéricas con un análisis 
morfosintáctico para identificar segmentos con significados numéricos, su ubicación relativa y el significado de ambos o la unión de éstos (De Bengoechea, 2009). Este análisis es aritmético, por cuanto persigue la interpretación aritmética de las palabras numéricas en mapunzugun.

\section{ETNOMATEMÁTICA EN EL CURRÍCULO ESCOLAR CHILENO}

En este apartado y consientes que el currículo de matemáticas actual no incorpora la etnomatemática mapuche, indagamos en los programas de lengua mapuzugun, en las orientaciones curriculares de matemáticas para contextos indígenas y en libros de textos de matemáticas anterior al año 2009 y actuales. Nuestro currículo nacional está orientado a la transmisión de contenidos que son establecidos a través de los estándares fijados a nivel nacional e internacional en torno al actual modelo por competencias que lidera la OCDE a través de PISA y nuestro país está inmerso en este proceso. Por ello consideramos necesario mirar cómo se ha planteado el conocimiento matemático del pueblo mapuche en el marco de la EIB, ya que por sus características es parte de su tradición oral, uno de los ejes temáticos ${ }^{15}$ de la EIB.

\subsection{Programa de estudio de la Lengua Mapuzugun}

Identificar los aspectos etnomatemáticos presentes en los Programas de Estudio de lengua "Mapuzugun" en los niveles de $1^{\circ}$ a $4^{\circ}$ año básico es fundamental para nuestra investigación. Esto nos permitirá la posterior descripción de la estructura morfomatemática. Estos programas se organizan en tres ejes temáticos: Tradición Oral, Comunicación Oral y Comunicación Escrita. Son una guía didáctica, que propone una serie de herramientas metodológicas para apoyar la gestión del docente en el aula; entrega una propuesta de clases y evaluación de aprendizajes. El Programa de estudios de la Lengua Mapuzugun (Ministerio de Educación, 2009) establece: los objetivos fundamentales (OF), contenidos mínimos obligatorios (CMO), como se muestra en el anexo 2, tabla 2.1; los objetivos fundamentales transversales (OFT) y los aprendizajes esperados (AE) y sus descriptores. Luego propone algunas actividades de las cuales enunciaremos sólo algunas para ejemplificar el uso del conocimiento matemático del Pueblo Mapuche (ver anexo 2). Finalmente presenta un resumen de los conceptos

\footnotetext{
${ }^{15}$ Uno de los temas centrales de que debe abordar la Educación Intercultural Bilingüe (EIB).
} 
abordados en la unidad con el repertorio lingüístico, mapa semántico y repertorio sintáctico.

Al revisar los programas de la Lengua Mapuzugun de $1^{\circ}$ a $4^{\circ}$ año de educación básica, nos hemos encontrado con la utilización de los números mapuches en los relatos escritos y orales, de los cuales seleccionamos algunos para visualizar nuestras afirmaciones y reflexionar sobre ello. Se puede apreciar en la Figura 2.1 del Anexo 2, un relato sugerido por el programa para la actividad en el aula (Ministerio de Educación. 2012. Lengua Mapuzugun, $3^{\circ}$ Básico, p. 57-58.). Esta actividad propuesta a los estudiantes tiene la particularidad matemática, que incorpora el numeral "dos mil" en la expresión "epu waragka”. El análisis de esta actividad nos lleva a plantear algunas interrogantes: ¿comprenderán la formación de números mayores a cien y la importancia del valor posicional?, ¿qué podemos intuir sobre las facetas interaccional, mediacional y ecológica del $\mathrm{CDM}^{16}$ del profesor?, sería interesante observar ¿qué comprensión tienen los estudiantes, a esa edad, del número epu waragka?, ¿cómo es planteado el aprendizaje a los estudiantes en el aula de matemática? De acuerdo al programa de matemáticas, para este nivel, el ámbito numérico de trabajo es hasta el 1.000 (Ministerio de Educación, 2012. Matemáticas $3^{\circ}$ Básico. p. 42). Esta expresión verbal del número dos mil, es una expresión compuesta con yuxtaposición de multiplicación de acuerdo a su estructura morfo-matemático, "epu waragka", es decir dos por mil. Desde la matemática podemos indicar que es un constructo complejo por la ubicación posicional de los dígitos, la presencia del "cero" y la yuxtaposición (multiplicación).

En otras oportunidades nos encontramos con relatos escritos en mapuzugun, pero utilizando los símbolos numéricos del sistema decimal posicional como se muestra en la Figura 2.2 del Anexo 2, (Ministerio de Educación, 2013. Lengua Mapuzugun, $4^{\text {o }}$ Básico, p. 122-123). En esta actividad se propone a los estudiantes un formato de escritura de una invitación, asumiendo a priori que los estudiantes, en este curso, son capaces de comprender la relación dialógica entre la etnomatemática mapuche y la matemática escolar, lo que les permite decidir cómo leer el símbolo numérico. Observar esta actuación, nos ayudaría identificar posibles ventajas y/o dificultades de aprendizaje en la articulación dialógica de dos conocimientos matemáticos.

Luego nos encontramos con una actividad propuesta en $2^{\circ}$ básico, en que se plantea a los estudiantes la forma de preguntar la hora y de responder en mapunzugun y español,

\footnotetext{
${ }^{16}$ Conocimiento Didáctico-Matemático del profesor de matemática. (ver Godino, 2009).
} 
como se aprecia en la Figura 2.3 del Anexo 2, (Ministerio de Educación, 2011. Lengua Mapuzugun para $2^{\circ}$ Básico, p. 72.). En esta actividad se plantea la orientación didáctica que hace mención a la importancia de la idea de cantidad, sin embargo no indica la enseñanza y aprendizaje de esta idea desde la escuela. Sólo menciona.... "Es necesario tener presente que Tunten y Chunten son dos conceptos que aluden a la idea de cantidad (¿cuánto?)”. Que complejo escenario, porque el estudiante de $2^{\mathrm{a}}$ básico debe "comprender cómo preguntar y decir la hora en mapunzugun" y relacionar este aprendizaje con un sistema de símbolos matemáticos $(1,2,3, \ldots)$, sobre un sistema de numeración sexagesimal (horario de base 60), su conocimiento de origen del tiempo y el espacio (medio día, antes de la puesta de sol, al ponerse el sol, etc.), un sistema de códigos lingüísticos en castellano (son las tres de la tarde, son las tres de la mañana, etc.) y finalmente asignar un significado al aprendizaje. Otro aspecto interesante de observar en la cognición del estudiante, ¿qué favorece o dificulta este aprendizaje?, ¿cómo se articulan estos saberes en la instrucción y en la cognición del estudiante? y otras interrogantes. Una parte de la actividad mencionada la vemos en la siguiente figura 2.3 del Anexo 2.

\section{* Aprenden a preguntar la hora: ¿Chunten pürapay antü?'¿Qué höa es?'}

\section{Ejemplos de posibles respuestas de uso frecuente:}

\begin{tabular}{|c|c|}
\hline $\begin{array}{l}\text { Regle horagey. } \\
\text { Mari horagey punh mu. } \\
\text { Kechu puwal kayugey. } \\
\text { Melhi hora naqanthü. }\end{array}$ & $\begin{array}{l}\text { 'Son las siete'. } \\
\text { 'Son las diez de la noche'. } \\
\text { 'Son cinco para las seis'. } \\
\text { 'Son las cuatro de la tarde'. }\end{array}$ \\
\hline $\begin{array}{l}\text { Epu Mari minutu rupal } \\
\text { kechu horagey, naqanthü. }\end{array}$ & Son las cinco y veinte de la tarde'. \\
\hline $\begin{array}{l}\text { Mari kechu minutu } \\
\text { rupal külha horagey }\end{array}$ & 'Son las tres y quince minutos'. \\
\hline
\end{tabular}

Parte de la actividad planteada en la Figura 2.3 del Anexo 2.

En la Figura 2.4 del Anexo 2, (Ministerio de Educación, 2011. Lengua Mapuzugun $2^{\circ}$ básico p. 83) propone una actividad relacionada con las actividades cotidianas de los niños en sus hogares. Compartes ideas como ir a buscar una cantidad de productos, hacer tareas como buscar una cantidad de palabras, todas ellas en mapuzugun. En esta actividad podemos apreciar el uso de la cantidad como cardinal de un conjunto específico. Sería interesante observar ¿qué conocimientos matemáticos pone en juego el 
estudiantes?, ¿utiliza su conocimiento de la matemática mapuche o de la matemática escolar? para comprender la instrucción y ejecutar la acción. Se valida en esta actividad, que a priori, se asume que hay un conocimiento matemático que utilizan los estudiantes en su contexto de origen. En la Figura 2.5 del Anexo 2 (Ministerio de Educación, 2011. Lengua Mapuzugun para $1^{\circ}$ Básico, p. 50.), se propone una actividad sobre versos tradicionales en la que se aprecian las palabras numéricas en mapuzugun. En ésta hay un uso de cuantificadores como parte de su tradición oral, sin embargo en el repertorio lingüístico, mapa semántico y repertorio sintáctico, so se hace alusión a la enseñanza y aprendizaje de éstos. Apriori se asume que los números en palabras (transitiva o intransitivamente) es parte de la cultura de origen que trae el estudiante a la escuela, por cuanto no requiere atención didáctica. ¿Qué sucede con la codificación y descodificación de los pequeños estudiantes de $1^{\circ}$ básico, en el proceso lingüístico y simbólico matemático? Sería interesante indagar sobre estos procesos, para sistematizar las correspondencias que establecen los estudiantes cognitivamente en el proceso de escolarización inicial.

En concordancia con los objetivos del programa de lengua mapuzugun, se aprecia que los estudiantes indígenas se familiarizan con los usos frecuentes de su lenguaje materno; sin embargo, el programa después de cada unidad presenta el repertorio lingüístico y mapas semánticos trabajados en cada lección, como son los verbos, sustantivos, adjetivos, poderes de la naturaleza, fiestas religiosa, oraciones, palabras de uso común, etc.; pero no menciona en ninguna lección el conocimiento matemático mapuche que está presente en ellos, como tampoco el artefacto kipu o püron ${ }^{17}$ mapuche, como sistema de registro del conteo. Hay una actividad en que se trabaja con formas geométricas (Figura 2.6. Anexo 2) y para ello se propone al docente o educador tradicional, en la orientaciones, introducir previamente las formas geométricas a trabajar, que se establecieron en el Taller de Renovación Lexical del Mapuzugun en mayo de 1996 (Ministerio de Educación, 2012. Lengua Mapuzugun 3º Básico, p 131132.). En las orientaciones didácticas de esta actividad hay una única mención a los números hasta el diez y luego hasta el cien de diez en diez, como se muestra en la Figura 2.6 del Anexo 2. Los conceptos geométricos abordados quedan reflejados en el repertorio sintáctico y el mapa semántico como se aprecia en la Figura 2.7 del Anexo 2. Las orientaciones dadas al docente para el tratamiento de cada contenido de estudio, se

\footnotetext{
${ }^{17}$ Artefacto mapuche de hilos horizontales tejidos y verticales sueltos, en las que registran a través de nudos.
} 
relaciona con el "Kimün" desde una mirada antropológica cultural, acentuado la focalización en los aspectos lingüísticos de lo estudiado. Sin embargo, el Kimün es un concepto amplio e integrador de la cosmovisión en la cultura del pueblo mapuche y hay aspectos de éste, que no son atendidos por los programas como es el caso del Rakin ${ }^{18}$, que si bien está presente en las ideas de "contar", "cardinal", "ordinal" no son estudiadas desde la lingüística. Los estudios revisados y los actuales grafemarios $\left(\mathrm{CONADI}^{19}, 2005\right)$ en mapunzugun indican que los numerales son parte del lenguaje tradicional mapuche y por tanto es necesario estudiarlos desde la lingüística y desde la matemática. El no abordar sus características morfosintácticas y su estructura morfomatemáticas origina lo que vemos hoy en el programa de lengua mapunzugun, que son aprendidas como palabras sueltas en versos recitados, sin asignarle significado ni con la profundidad que merece el estudio del Rakin.

Esta revisión refleja que de alguna forma, los programas de Lengua Mapuzugun dan cuenta de aspectos sociales y culturales del Pueblo Mapuche, es decir el “....Mapuzugun es portadora de la historia, filosofía, religiosidad y cultura del pueblo mapuche...." (Ministerio de Educación. 2012. Lengua Mapuzugun, $3^{\circ}$ Básico.). Sin embargo, quedamos con la sensación que los programas de Lengua Mapuzugun no reflejan el espíritu de la EIB, en cuanto al fortalecimiento de la identidad estudiante mapuche, por cuanto hay contenido matemáticos utilizados por estos programas que no son tratados con la importancia epistémica que tienen y se merecen. En nuestra revisión se constata la utilización constante de expresiones orales que aluden al conocimiento matemático mapuche, por lo que se hace imprescindible su estudio y comprensión. El comprender el significado institucional y personal de la aritmética mapuche presente en sus prácticas cotidianas, nos permitirá contar con herramientas analíticas para la articulación del conocimiento matemático mapuche y la matemática escolar, que promueva un aprendizaje significativo y crítico de las matemáticas actuales comprendiendo las ventajas y/o limitaciones de cada una en su contexto.

\subsection{Orientaciones curriculares en matemáticas para contextos interculturales}

Nuestro currículo de matemáticas establece los estándares mínimos a alcanzar en este sector (asignatura) de aprendizaje por todos los estudiantes en los distintos niveles educacionales en todo el territorio nacional, sin distinción de raza, credo, nivel

\footnotetext{
${ }^{18}$ Sistema de conteo mapuche

${ }^{19}$ Corporación de Desarrollo Indígena
} 
socioeconómico ni ningún otro tipo de excepción. Sin embargo, en el caso de la EIB, el Ministerio de Educación en colaboración directa con otros organismos del estado, como lo es la Corporación Nacional de Desarrollo Indígena, han elaborado documentos específicos para otros sectores de aprendizaje, lenguaje, matemáticas, comprensión del medio social, educación física, educación artística y educación tecnológica; a modo de orientaciones didácticas para la contextualización de los planes y programas nacionales en la educación intercultural bilingüe. Es así, como existe el documento específico de matemática, el que conjuga de alguna manera la propuesta didáctica del programa oficial de matemática para la educación básica y el contexto cultural en que se implementará esta enseñanza.

Este documento se estructura de la misma forma que los programas del SLI, ya que presenta, para cada uno de sus ejes temáticos: números, operaciones aritméticas, forma y espacio; los objetivos fundamentales verticales (OFV) y los contenidos mínimos obligatorios (CMO). Luego para cada semestre se presentan los aprendizajes esperados (AE), las actividades genérica (ver tabla 3.1 del anexo 3) y la propuesta de evaluación. Es importante señalar, que este documento se elaboró en el año 2005 en el marco de ley vigente en ese entonces, la Ley Orgánica Constitucional de Enseñanza (LOCE), por ello mantiene la estructura, objetivos y contenidos de acuerdo al currículo de matemáticas anterior a los ajustes curriculares que han introducidos a partir de la actual LGE a partir del año 2009.

Desde nuestro marco conceptual y de acuerdo a nuestros objetivos trazados, hemos mirado el primer semestre del nivel $1^{\circ}$ y $2^{\circ}$ básico en el eje temático "Números", para vislumbrar los aspectos etnomatemáticos y exponer el actual escenario institucional de la educación matemática en el marco de la EIB. Por ser este estudio de tipo exploratorio no hemos generado categorías, ya que sólo buscamos la presencia de la etnomatemática mapuche. En primer lugar, para evidenciar su reconocimiento oficial y por último observar cómo es abordado el diseño didáctico propuesto por la institucionalidad. Por ello, en la tabla 3.1 del anexo 3 presentamos las sugerencias de actividades matemáticas propuestas por la institucionalidad para contextos interculturales, en los momentos iniciales de la escolarización.

El primer encuentro con este documento, en la búsqueda de la etnomatemática, fue con su concepción de la matemática y su objetivo, lo que reafirma la dimensión sociopolítica de la matemática en la historia (Vithal y Skovsmose, 1997), ya que dice en la presentación. 
“(...) el objetivo de este subsector es convertirse en un motor de razonamiento poderoso que le acompañe en el transcurso de toda su vida, entregándoles herramientas para poder entender que hay otro mundo, organizado y perfecto, más allá de las caóticas sensaciones” (Ministerio de Educación, 2005, p. 129).

Desde nuestro punto de vista socio-crítico y asumiendo las dimensiones socio-políticas de la educación crítica y la etnomatemática, que de alguna forma se ven cargadas de ideología, reafirmamos que la educación matemática también tiene su cuestión ideológica en su dimensión socio-política, como apreciamos en párrafo anterior y que marca nuestro currículo nacional. Decir que el estudio de la matemática escolar te entregará herramientas para "entender" que existe un mundo organizado y perfecto más allá de las caóticas sensaciones (Ministerio de Educación, 2005, p.129), pero no para insertarse en él, es transmitir una ideología sociopolítica de la matemática. Aún cuando el discurso de neutralidad ideológica de la matemática en el currículo (Moreno, 2004) se hace explícita en la dialéctica discursiva. Este párrafo nos hace reflexionar sobre los valores inherentes que pretende transferir el currículo de matemática en ámbito formal. Sólo compartimos la idea de ser un motor de razonamiento, pero al servicio del desarrollo del pensamiento crítico que les permita la toma decisiones para un mejor porvenir.

Luego sugiere la contextualización de los contenidos a estudiar, haciendo mención a los patrones de enseñanzas en la cultura de los pueblos indígenas como lo es la observación, actitud analítica, la conversación reflexiva, como herramienta de planteamientos de problemas y la comunión equilibrada con la naturaleza, que promueve el orden, equilibrio y simetría. Las orientaciones curriculares contienen la matemática escolar que proponen los programas nacionales para la educación chilena, con las correspondientes recomendaciones y sugerencias didácticas para contextualizar las actividades propuestas a los estudiantes en contexto indígena. Sin embargo, la transposición didáctica del saber matemático, mapuche y escolar, a enseñar para el contexto mapuche requiere más que una orientación a la contextualización de las actividades. Requiere que los profesores tengan un conocimiento didáctico matemático (CDM) (Godino, 2009) que les provea de herramientas teóricas y metodológicas para enfrentar este desafío de articular dos o más saberes matemáticos de manera adecuada. Las orientaciones plantean sugerencias, como “(...) es necesario que el docente, si no es hablante de lengua indígena, al menos se interiorice de la cosmovisión del pueblo de origen, preocupándose de conocer la forma de nombrar, contar y comprender el 
mundo....", de la procedencia étnica de sus estudiantes (Ministerio de Educación, 2005). Es decir, hace hincapié en el CDM del profesor de matemáticas, específicamente en la dimensión didáctica del conocimiento del profesor en cuanto a las facetas: epistémica, cognitiva, afectiva, ecológica, interaccional y mediacional (Godino, 2009), para la enseñanza de la matemática escolar en las comunidades indígenas. Sin embargo, estos profesores no han sido formados con tales conocimientos para la enseñanza de la matemática mapuche y escolar en este contexto. Es decir, les transfiere a los profesores de aula gran responsabilidad sin haberles dotado de las herramientas necesarias para ello; entonces nos preguntamos ¿el conocimiento matemático mapuche está sistematizado e institucionalizado?, ¿los libros de texto incluyen conocimiento matemático en mapuzugun?, ¿la formación de profesores de matemáticas aborda el CDM del profesor e incorpora el conocimiento de las culturas originarias?, ¿en qué conocimientos se apoyan los profesores de aula para preparar las enseñanza de la matemática escolar en escuelas situadas en contexto mapuche? De acuerdo a nuestra revisión, hemos constatado que los libros de textos son uniformes para toda la educación básica en el país y no incluyen conocimientos etnomatemáticos de las culturas originarias. Sobre investigaciones, desde la didáctica de la matemática, que sistematice el conocimiento matemático de las culturas originarias y cómo se puede articular con la matemática escolar, ya hemos mencionado que no existen. Sin embargo, con la implementación de la EIB se están creando oportunidades de investigar en esta materia. Sobre el CDM del profesor de matemática de educación básica en nuestro país, la investigación es incipiente. Sin embargo, no hay antecedentes sobre la formación de profesores de matemáticas para contextos interculturales. Actualmente la Universidad Católica de Temuco imparte la carrera de Profesor de Educación Básica Intercultural en Contexto Mapuche el que contempla algunos cursos de matemática mapuche, pero de acuerdo a los antecedentes recogidos, en estos módulos se aborda la contextualización de los contenidos del currículo de matemática nacional a la cultura del pueblo mapuche. Otra recomendación al docente, dice: (...) el profesor debe tener presente que se está nombrando los números en dos lenguas, pero la escritura es en una sola. (Ministerio de Educación, 2005. p. 143.). En los ejemplos dados por el programa de lengua mapuzugun encontramos muchos números mapuches en palabras y si los estudiantes no los escriben en mapuzugun, ¿cómo los reconocen en los textos que leen? Considerando, además, que los programas de mapuzugun, no promueven el estudio de las palabras numéricas. Por ello, creemos que esta recomendación hace referencia a la escritura 
simbólica numérica y no a la escritura en palabras. Entonces, ¿los números en palabras deben ser escritos en castellano?, esta interrogante no encuentra respuesta en la revisión. Sería interesante abordar la escritura en mapuzugun de los números para observar si este conocimiento favorece la comprensión de su estructura morfo-matemática y la interpretación aritmética.

Este documento oficial, reconoce la existencia de los sistemas numéricos aymara, mapuche y lican antai como (...) de base decimal y con características análogas al sistema occidental de base diez..(Ministerio de Educación, 2005. p. 130.). Sin embargo, no plantea cómo articular estas características ni explicita qué relaciones se pueden establecer entre sus regularidades. La dificultad en este aspecto, es que no existen investigaciones que aclaren dichas relaciones en términos matemático y que sirvan de ayuda al profesor en cuanto al diseño de la instrucción en el aula que favorezca el establecimiento de correspondencia entre dos culturas matemáticas distintas.

Estas orientaciones insiste en el uso de ambas lenguas en la oralidad (castellano y mapuzugun), como se plantea en el inicio de la escolarización con la actividad de (...) El profesor pide a los niños que nombren a coro las partes de su cuerpo, en ambas lenguas (una cabeza, dos orejas, cinco dedos etc.) (Actividad genérica 1 p.139. Tabla 3.1. Anexo 3), lo que indica un primer encuentro entre ambas culturas matemáticas, asumiendo que los estudiantes ingresan a $1^{\circ}$ básico bilingües y que comprenden la estructura morfo-matemática de los números en palabras en castellano y mapuzugun. Nos preguntamos ¿para qué un aprendizaje intransitivo en dos lenguas?, sería interesante observar que ventajas para el aprendizaje transitivo de la noción de cantidad otorga esta actividad. Luego, en la misma actividad, sugiere la introducción del concepto "cero", sustentado en algo concreto y para ello propone.

(...) El profesor agrupa a los niños y niñas de a tres y les nombra algún número, en ambas lenguas. Lo escribe en la pizarra, pidiéndole que lo representen con los dedos de sus manos. Si pedimos un número menor que 3, uno o dos niños no aportan dedo, con lo que expresamos la idea de que un niño no aporta nada, introduciendo el concepto de cero, sustentado sobre algo concreto (Actividad genérica 1. p.139. Tabla 3.1. Anexo 3).

Este párrafo manifiesta el aprendizaje del cero como dígito que representa la ausencia de algo, sin embargo creemos que en el tratamiento del cero debe haber un análisis didáctico matemático más profundo de como incorporar su simbología en el conocimiento matemático mapuche, ya que de acuerdo a su cosmovisión existen 
palabras para indicar la ausencia de objetos concretos como lo es "ñielay" (Actividad genérica 1. p.139. Tabla 3.1. Anexo 3) y tenían un forma de registro que indicaba tal ausencia. En relación a este problema de las palabras para nombrar los números, se plantea al docente:

(...) Es importante para el profesor observar con detalle las respuestas que darán los alumnos a la pregunta ¿qué otros nombres pueden tener los números once, doce, trece, catorce y quince? Se esperaran respuestas tales como: “dieciuno", “diecidos”. Lo anterior, indica que los niños están entendiendo la estructura de formación de números de dos cifras y están incorporando el nuevo conocimiento (Actividad genérica 1. p.139. Tabla 3.1. Anexo 3).

Esta orientación no considera que los números entre el "once" y "quince" en su oralidad y escritura castellana no se aprecia explícitamente la existencia del "diez" más la unidad. Para un adulto puede resultar fácil identificar que "on" es 1 y "ce" es 10, por lo tanto, once es 11. Pero a un niño de 5 o 6 años, no es tan obvio. Más aún, si viene con un conocimiento que le dice que "mari kiñe" es 11 porque mari es 10 y kiñe es 1 , entonces se tiene 10 (mari) $+1($ kiñe $)=11($ mari kiñe $)$ y se aprecia literalmente la presencia de 10 y 1 . Entonces, si el docente pregunta ¿de qué otra manera podemos nombrar "mari kiñe", "mari epu"? y es probable, no lo podemos asegurar, que el estudiante pueda decir "diez y uno", "diez y dos", ya que en mapuzugun podemos apreciar claramente la regularidad de la estructura morfo-matemática, es decir mari epu es $10+2$, por tanto en castellano sería diez y dos. Los matemáticos han convenido que el segmento "ce" representa al 10, pero podría ser que el estudiante asociara el agregado "ce" a "cero", por estar más cerca de su escritura literal. En este caso, se perdería la yuxtaposición de la adición en la formación del "doce" y no se comprendería que estamos frente a $10+2$ y no al $2+0$, como podría interpretarse literalmente la palabra doce, ya que el segmento "ce" está más cerca de parecerse a "cero" que a "diez". Complejo escenario, ya que la relación del símbolo numérico y la palabra, requiere de una abstracción en la comprensión de la formación sintáctica de esa palabra y la relación con el signo que representa. Entonces si se ha trabajado el aprender la secuencia numérica en palabras recitando y cantando, estamos frente a un aprendizaje “intransitivo" del número (Cid, Godino y Batanero 2003). Por tanto no se puede determinar que estén comprendiendo la estructura morfo-matemática, si no ha habido una adecuada articulación entre "mari kiñe" y "diez y uno", para luego llevarlos a la palabra "once". 
Otro aspecto interesante de destacar es la mención de los artefactos en las culturas andinas y mapuche para el acto de contar, con el uso del "Quipu" y "Müron" (Ministerio de Educación, 2005), respectivamente. En este sentido las orientaciones proponen un primer encuentro con estos artefactos en actividades iniciales en primero básico, una de ellas dice (...) Se sugiere desarrollar la actividad jugando con el püron (nudo) como inicio para el pueblo mapuche y jugando con el quipu (nudo) para el mundo andino (Actividad genérica 2. p.140. Tabla 3.3. Anexo 3). Según la historia precolombina, los "Quipu”, fue un tipo de sistema de registro contable común a varios pueblos precolombinos en América, siendo una herencia cultural milenaria en América. Según nuestro informante clave, Juan Nanculef Huaiquinao, este artefacto era

(...) "una especie de ábaco mapuche, construido sobre la base de un tejido de hilos horizontales tejidos y verticales sueltos. Los hubieron de 10 por 10, de 20 por 20, de 40 por 40, de 50 por 50, y otros infinitos, de hasta 100 por 100, es decir 100 hilos trenzados horizontales, por 100 hilos colgados verticales los que eran utilizados algo así como mágico religioso: el más común es el de $10 \times 10$, los que eran de uso simple, al parecer solo para sumar y restar”...

En las observaciones al docente, encontramos la recomendación de (...) “El profesor debe construir un muestrario de nudos con la finalidad de crear un set de elementos que puedan ser asociados a los números” (Actividad genérica 2. p.140. Tabla 3.3. Anexo 3). El püron (cultura mapuche) y el quipu (cultura andina) son elementos de gran fertilidad en el proceso de aprendizaje del acto de contar (Actividad genérica 2. p.140. Tabla 3.3. Anexo 3). Si bien recomienda el uso de artefactos, no hay en la literatura antecedentes sobre su utilización, entonces creemos que en este aspecto se requiere sistematizar dicho conocimiento para que sea de utilidad al docente. No es suficiente con decir "jugar con el püron" y hacer nudos, debe haber un constructo a desarrollar en ese juego, como puede ser el valor posicional.

En cuanto al desarrollo del concepto número asociado a cantidad, se aprecia un énfasis en la contextualización de la matemática escolar al mundo mapuche. Se recomienda al docente ir paulatinamente desarrollando el sentido de cantidad, pero no se aprecian las recomendaciones didácticas para dicho proceso. Luego destacamos la actividad de “Componer y descomponer en forma aditiva" (Actividad genérica 6. p.144. Tabla 3.3. Anexo 3), se orienta a que los estudiantes comprendan el recorrido de las "partes al total" o del "total a las partes". Se plantea un trabajo con fichas o con palitos, inmersos 
en la matemática escolar, sin mención a la matemática mapuche. En las observaciones al docente, encontramos la recomendación.

(..) El profesor debe tener en claro que, si bien el dominio de la composición y descomposición canónica es un objetivo, el cómo se alcance debe ser de manera flexible y creativa, exponiendo a los alumnos a variadas formas de descomposición y composición (Actividad genérica 6. p.144 Tabla 3.3. Anexo 3)

En este punto, se habla de la composición y descomposición numérica como objetivo para $1^{\circ}$ básico, pero no tiene en consideración que en edad el aprendizaje está, necesariamente, mediado por el habla y las regularidades de las palabras numéricas en mapuzugun podrían ser un potencial educativo. En el siguiente apartado analizaremos la estructura morfo-matemática de la escritura en palabras de los números en castellano y mapuzugun, si bien la asimilación de la escritura en castellano es compleja de entender a partir del "once" por los diferentes segmentos en palabras que representan las decenas, las centenas, unidades; toma importancia el aprovechar la regularidad de la estructura morfo-matemática de los números en mapuzugun, ya que éstos no cambian palabras, sólo cambian posición de acuerdo a la yuxtaposición (suma o multiplicación).

A modo de conclusión, podemos apreciar en ambos niveles un trabajo matemático escolar basado en el currículo de matemática monocultural, que pone énfasis a la contextualización de la matemática escolar a la cultura de origen de los estudiantes. Es importante señalar, aunque no profundizaremos en ello, que sería interesante comprender la dimensión institucional al referirse al "contexto", ya que como plantea Valero (2002) el contexto "esta" y "es", pero no necesariamente afecta lo que sucede en el aprendizaje y enseñanza de las matemáticas.

En esta revisión hemos podido constatar que hay presencia y reconocimiento formal de la etnomatemática mapuche, ésta no es abordada desde el punto de vista epistemológico como parte del "Kimün". Desde el punto de vista didáctico-matemático hay pocos argumentos en los que se puede sustentar el trabajo pedagógico en el aula, es decir no basta con contextualizar los contenidos sino además, deben apoyarse en conocimientos previos de tal forma que se articulen con los nuevos conocimientos a construir de manera significativa. Se aprecian los esfuerzos e intenciones, pero no son suficientes. Estos antecedentes ponen de manifiesto la necesidad de sistematizar el conocimiento matemático mapuche y de investigar sobre cómo incide la numeración hablada, en mapuzugun y en castellano, en el aprendizaje de la matemática escolar, cómo aprende el niño mapuche, cómo articular ambos conocimientos matemáticos, qué conocimientos 
didáctico-matemáticos necesita el docente de matemática para la educación básica que le permita atender la diversidad cultural y otras cuestiones. Más aún, si estos aprendizajes implican una re-significación y adaptación a códigos ajenos a su cultura. Si el conocimiento matemático de nuestros pueblos originarios, forman parte de su patrimonio cultural, entonces, debe re-valorarse y enseñarse en la escuela para potenciar el espíritu crítico y de reapropiación de su historia y patrimonio cultural.

\section{EL CASO DE LA ARITMÉTICA MAPUCHE}

Matemática mapuche, aritmética mapuche y conocimiento matemático mapuche son términos que tal vez no representan el Rakin como parte del Kimün, como tampoco representa el significado occidental para estas mismas palabras. En este estudio utilizamos estos términos para referirnos a distintos componentes de un conocimiento del pueblo mapuche; por ello cuando decimos "conocimiento matemático mapuche", nos referimos a un conocimiento más amplio relacionado con la cosmovisión, cosmología, circularidad y otros conceptos de la cultura de este pueblo. Matemática mapuche, alude a un conjunto de conceptos que lo componen (cardinales, ordinales, quebrados, geometría, etc); y al decir "aritmética mapuche" nos referimos a la numeración mapuche o sistema de conteo mapuche y a su forma de calcular. Para comprender y contextualizar la matemática mapuche, describiremos algunos aspectos de la matemática mapuche que nos conducirán al conocimiento de la aritmética mapuche.

\subsection{Características del Rakin, matemática mapuche.}

Toda sociedad y cultura ha desarrollado sus propias técnicas de recuento, al igual que el pueblo mapuche, que basa su recuento en unas palabras cuantificadoras que mantienen un orden lógico, es decir estas palabras en mapuzugun forman un conjunto ordenado en el que hay un primer elemento y un siguiente para cada una de ellas. Para obtener la cardinalidad del conjunto, se asigna a cada elemento contado una palabra numérica distinta y sólo una; la palabra asignada al último elemento contado representa la cardinalidad del conjunto (Cid et al. 2003).

Todo ser humano aprende a contar elementos u objetos tangibles, no se aprende a contar en abstracto y la existencia de números en palabras son fruto de la necesidad de contar algo concreto. La tarea compleja de contar es coordinar el número en palabras con los dedos de la mano, la vista o con la técnica de tachar o marcar lo que se cuenta. El 
sistema de conteo del pueblo Mapuche tiene su origen en la necesidad de contar y por ende, crearon el lenguaje numérico en palabras en la medida que tuvieron la necesidad de contar más y más elementos. Su sabiduría les permitió utilizar un grupo de diez palabras básicas con las cuales ampliaron el ámbito numérico. El valor de la cifra que forman dependerá de la ubicación de la palabra numérica. Incorporaron dos nuevas palabras para indicar unidades de segundo (decenas) y tercer (centenas) orden.

Las primeras descripciones de los numerales mapuches, usados como cardinales, se hicieron en el siglo XVII (1684) por el Padre Luis de Valdivia, quien en su obra describe los nombres de los números que los mapuches usaban al hablar, hasta el mil. Esta descripción es muy acertada con la actualidad, sólo existen algunas diferencias en la escritura de éstos, pero la dificultad morfosintáctica existe hasta hoy, ya que de acuerdo a la zona geográfica en la que se recogen los datos varía la información sobre su escritura (Belloli, 2009). Valdivia describe lo siguiente en su obra (...)

(...)Los nombres de numero que llaman Cardinales (por fer principios de todo numero, conque fe nobran los demàs) fon eftos. Quiñi.1. Epu.2. Quila. 3. Meli.4. Quecho.5. Cayo.6. Relge.1. relue.7. Pura.8. Aylla.9. Mari.10. Para dezir onze, dizen quiñe huente, y para dezir doze, dizen epu huente, y no es menefter añadir la palabra mori, diziendo mari quiñe huente, porque hafta el numero 19, fe entiende fiempre el mari, aunque no fe diga, por fer frafis elegáte dezir, quiñe huente, que es vno encima, dos encima \&c.Tanbien vfan decir mari quiñe 11. Mari epu, 12. Jin poner (huente. Epu mari. 20. Cula mari. 30. \&c. Pataca 100. Para dezir 21. dicen Eри mari quiñe huete.1. ери mari quiñe. Ери mari ери.22. \&c. Pataca quiñe huete 101. Huaranca-1000. Huaranca quiñe pataca huente 110. (...) Raquin es contar, enturaquin descontar(...).(Valdivia, 1684, p. 65)

Luego hubieron otros misioneros que describieron los cardinales, como el Jesuita Febrés en 1765, el que plantea algunas diferencia de escritura sobre el siete e incorpora el adverbio de cantidad "yom" en mapuzugun en la conformación de los números, indicando por ejemplo que el número 12 se escribía mari yom epu, es decir diez más dos. Sin embargo este aporte no ha tenido mayor impacto en la comunidad científica porque ningún otro investigador ha concordado con este hallazgo y el resto de las investigaciones corroboran que el principio aditivo ha estado siempre implícito en la oralidad del cardinal al verbalizar "mari epu" para referirse a doce.

Posteriormente la obra del Padre Augusta en 1903, Misionero Apostólico Capuchino, describe más exhaustivamente la matemática del pueblo mapuche, abordando los 
cardinales, ordinales, partitivos, distributivos, colectivos, múltiplos, división utilizada por el pueblo mapuche. En este trabajo aparece un nuevo vocablo que es "millón", un concepto adquirido de la cultura occidental, ya que de acuerdo a la estructura regular de conteo en mapuzugun, un millón sería "waragka waragka" (1.000 por 1.000). Este aporte es significativo, ya que no sólo describe la estructura sintáctica de los números cardinales sino que aborda otros aspectos de la matemática mapuche y de manera incipiente la forma de calcular del pueblo mapuche. De Augusta (1903) describe los cardinales en la página 33 de su obra y señala que la composición de los números es tan fácil que no requiere explicación. El sustantivo acompañado del numeral no necesita signo plural $(\ldots)$

(...) 1 kiñe, 2 epu, 3 küla, 4 meli, 5 kechu, 6 kayu, 7 re,lge ó regle, 8 pura, 9 ailla, 10 mari ó kiñe mari, 11 mari kiñe o kiñe mari kiñe, 12 mari epu, 13 mari küla, 14 mari meli, 15 mari kechu, 16 mari kayu, 17 mari regle, 18 mari pura, 19 mari ailla, 20 ери mari, 21 ери mari kiñe, 22 ери mari ери, 23 ери mari küla, 24 epu mari meli, 30 küla mari, 40 meli mari, 50 kechu mari, 60 kayu mari, 70 regle mari, 80 pura mari, 90 ailla mari, 100 pataka ó kiñe pataka, 101 pataka ka kiñe, 102 pataka ka epu, 112 pataka kiñe mari epu, 195 pataka ailla mari kechu, 200 epu pataka, 300 küla pataka, 400 meli pataka, 900 ailla pataka, 1000 waranka ó kiñe waranka, 2000 epu waranka, 10000 kiñe mari waranka, 20000epu mari waranka, 100000 pataka waranka, 900000 ailla pataka waranka, 1000000 millon ó kiñe millón, 526 kechu pataka epu mari kayu, 6638 kayu earanka kayu pataka küla mari pura, 24621 epu mari meli waranka kayu pataka epu mari kiñe, 2702315 epu millón regle pataka ka epu waranka küla pataka kiñe mari kechu (...)(De Augusta, 1903, p. 33)

La utilización de las partículas "ka" y "chi”, hacen alusión a los términos suma y multiplicación respectivamente, pero habitualmente ellos no la explicitaban; es posible que esta incorporación en la escritura fuese producto de la aculturación. En la página siguiente Augusta nos describe los ordinales, y sus reglas de formación en mapuzugun $(\ldots)$

(...) $1^{o}$ Se forman los ordinales agregando el numeral cardinal, nelu, que es el participio del verbo nen, ó lelu.

\footnotetext{
${ }^{20}$ También se puede encontrar escrito como "warangka" o "waranka". El fonema es parecido a "n".
} 
Aunque la lengua tenga numerales ordinales, parece que no se usan con frecuencia, excepto Wonen é inan.

$2^{o}$ Las formas en nelu y lelu son participios y se posponen al sustantivo; sustituyéndose lu por chi se adjetivan, entonces se le anteponen.

\section{Carles tercero, $\quad$ külanechi Karlos}

Fernando primero, wanen Fernando

Lección doce, $\quad$ lección mari epu ó mari epunelu, ó mari epunechi leccion (....)

Según este autor, los mapuches, sin tener conocimiento de fracciones eran capaces de expresar: medio pan, kiñe raniñ kofke (un medio pan); medio año, kiñe raniñ tripantu (un medio año) y hace mención a que (....)

Los indios no conocen las fracciones, pero parece que no habría inconveniente en adoptar las denominaciones que á continuación se expresan, ya que se asimilan al genio y á la índole del idioma

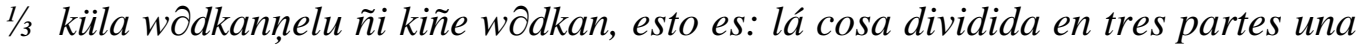

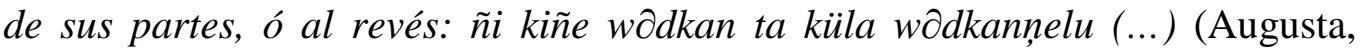
1903. p. 35)

Luego analiza los múltiplos, en la misma obra, señalando que comprenden el sentido de dos veces, tres veces,... Nos explica que en frases como "dos veces más" no se expresa el sustantivo "veces", y así dicen: epu fenten, küla fenten (dos tantos, tres tantos), y transformando fenten en el verbo fentenn, ser tan grande, ó ser tanto, dicen: epu fenteni, es dos veces más grande; mari fenteni, es diez veces más grande (Augusta, 1903. p. 36). En el mismo párrafo plantea una forma en que los mapuches comprenden bien la multiplicación, es decir ya se trabaja en la enculturación matemática, pero Augusta en esa época consideraba el conocimiento previo propio de la cultura del pueblo mapuche. Augusta en la página 36 propone para el aprendizaje de la multiplicación:

3 veces 4 son doce küla naq meli - mariepu

Küla naq meli ta mariepu

Küla naq meli mariepu nei

En relación al reparto, Augusta describe una forma en que entendían la división utilizando su concepción de la multiplicación, “...tengo tanto, tantas veces...”. En este sentido, Augusta, buscaba una forma de interpretar el razonamiento matemático de la cultura indígena de la época. Completa esta descripción con el método de operar con la adición y sustracción. Mostrando que la adición era parte a parte, es decir cuando habían 
tres sumando, sumaban dos primeros y luego el resultado lo sumaban con el siguiente sumando. En el caso de la sustracción, cuenta Augusta, que del minuendo salía una cantidad y quedaba una diferencia (Augusta, 1903. p. 36).

Luego de más de 70 años, la descripción de los numerales del pueblo mapuche realizada por Augusta, ha servido de base para investigaciones posteriores como la de Adalberto Salas (1980), que no aporta nuevos antecedentes, sin embargo actualiza la investigación sobre el conocimiento matemático del pueblo mapuche e interpreta la composición de las palabras cuantificadoras, de acuerdo a los principios aditivos y multiplicativos que subyacen en ellas.

En el nuevo contexto socio-político del país a partir de los años noventa, entre los años 1996 y 2009, el programa de estudios de Educación Matemática para $7^{\circ}$ año básico, establecía la unidad didáctica denominada "Sistemas de numeración en la historia y actuales" (Ministerio de Educación, 2002). El tipo de actividad propuesto por el marco curricular de la época, propició que los textos escolares (Ministerio de Educación, 2004) de ese entonces, incorporaran los números mapuches en dicha unidad de aprendizaje, como se aprecia en la figura 4.1. La actual Ley General de Educación (LGE) aprobada el año 2009, introduce nuevos ajustes curriculares y retira esta unidad didáctica del currículo de matemáticas. Los libros de textos también retiran esta unidad y desde esa fecha no existe presencia de etnomatemática mapuche en ellos.
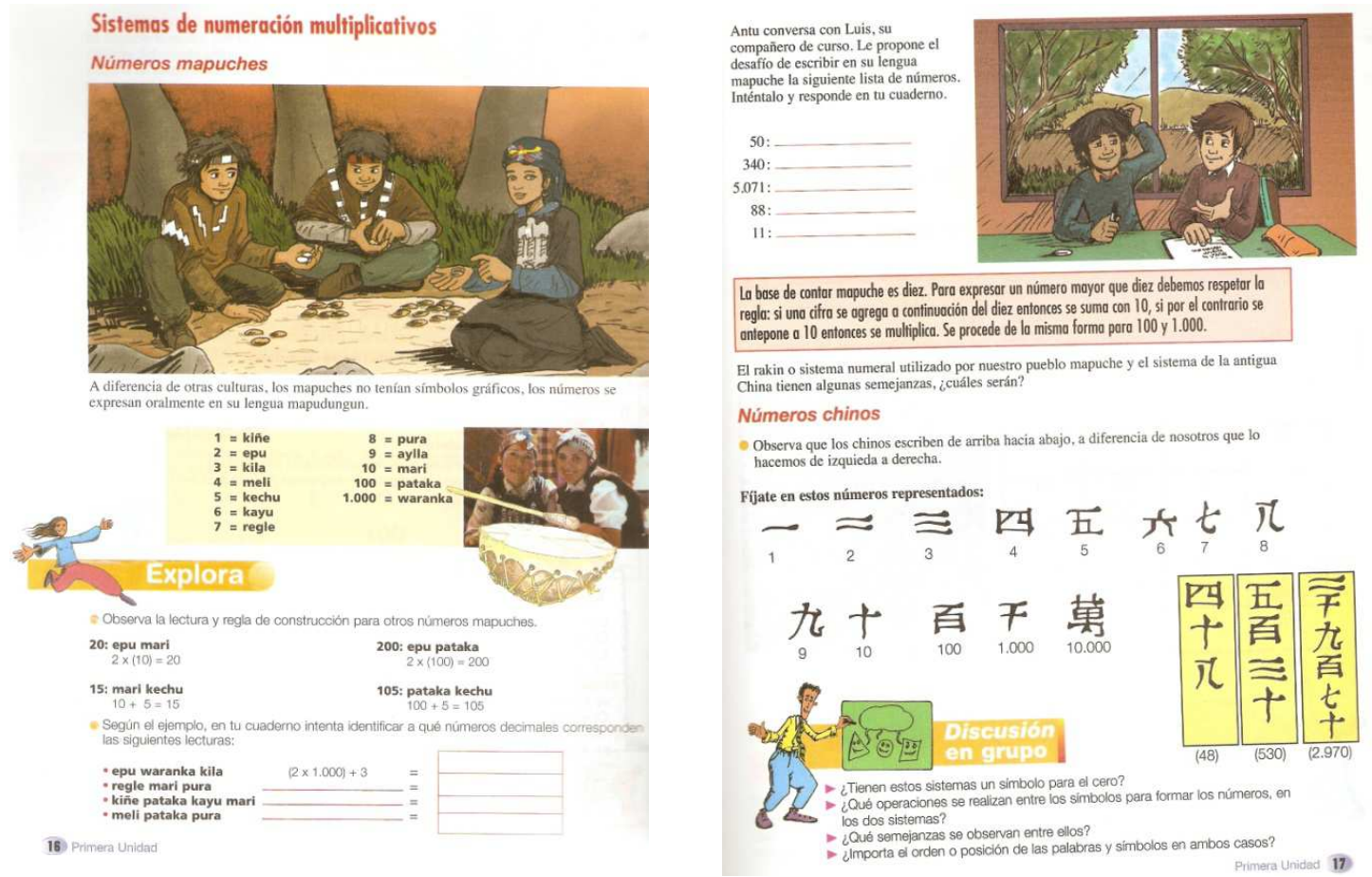

Figura 4.1 Actividades Libro de texto 2004 - 2005. Editorial Cal y Canto. MINEDUC. 


\subsection{Análisis Morfo-matemático}

Con los antecedentes encontrados en este estudio y el marco propuesto por De Bengoechea desarrollamos nuestra descripción morfo-matemática de la numeración oral en castellano y mapuzugun.

Tabla 4.1. Los primeros 20 números en español.

\begin{tabular}{|l|l|l|l|l|l|l|}
\hline Número & Castellano & Interpretación aritmética & & Número & Castellano & Interpretación aritmética \\
\hline 1 & Uno & 1 & 11 & Once & $1+10$ \\
\hline 2 & Dos & $1+1$ & 12 & Doce & $2+10$ \\
\hline 3 & Tres & $2+1$ & 13 & Trece & $3+10$ \\
\hline 4 & Cuatro & $3+1$ & 14 & Catorce & $4+0$ \\
\hline 5 & Cinco & $4+1$ & 15 & Quince & $5+10$ \\
\hline 6 & Seis & $5+1$ & 16 & Dieciséis & $10+6$ \\
\hline 7 & Siete & $6+1$ & 17 & Diecisiete & $10+7$ \\
\hline 8 & Ocho & $7+1$ & 18 & Dieciocho & $10+8$ \\
\hline 9 & Nueve & $8+1$ & 19 & Diecinueve & $10+9$ \\
\hline 10 & Diez & $9+1$ & 20 & Veinte & $2(10)$ ó $10+10$ \\
\hline
\end{tabular}

Como se observa en la Tabla 4.1, los primeros 10 números se forman agregando uno al número inmediatamente anterior. También se puede apreciar que de acuerdo a su expresión oral, se puede establecer una interpretación numérica. Aparecen nuevas palabras con los números del 11 al 15 que tienen en común el término "ce" que se corresponde con diez y con los prefijos on (uno), do (dos), tre (tres) y cator (cuatro) y quin (cinco). Luego observamos que los números del 16 al 19 tienen en común la palabra "dieci" que representa a diez y puede o no tener la conjunción "y" para formar la expresión oral de estos números, agregando la palabra que representa al 6, 7, 8 y 9. El veinte es una nueva palabra y su interpretación puede ser aditiva o multiplicativa.

En la tabla 4.1 podemos apreciar la complejidad de la estructura morfosintáctica de las palabras numérica en castellano, que deben aprender los estudiantes los primeros años de escolarización y que se inicia de manera intransitiva. Si observamos su estructura morfo-matemáticas podemos apreciar sus irregularidades a partir del "once". No se aprecia claramente la participación del diez ni la yuxtaposición en términos de un aprendizaje inductivo. Es decir, escenario de aprendizaje complejo por cuanto se ponen en juego los procesos de codificación y descodificación, la correspondencia entre la palabra numérica y el símbolo. Como reporta De Bengoechea en su estudio, sólo en los 
primeros 20 números encontramos cuatro maneras diferentes para decir "10" (diez, ce, dieci, inte) y para decir “2” tenemos tres forma (dos, do y ve).

En la siguiente tabla (4.2) observamos los primeros veinte números en mapuzugun.

Tabla 4.2. Los primeros 20 números en mapuzugun.

\begin{tabular}{|l|l|l|l|l|l|l|}
\hline Número & Mapuzugun & $\begin{array}{l}\text { Interpretación } \\
\text { aritmética }\end{array}$ & Número & Mapuzugun & $\begin{array}{l}\text { Interpretación } \\
\text { aritmética }\end{array}$ \\
\hline 1 & Kiñe & 1 & 11 & Mari kiñe & $10+1$ \\
\hline 2 & Epu & $1+1$ & 12 & Mari epu & $10+2$ \\
\hline 3 & Küla & $2+1$ & 13 & Mari küla & $10+3$ \\
\hline 4 & Meli & $3+1$ & 14 & Mari meli & $10+4$ \\
\hline 5 & Kechu & $4+1$ & 15 & Mari kechu & $10+5$ \\
\hline 6 & Kayu & $5+1$ & 16 & Mari kayu & $10+6$ \\
\hline 7 & Regle & $6+1$ & 17 & Mari regle & $10+7$ \\
\hline 8 & Pura & $7+1$ & 18 & Mari pura & $10+8$ \\
\hline 9 & Aylla & $8+1$ & 19 & Mari aylla & $10+9$ \\
\hline 10 & Mari & $9+1$ & 20 & Epu mari & $2(10)$ \\
\hline
\end{tabular}

Como se observa en la Tabla 4.2, los primeros 10 números se forman agregando uno al número inmediatamente anterior, se aprecia en esta regularidad uno de los Axiomas de Peano "Todo número natural $n$ tiene un único sucesor $n+1$ ”. El 1 no es sucesor de ningún número. De acuerdo a su expresión oral, se puede establecer una interpretación numérica desde nuestro conocimiento matemático occidental. Las diez primeras palabras permiten formar los siguientes números con un principio aditivo regular, hasta el 19, ya que el veinte mantiene el uso de las mismas palabras, pero el principio cambia al multiplicativo. Si comparamos los primeros veinte números en castellano y en mapuzugun, podemos apreciar que el mapuzugun posee un potencial educativo inductivo, ya que no introduce prefijos ni sufijos y la yuxtaposición se podría inferir a partir de la regularidad en un trabajo didáctico delineado para ese fin. Su estructura lógica y la utilización de las mismas palabras numéricas, puede favorecer el aprendizaje en la escuela.

A continuación observaremos las regularidades de algunos números que se van formando en la medida que se amplía el ámbito numérico y su expresión oral en castellano y mapuzugun. Según Salas (1980) se conoce una expresión oral limitada de los números mapuches, hasta el 9.999; en esta caracterización, basándonos en Augusta (1903), ampliamos su continuidad oral siguiendo la lógica epistémica del conocimiento matemático mapuche. 
Tabla 4.3. Algunos números y potencias de diez en castellano.

\begin{tabular}{|l|l|l|l|l|l|l|}
\hline Número & Castellano & $\begin{array}{l}\text { Interpretación } \\
\text { aritmética }\end{array}$ & Número & Castellano & $\begin{array}{l}\text { Interpretación } \\
\text { aritmética }\end{array}$ \\
\hline 30 & Treinta & $3(10)$ & 1000 & Mil & $10(100)$ \\
\hline 40 & Cuarenta & $4(10)$ & 2000 & Dos mil & $2(1000)$ \\
\hline 50 & Cincuenta & $5(10)$ & 5000 & Cinco mil & $5(1000)$ \\
\hline 60 & Sesenta & $6(10)$ & 10000 & Diez mil & $10(1000)$ \\
\hline 70 & Setenta & $7(10)$ & 30000 & Treinta mil & $30(10000)$ \\
\hline 80 & Ochenta & $8(10)$ & 80000 & Ochenta mil & $80(1000)$ \\
\hline 90 & Noventa & $9(10)$ & 100000 & Cien mil & $100(1000)$ \\
\hline 100 & cien & $10(10)$ & 500000 & Quinientos mil & $500(1000)$ \\
\hline 200 & Doscientos & $2(100)$ & 1000000 & Un millón & $1(1000000)$ \\
\hline 300 & Trescientos & $3(100)$ & 10000000 & Diez millones & $10(1000000)$ \\
\hline 400 & Cuatrocientos & $4(100)$ & & 100000000 & Cien millones & $100(1000000)$ \\
\hline 500 & Quinientos & $5(100)$ & & 1000000000 & Diez mil millones & $10(1000)(1000000)$ \\
\hline 600 & Seiscientos & $6(100)$ & 1000000000000 & Un billón & $1(1000000)(1000000)$ \\
\hline
\end{tabular}

La tabla 4.3 muestra la interpretación literal de la expresión oral en castellano de algunos números y algunos números potencias de diez. Como se puede observar los números del 30 al 90 tienen en común la terminación "enta", antecedidos por un segmento de la expresión oral de los números del 4 al 9, con excepción del 30 cuya terminación es "inta"; es decir se componen de dos segmentos de palabras. En esta composición se aprecia el principio multiplicativo. El cien es una nueva palabra, se deduce de la regularidad anterior que se forma 10 por 10; para los siguientes números en el ámbito del cien se forman con el principio multiplicativo y son palabras compuestas por la expresión oral de los número del 2 al 9 y con terminación común en “cientos", con excepción del "quinientos", que tiene terminación "ientos" y se antepone “quin”. Mil, también es una nueva palabra y se deduce que seria 10 por 100. A partir del millón, que es otra palabra nueva y como se puede observar en la tabla 4.3. se aprecia la continuación de la numeración manteniendo la regularidad del principio multiplicativo, hasta cuando se llega al billón y posteriormente el trillón, que pasan a ser palabras compuestas por segmentos de palabras anteriores y que tienen en común la terminación llón que viene del millón y se les antepone "bi" que significa dos y "tri” que significa tres. 
A lo descrito en la tabla 4.1 respecto de las formas de decir "10", podemos agregar dos nuevas formas (inta, enta), concluyendo para el "10" en los primeros 100 números hay 6 formas distintas de referirse a él en castellano. En mapuzugun hay sólo una forma.

Tabla 4.4. Algunos números y potencias de diez en mapuzugun.

\begin{tabular}{|l|l|l|l|l|l|}
\hline Número & Mapuzugun & $\begin{array}{l}\text { Interpretación } \\
\text { aritmética }\end{array}$ & Número & Mapuzugu & $\begin{array}{l}\text { Interpretación } \\
\text { aritmética }\end{array}$ \\
\hline 30 & Küla mari & $3(10)$ & 1000 & Waragka & $10(100)$ \\
\hline 40 & Meli mari & $4(10)$ & 2000 & Epu waragka & $2(1000)$ \\
\hline 50 & Kechu mari & $5(10)$ & 5000 & Kechu waragka & $5(1000)$ \\
\hline 60 & Kayu mari & $6(10)$ & 9999 & Aylla waragka aylla $9(1000)+9(100)+$ \\
pataka aylla mari aylla & $9(10)+9$ \\
\hline 70 & Regle mari & $7(10)$ & 10000 & mari waragka & $10(1000)$ \\
\hline 80 & Pura mari & $8(10)$ & 30000 & kila mari waragka & $30(10000)$ \\
\hline 100 & Aylla mari & $9(10)$ & 80000 & Pura mari waragka & $80(1000)$ \\
\hline 200 & Eataka & $10(10)$ & 100000 & Kiñe Pataka waragka & $(100)(1000)$ \\
\hline 300 & Kila pataka & $3(100)$ & 1000000 & Waragka waragka & $1000(1000)$ \\
\hline 400 & Meli pataka & $4(100)$ & 10000000 & Mari waragka waragka & $10(1000000)$ \\
\hline 500 & Kechu pataka & $5(100)$ & 100000000 & Pataka waragka waragka & $100(1000000)$ \\
\hline 600 & Kayu pataka & $6(100)$ & 1000000000 & Mari waragka waragka $10(1000)(1000000)$ \\
\hline & & & & waragka & \\
\hline
\end{tabular}

Como podemos observar en la tabla 4.4, la regularidad del conteo en mapuzugun se comprende fácilmente; por cuanto se aprecia el principio multiplicativo para formar números grandes. Para el 100 y el 1000 aparecen nuevas palabras "pataka" y "waragka", con la cuales se forman el resto de los números intermedios conocidos hasta el 9.999 en mapuzugun Aylla waragka aylla pataka aylla mari aylla. Es decir, ellos podían seguir contando más allá del diez mil, repitiendo las mismas palabras pero en una ubicación diferente.

De acuerdo a lo observado en la estructura morfosintáctica de los numerales mapuches, se aprecia una regularidad que le permite configurar un número cualquiera, dentro de un ámbito numérico específico, de manera oral. No hay que memorizar una gran cantidad de nuevas palabras para llevar a cabo dicha acción, es decir su regularidad optimiza el aprendizaje de la numeración oral. A diferencia de las palabras numéricas en castellano, que requieren de una mayor abstracción en los códigos lingüísticos para la asociación de algunos segmentos de palabras al número, como cinco a quince a quinientos ó uno a 
"on" en once u otros como los números doce, trece y catorce, en los que no se aprecia la presencia del diez ni la regla de composición morfo-matemática. De acuerdo a los estudios realizados por Bengoechea, para un hablante adulto puede ser fácil identificar que el segmento "ce" alude al diez y los segmentos "do", "tre" y "cator", aluden al dos, tres y cuatro respectivamente. Sin embargo para a un estudiante que inicia su formación escolar no es tan obvio, lo que nos lleva a afirmar que el sistema de conteo escolar oral posee muchas irregularidades sintácticas lo que complejiza la asociación del símbolo matemático que lo representa al superar el ámbito de diez. A diferencia del Rakin, que por ser muy regular en su expresión oral, facilita la comprensión de su composición sintáctica y tal vez la asociación del símbolo matemático que lo representa, como 12 es mari epu, siendo mari 10 y epu 2; el 15 es mari kechu, donde mari es 10 y kechu es 5 .

Para los números del 16 al 19, se aprecia una mayor regularidad puesto que se distingue el diez en su composición con el segmento "dieci” que alude a diez y agregando las palabras de los números $6,7,8,9$. A diferencia del Rakin, que sigue la misma lógica anterior, es decir el 16 es mari kayu siendo mari 10 y kayu 6. Para los siguientes números en castellano, apreciamos nuevas palabras "veinte" que no tiene una raíz alusiva a dos y la yuxtaposición, que es la multiplicación, tampoco se aprecia; para los siguientes 30, ... 90 si se aprecia una raíz y el segmento agregado "inta", "renta"..."enta", que en español todas aluden a diez. En el caso del Rakin, su regularidad y lógica permite apreciar la formación y yuxtaposición (multiplicación) para los siguientes números, 20 epu mari donde epu es 2 y mari 10, pura mari donde pura es 8 y mari $10, \ldots$ Ambos sistemas introducen una nueva palabra para 100 y en castellano se comienza a ver mayor regularidad, ya que comparten el segmento "ciento" con una raíz correspondiente a la unidad como 200 doscientos, ...., se diferencia de esta regularidad el 500 que utiliza la raíz de quince (15). El Rakín introduce para 100 el término pataka y la formación de los números intermedios siguen la misma lógica anterior, es decir 200 sería epu pataka y 345 sería küla pataka meli mari kechu con yuxtaposición multiplicación y adición $(3 * 100+4 * 10+5)$. A partir del 1000 , ambos sistemas mantienen las regularidades anteriores con la nueva palabra introducida, mil y waragka.

Este análisis no está acabado, por ello consideramos necesaria esta reflexión ya que los currículos de matemáticas incorporan el aprendizaje de la numeración oral. Es válido preguntarse sobre las implicancias del aprendizaje descontextualizado en el caso de los estudiantes mapuches, cuando deben aprender una configuración oral del símbolo 
numérico muy ajeno a su lenguaje y muy complejo en su construcción morfosintáctica, con una estructura morfo-matemática compleja en cuanto a la relación palabra símbolo numérico. Si agregamos a esto, que el aprendizaje de la escritura está mediado por el habla y las habilidades puestas en juego en el proceso de descodificación y codificación en el lenguaje es compleja, sobre todo en los inicios de la escolarización en un sistema formal estructurado, es decir, estamos frente a un escenario que requiere de nuestra atención como investigadores en didáctica de la matemática.

\subsection{Operaciones aritméticas en la cultura mapuche}

De acuerdo a lo reportado por Augusta, los mapuche utilizaban sus cardinales agregando algunas palabras que les permitía expresar algunas nociones de multiplicación. El autor llamó múltiplos a las palabras que utilizaban expresaban el doble, tres veces, cuádruplo, en diez veces más grande y otros que mostraremos a continuación.

- Epu fenten (dos tantos) hacía referencia al doble $\rightarrow 2 \mathrm{n}$

- Küla fenten (tres tantos) hacía referencia al triple $\quad \rightarrow \quad 3 n$

- Meli fenten (cuatro tantos) hacía referencia al cuádruplo $\rightarrow 4 n$

Para referirse a una vez, dos veces, tres veces.... El Padre Augusta identifica más de una forma:

- Al cardinal respectivo se agrega el sufijo "chi”, kiñechi, epuchi, külachi, marichi ....; haciendo referencia a una vez, dos veces, tres veces, diez veces.

- Traduciendo la palabra "vez" por "naq", "rupa" o "rüto", luego utilizándolos como sufijo se configura kiñenaq, kiñerupa o kiñe rüto para referirse a una vez.

- Transformando el "fenten" (tanto) en el verbo "fertenn", para expresar "ser más grande" ó "ser tanto más grande", utilizan epu fenteni para decir "es dos veces más grande"(...) (Augusta, 1903, p. 36)

A partir de estos hallazgos y supuestos, Augusta plantea el modo en que los mapuches comprendían bien el algoritmo de la multiplicación:

- Tres veces cuatro son doce küla naq meli - mari epu

Küla naq meli ta mari epu .....

Luego tomando como referente la multiplicación, describe como expresan la división. $\mathrm{Al}$ respecto señalaba, para expresar 24:6 = 4 decían tiene seis cuatro veces, es decir epu mari meli niei kayu meli naq (Augusta, 1903, p.36). 
En cuanto a la forma de calcular no hay antecedentes actuales. Buscando información sobre este tema y nuestro agente clave nos aportó algunos antecedentes que indicaban la utilización de un sistema de representación concreta a través del "kipu”, "Quipu” ó "Püron" (Ver figura 4.2). Según datos históricos, tomados del Museo de Arte Precolombino de Chile, estos instrumentos eran utilizados para la administración económica y social en aquellas épocas, por los Aymaras en el norte de Chile y el Imperio Inka. La extensión del Imperio Inka llegó hasta la zona central de Chile, siendo el pueblo mapuche, llamado por los cronistas araucanos, quienes derrotaron el avance del Imperio Inca hacia el Chile austral, en la llamada "Batalla del Maule" (Museo Chileno de Arte Precolombino, 2009). En este proceso de expansión de la cultura Inka, se fueron absorbiendo nuevas expresiones culturales y con el trabajo diplomático de los Inkas, se produjo este intercambio cultural y la adopción de nuevas expresiones culturales. Es en este proceso histórico, el quipu se convierte en un artefacto común a nuestros pueblos precolombinos. El kipu o püron mapuche, de hilos horizontales tejidos y verticales sueltos en los que registran a través de nudos, ellos expresaban datos económicos, de localización, demográficos o mensajes cifrados. Los había de varios tamaños, de acuerdo a los datos que se registraban. En el caso del pueblo mapuche, hasta hoy esta acción de contar y anudar es la base de los telares mapuche.

Las orientaciones curriculares en matemática para la EIB, reconoce la existencia del kipu o püron y promueve su utilización en la escuela como un sistema de registro del conteo a través de nudos. Sin embargo, no entrega mayores antecedentes de la forma de operar con este artefacto, lo que limita su utilización en la escuela.

Figura 4.2 Quipu o Püron

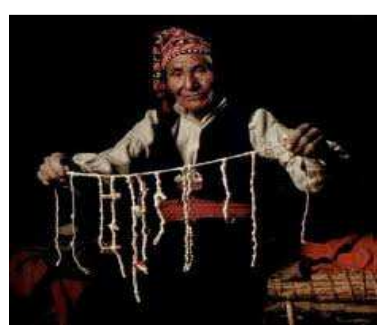

Kipu o Püron mapuche

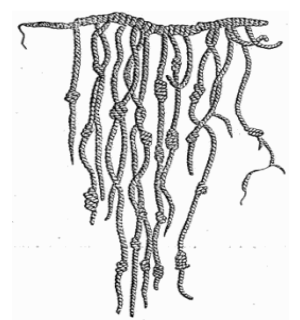

Quipu precolombino

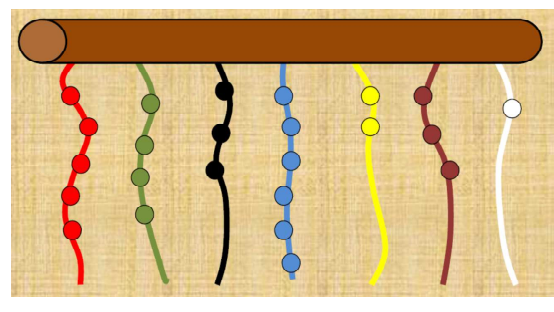

Rakin Püron mew (el conteo a través de nudos)

Lamentablemente, no hay estudios acabados sobre el origen de la utilización del kipu o püron. Hemos encontrado algunos antecedentes del Lonko Kilapan (Pozo, 2007), la escritura simbólica del pueblo mapuche era a través del "prom" ó "Püron", nudos, que se hacía en cuerda de lanas de distintos colores...”. Pozo, (2007) hace una 
representación de este instrumento, como se muestra en la Figura 4.2 la que no podemos afirmar que sea la representación más adecuada del püron, sin embargo, es un valioso antecedente para futuras indagaciones. En nuestro estudio, a pesar de haber recogido información de informantes claves y tener conocimiento empírico de que en el telar mapuche se utiliza el sistema de nudos, no podemos afirmar que el sistema numérico mapuche fuese posicional o describir de qué manera se registraba o calculaba con el püron.

Resumiendo algunas ideas, podemos señalar que existen antecedentes históricos que se refieren a un sistema numérico mapuche, que actualmente es reconocido por la institucionalidad. Que reúnen algunas características visiblemente regulares, en su estructura morfo-matemática. La existencia de un sistema de cálculo, con el kipu o püron. Sin embargo la carente investigación actual sobre estas temáticas planteadas junto al modelo educativo monocultural en el país, conjugan un escenario complejo para avanzar en la reconstrucción de un saber matemático propio de la cultura del pueblo mapuche que posiblemente puede otorgar ventajas en su incorporación al aula de matemáticas de la EIB. Seguir investigando en esta línea nos puede ayudar a plantear aquellos aspectos de la matemática mapuche posible de llevar al aula, la construcción de un saber o nuevos saberes organizado de éstos, la interacción de estos saberes con el saber matemático escolar a enseñar y qué debemos saber los profesores de matemáticas de educación básica para ayudar a esta relación dialógica entre saberes. En cuanto a lo extraído de la estructura morfo-matemática, si podemos afirmar que la adición y la multiplicación subyacen en su estructura, lo que hace presumir que los estudiantes mapuches al ingresar a la educación formal pueden traer conocimientos previos de estas operaciones. En el próximo apartado explicamos un primer acercamiento a estas cuestiones.

\subsection{Estudio comparativo de la aritmética mapuche con la aritmética escolar}

En este apartado iniciamos un estudio comparativo de la aritmética mapuche y la aritmética escolar. No tenemos la pretensión de realizar un análisis formal sistémico de la matemática mapuche, sino más bien, por ahora, un análisis socio-crítico desde la matemática a lo observado en los antecedentes recogidos. También haremos una interpretación de algunos contenidos de la matemática mapuche que puedan contribuir al actual modelo de educación intercultural y a las orientaciones curriculares en 
matemática escolar establecida para los niveles de educación básica en contextos interculturales.

La necesidad de contar viene de tiempos prehistóricos; todas las sociedades estudiadas responden a preguntas como, ¿cuántos hay?, ¿cuántos son?, como también la necesidad de establecer un orden de actuación como, ¿quién es primero, segundo....? (Cid et al. 2003). Es así cómo se da respuesta sobre el tamaño de una colección de objetos (Cardinal) y el lugar que ocupa o debe ocupar un objeto en una colección ordenada (Ordinal). A partir de estas necesidades sociales de contar, se desarrollan diferentes técnicas de recuento que permitan distinguir en cada paso el subconjunto ya contado. Los mapuches han desarrollado su conocimiento matemático, el que satisface la necesidad de resolver problemas de su vida cotidiana y su cultura. Sería interesante preguntarse en la actualidad, ¿qué técnica de recuento utilizan los mapuches?, ¿será un trazado mental del camino seguido en el conteo, marcar los objetos u otra técnica?, ¿cómo les ayuda el kipu o püren mapuche en esta tarea? Al respecto no hay antecedentes empíricos, sólo tenemos el kipu o püron mapuche como referencia a la notación que hubiesen podido hacer de una determinada cantidad. La habilidad de contar, en castellano o mapuzugun, está precedida de una coordinación, al mismo tiempo, entre los elementos a contar y las manos o la vista, y la emisión de la palabra cuantificadora en el orden establecido por ellos como cultura. Como plantea Cid et al. (2003), las técnicas de contar para obtener los cardinales, en el caso del pueblo mapuche, pone de manifiesto los principios necesarios para entender y contar correctamente:

- Principio de orden estable. Las palabras numéricas kiñe, epu, küla, ... deben recitarse siempre en el mismo orden, sin saltarse ninguna.

- Principio de la correspondencia uno a uno. A cada elemento del conjunto sometido a recuento se le debe asignar una palabra numérica distinta y sólo una.

- Principio de irrelevancia del orden. El orden en que se cuentan los elementos del conjunto es irrelevante para obtener el cardinal del conjunto.

- Principio cardinal. La palabra adjudicada al último elemento contado del conjunto representa, no sólo el ordinal de ese elemento, sino también el cardinal del conjunto.

Un ejemplo: (...) yemege kayu kuram, buscar seis huevos (Ministerio de Educación, 2012. Lengua Mapuzugun $2^{\circ}$ básico, p. 83) 
El estudiante mapuche debe desarrollar estas habilidades en dos lenguajes al mismo tiempo. Al observar y conocer estos elementos de la matemática mapuche, podemos identificar en el contar la puesta en correspondencia de cada elemento de un conjunto con los elementos de otro conjunto, vale decir la coordinabilidad (ver Cid et al. 2003). Se puede apreciar que subyace la biyección entre un conjunto de elementos a contar y el conjunto de números en palabras, en un contexto concreto no abstracto, es decir el "uno a uno". En la medida de sus necesidades se ha ido ampliando su numeración, pues en los primeros diez números creados tenían el referente de los dedos de las manos y tal vez a eso obedece también el sentido decimal. Frente a la necesidad de contar más de diez, se utiliza los mismos numerales hasta el 19 y una forma que podemos representarlo es como $10+\mathrm{n}$, siendo " $\mathrm{n}$ " cualquier número del uno al nueve, es decir "mari + n”. Para los siguientes números aparece una nueva configuración, en el ámbito del 20 al 99 y que podemos modelar como n (10) + n, siendo "n" cualquier número del uno al nueve, es decir n (mari) + $\mathrm{n}$. Cuando llegan a la necesidad de contar cien, introducen una nueva palabra, Pataka, con la que forma los siguientes números hasta el 999 y que podemos representar como n (100) + n (10) + n, siendo " $n$ " cualquier número del uno al nueve, es decir $n$ (pataka) $+n$ (mari) $+n$; un ejemplo para entender sería el número $345: \mathrm{n}(100)+\mathrm{n}(10)+\mathrm{n}=3(100)+4(10)+5$ y en mapuzugun sería $\mathrm{n}($ pataka $)+\mathrm{n}($ mari $)+\mathrm{n}=$ küla pataka meli mari kechu. Al llegar al mil, se requiere una nueva palabra, waragka, y se sigue la misma lógica. De acuerdo a los antecedentes históricos, ellos no registraban interpretaciones de manera simbólica. Sin embargo hay antecedentes que indican que sus registros eran en el kipu o püron y en dibujos, de los cuales hay muy pocos artefactos debido a lo tardío de las políticas socioculturales y educativas de nuestro país sobre la pervivencia de nuestro patrimonio y raíces culturales.

Otro elemento de relación es la yuxtaposición en la estructura morfo-matemática de los números en mapuzugun, en la que podemos apreciar fácilmente la relación entre las cifras y que podríamos indagar sobre qué tanto nos puede ayudar esta regularidad en el aula para: abordar problemas abiertos de tipo aditivo o multiplicativo que incorporen esta relación y que nuestros estudiantes no logran resolver eficientemente, en los primeros niveles de la educación básica. Cómo podemos asociar esta regularidad al proceso de composición y descomposición y que de acuerdo a la experiencia e investigaciones al respecto, existe una gran dificultad en dicho aprendizaje. Recordemos, que en apartados anteriores hemos descrito los problemas que se pide 
resolver a los estudiantes contextualizados en la EIB, sería interesante abordar de manera sistémica un estudio respecto de los problemas aritméticos de enunciado verbal (paev) que las orientaciones curriculares en matemática para la EIB proponen. Reconocer el tipo de problema y su estructura operatoria y semántica (Ayllón, 2012), la invención de problemas en contextos multiculturales. ¿Los profesores de matemáticas en la EIB tendrán conocimientos sobre los tipos de problemas y los paev?, ¿conocerán y comprenderán las ventajas de la invención de problemas? Profundizar en estas cuestiones sería importante para el contexto intercultural y su cosmovisión, ya que la aritmética mapuche, históricamente ha sido una herramienta de resolución de problemas para este pueblo.

Concordamos con algunas investigaciones que plantean que existe relación entre la etnomatemáticas y la matemática escolar, sin embargo creemos que es necesario analizar dichas relaciones, observar a los sujetos en la actuación matemática y aportar a la construcción de un saber matemático que pueda ser llevado al aula y que favorezca el aprendizaje, contribuyendo, además, a la revalorización cultural del conocimiento mapuche. Debido a las limitaciones de nuestro estudio, no será posible un análisis sistemático de dichas relaciones, pero nos interesa abrir el debate sobre estas y otras cuestiones del saber matemático mapuche y por ello recurrimos a dos estudiantes mapuches y sus profesores, para una indagación sobre qué pasa en el aula, qué opinan sus profesoras sobre nuestra inquietud investigativa y que exponemos en el siguiente apartado.

\subsection{Potenciales ventajas o dificultades de aprendizaje del alumno mapuche}

De manera apriori podemos suponer algunos conflictos en los estudiantes mapuches al ingresar a la escuela y que no requieren mayor análisis porque están ampliamente estudiadas y reconocidas en la comunidad científica, nos referimos a los aprendizajes previos, la contextualización y las situaciones de aprendizaje significativas para los estudiantes. En nuestro desarrollo investigativo, hemos podido constatar que en la matemática escolar de nuestro país, los conocimientos previos y la contextualización, no pasan de ser un discurso, ya que en los recursos que provee el Ministerio de Educación (programas, libros de textos y otros) no se visualiza el conocimiento previo del estudiante que viene con él a la escuela desde su cultura de origen; sino más bien visualizamos el énfasis en los conocimientos previos matemáticos que hacen referencia 
al nivel inmediatamente anterior. Si en Chile la educación obligatoria se inicia a los 6 años, cabe preguntarse, ¿qué conocimientos previos deben considerarse?, según el marco institucional. Importante señalar que la educación de párvulos, en nuestro país, no es obligatoria por lo cual no todos los niños asisten a ella. A finales del año 2013 se promulgó la Ley que establece el Kinder obligatorio para niños de 5-6 años, aumentando de 12 a 13 años la educación obligatoria (está aún en proceso su entrada en vigencia).

Si los objetos matemáticos son símbolos de unidades culturales (D'Amore \& Godino 2007), que emergen de los sistemas de prácticas de los individuos (Godino y Batanero, 1994), estamos frente a un sistema de prácticas matemáticas, mediadas por unas prácticas discursivas, las que no se aprecian en el currículo de matemáticas. Ahora miraremos estas cuestiones para identificar posibles conflictos semióticos y por supuesto identitarios.

Como un primer paso para estudiar las relaciones entre la aritmética mapuche y el aprendizaje de la aritmética escolar utilizaremos dos casos-tipos, un estudiante de escuela en contexto mapuche, de la región de la Araucanía y otro de contexto no mapuche (aculturado) en Valparaíso. Para ello analizamos la resolución de un problema matemático, por dos estudiantes mapuches y un cuestionario cumplimentado por sus profesoras. El problema aritmético lo hemos elaborado teniendo en cuenta las orientaciones curriculares para contextos interculturales, libros de texto del primer ciclo de primaria y la actividad sobre aprendizaje de la decena analizada en Godino, Font, Wilhelmi y Lurduy, (2011).

Uno de los niños, estudia en la Araucanía (zona sur de Chile) en una escuela municipal rural que implementa el programa de EIB y que su matrícula es 98\% mapuche; la segunda estudiante es de una escuela municipal de la zona urbana de una comuna de la Valparaíso (zona centro de Chile), en la que no se implementa el programa de EIB, por tener una matrícula indígena de un 9\% (menor al 20\%) de su matrícula total. En el segundo caso, tenemos un estudiante altamente aculturado, por la zona en que vive y por las condiciones de su desarrollo escolar. Ambos estudiantes cursan $2^{\circ}$ año básico (78 años). A las docentes de dichos estudiantes, les solicitamos cumplimentar un cuestionario, con el fin de conocer su opinión frente a nuestro tema, sobre su formación profesional y su conocimiento del aprendizaje matemático de los niños de ascendencia mapuche. Una de ellas es profesora de Educación General Básica en Educación Intercultural (profesora en la Araucanía), 9 años de experiencia profesional y 8 de ellos 
en contexto intercultural. La segunda es profesora de Educación General Básica (profesora en Valparaíso), sin especialidad, con 30 años de experiencia y declara no tener experiencia en educación intercultural. Con el fin de facilitar la transcripción y comparación cualitativa, a nuestra profesora de la Araucanía le llamaremos Profesor 1 y a nuestra profesora de Valparaíso le llamaremos Profesor 2. A igual haremos con los estudiantes, Araucanía Estudiante 1 y Valparaíso Estudiante 2.

Esta aplicación no pretende ser un estudio de caso, como también el análisis que haremos de éstas cuestiones no tiene un carácter formal sistémico, ya que nuestra intención en esta aplicación, teniendo claras sus limitaciones, es más bien de una primera "toma de contacto" sobre qué está pasando en las aulas donde se escolarizan los estudiantes mapuches. Esto nos permite cuestionarnos sobre futuras acciones investigativas y además, señalar un análisis socio-crítico desde la matemática y socioantropológico respecto del desarrollo identitario del sujeto, de acuerdo a nuestro marco de referencia. La tabla 4.5, nos muestra el desarrollo resolutivo de un mismo problema en ambos ambiente, con EIB y sin EIB.

Tabla 4.5. Respuestas de estudiantes mapuches a cuestiones matemáticas.

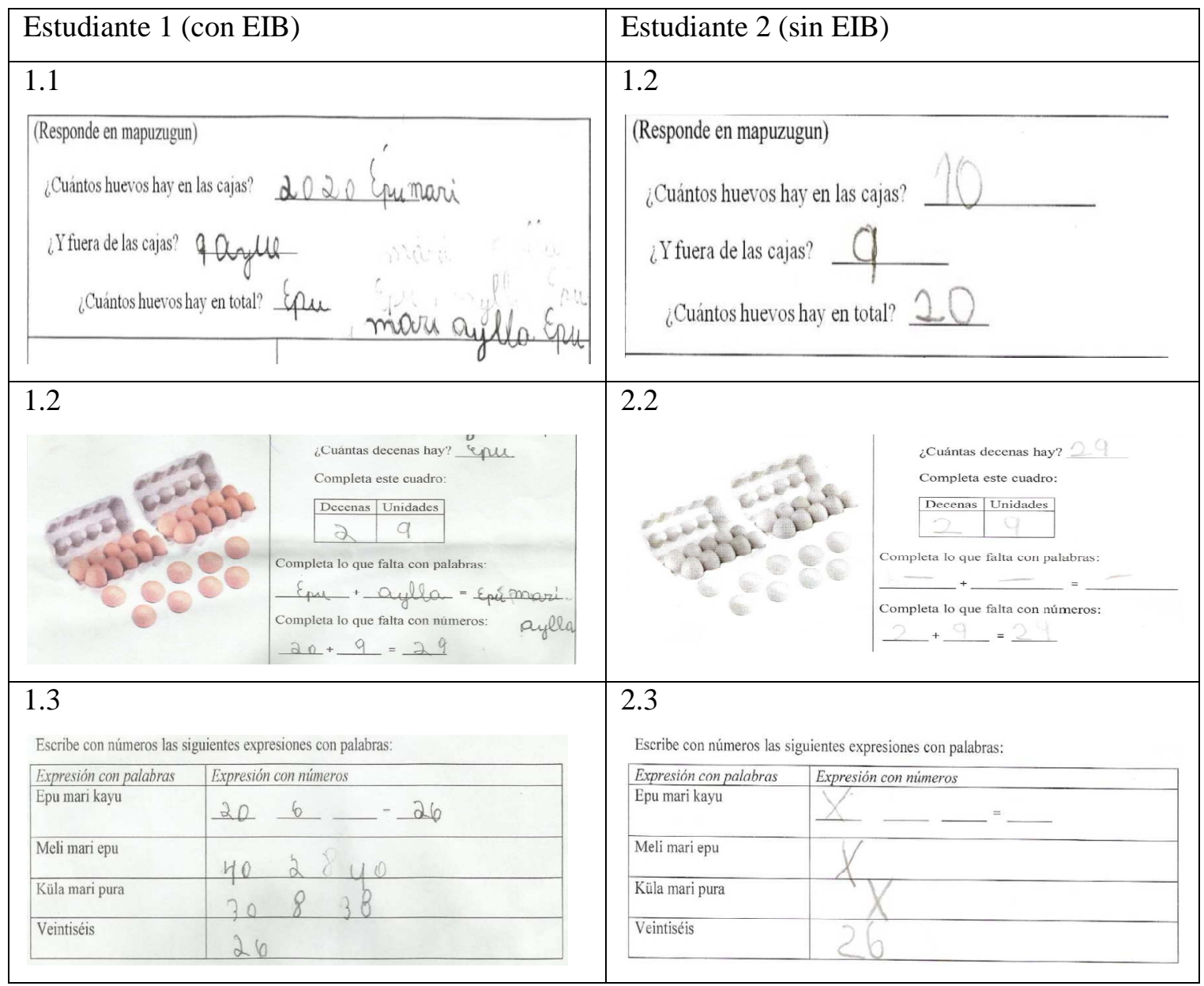


Pensamos en estudiantes de $2^{\circ}$ año básico, porque en este nivel debiera estar presente la lectura autónoma y la escritura, de acuerdo al marco curricular en nuestro país. Por otro lado, en este nivel muestran mayor autonomía en el quehacer escolar y son capaces de expresar sus ideas, dudas y posibles soluciones, de acuerdo a su edad. El no contar con grabaciones u otro medio de registro en la aplicación, dificulta aún más nuestro intento por conocer la actuación matemática de los estudiantes mapuches en distintos ambientes o contextos. Sin embargo, creemos que a partir de esta actuación se puede reflexionar sobre algunas cuestiones a abordar en futuras investigaciones sistemáticas que nos ayuden a comprender este complejo escenario para la educación matemática en la EIB. En el recuadro 1.1 y 2.1 de la tabla 4.5, respectivamente, esperábamos apreciar alguna técnica auxiliar de recuento que quedara registrada en la hoja de trabajo, que diera cuenta de alguna estrategia escrita de coordinación y por otra parte conocer la escritura de números en mapuzugun que conocen los estudiantes de origen mapuche. Situación que no logramos disipar, por las mismas limitaciones de la aplicación y por los antecedentes expuestos por las profesoras en cuanto a que ambos estudiantes aún no desarrollan la lectura. Aún con las limitaciones propias de la aplicación, consideramos interesante dejar planteadas algunas cuestiones sobre:

¿qué técnicas auxiliares de recuento utilizan los estudiantes mapuches en la escuela o en su vida cotidiana?,

$>$ ¿qué tipo de conjunto es más amigable de contar para un estudiante mapuche?,

$>$ ¿depende de la configuración geométrica del conjunto, del tipo de objeto o la movilidad del objeto?,

$>$ ¿qué conflictos cognitivos se aprecian en la resolución de un problema matemático de recuento?,

$>$ ¿el artefacto püron o kipu mapuche favorece el recuento de objetos?,

$>$ ¿los estudiantes mapuches ingresan a la escuela con el conteo intransitivo o transitivo de los números en mapuzugun?

En el ejemplo 1.2 y 2.2 de la tabla 4.5., esperábamos apreciar cuestiones como la escritura en palabras (castellano o mapuzugun), la descomposición del cardinal en palabras y números, la asociación del valor posicional y la yuxtaposición en la conformación de las palabras numérica. Aún cuando se aprecian algunas de éstas cuestiones, dejamos planteadas las siguientes interrogantes: 
$>$ ¿la estructura morfo-matemática de los números en mapuzugun puede contribuir al aprendizaje del valor posicional?, ¿cómo?,

$>$ ¿qué conflictos semióticos se producen en la actuación del estudiante mapuche en la solución de un problema matemático relacionado con el conteo superior a la decena?

$>$ ¿qué significado atribuye el estudiante al principio de agrupamiento y su relación con los números en palabras (mapuzugun, español)?

$>$ si utilizan el püron, ¿qué sistema de agrupamiento realizan con este artefacto?

$>$ ¿el material contextualizado a la vida cotidiana del estudiante mapuche puede re-significar el estudio de la matemática?, ¿cuál es el contexto mapuche?, ¿este contexto es conocido por los distintos actores participantes en el proceso? (directivos, profesores, editoriales de libros de textos)

$>$ ¿comprende la yuxtaposición de la estructura morfo-matemáticas de los números en español o en mapuzugun?, y otras cuestiones que podemos repensar o replantear, a partir de esta resolución.

En el último ejemplo, 1.3 y 2.3 de la tabla 4.5., esperábamos visualizar la comprensión de los números en palabras y su yuxtaposición implícita, la asociación de la palabra numérica al símbolo numérico de acuerdo a su estructura morfo-matemática. Sin embargo, la actuación de los estudiantes nos hace reflexionar sobre: el currículo de matemáticas plantea como objetivo a partir de $1^{\circ}$ básico la composición y descomposición canónica, pero no plantea cómo, por ello nos preguntamos,

$>$ ¿el aprendizaje de secuencia numérica en palabras (mapuzugun o castellano), de manera intransitiva o transitiva, cómo aporta al aprendizaje de la composición y descomposición?, considerando que el lenguaje hablado es mediador sobre aprendizaje simbólico.

$>$ ¿es posible trabajar la descomposición a partir de la estructura morfomatemática de los números en mapuzugun?,

$>$ ¿en 23 o veintitrés o epu mari küla, ven la estructura matemática y la yuxtaposición (suma y multiplicación)?

$>$ ¿en sus hogares hay reflexión sobre lo que se estudia en la matemática escolar respecto del conocimiento matemático familiar?

A modo de conclusión sobre la actuación de los estudiantes, podemos señalar que hay mucho que investigar. Ambos estudiantes aún no desarrollan la lectura ni escritura en castellano (información dada por sus profesoras) y es probable que tampoco en 
mapunzugun. Por tanto sus profesoras les leían las instrucciones en castellano, porque no hablan mapunzugun. Frente a estos resultados, hemos optado por expresar nuestras interpretaciones en las siguientes preguntas abiertas a futuras investigaciones:

$>$ ¿qué conocimiento matemático de la cultura de origen puede favorecer la articulación con la matemática escolar en los primeros años de escolarización?

$>$ ¿por qué, aparentemente, el estudiante mapuche altamente aculturado muestra menos conocimiento de la matemática escolar?, si como dice su profesora esta insertado en "una sociedad normal",

$>$ ¿la pérdida identitaria representa una dificultad para el aprendizaje de la matemática escolar?,

$>$ ¿es posible que la estudiante de Valparaíso se sienta identificada con la identidad mapuche?,

$>$ ¿la falta de articulación del conocimiento matemático mapuche y escolar afecta el desarrollo idetitario del estudiante mapuche?

Podemos seguir planteando interrogantes, pero nos quedaremos con la reflexión que para dar respuesta a estas y otras interrogantes, sólo lo haremos con más investigación sistemática en esta área del conocimiento.

En la tabla 4.6., exponemos las respuestas de las dos profesoras en paralelo, para ir mirando ambos contextos culturales, lo que nos permitirá reflexionar y plantearnos algunas preguntas abiertas a la investigación.

Tabla 4.6. Respuesta de profesores de estudiantes mapuches.

\begin{tabular}{|c|c|}
\hline Profesor 1 (con EIB) & Profesor 2 (sin EIB) \\
\hline $\begin{array}{l}\text { De acuerdo a su experiencia y conocimiento } \\
\text { didáctico - matemático, por favor, responda a las } \\
\text { siguientes preguntas. }\end{array}$ & $\begin{array}{l}\text { De acuerdo a su experiencia y conocimiento } \\
\text { didáctico - matemático, por favor, responda a las } \\
\text { siguientes preguntas. }\end{array}$ \\
\hline $\begin{array}{l}\text { 1) En su formación de grado, ¿recibió el } \\
\text { conocimiento didáctico-matemático para atender } \\
\text { la diversidad cultural, en el ejercicio de su } \\
\text { profesión? Explique brevemente. } \\
\text { Solo un poco, se nos enseño a contextualizar los } \\
\text { contenidos según la necesidad del estudiante o } \\
\text { ubicación del establecimiento, ya que la mayor } \\
\text { cantidad de estudiantes mapuche se encuentran en } \\
\text { las zonas rurales }\end{array}$ & $\begin{array}{l}\text { 1) En su formación de grado, ¿recibió el } \\
\text { conocimiento didáctico-matemático para atender } \\
\text { la diversidad cultural, en el ejercicio de su } \\
\text { profesión? Explique brevemente. } \\
\text { No recibí conocimiento para atender la diversidad } \\
\text { cultural de mi país. }\end{array}$ \\
\hline $\begin{array}{l}\text { 2) El conocimie } \\
\text { formación profes } \\
\text { matemáticas y }\end{array}$ & $\begin{array}{l}\text { 2) El conocimiento matemático } \\
\text { formación profesional, ¿abordaba }\end{array}$ \\
\hline
\end{tabular}


matemático de las culturas originarias de Chile?

Aborda historia de matemática pero del mundo un porcentaje muy poco sobre las culturas originarias en chile, la mayoría lo realiza cuando hace algún tipo de investigación a parte

3) ¿Qué dificultades observa usted en los estudiantes mapuches al iniciar el aprendizaje de la matemática escolar (tradicional)?

Cuando la familia fomenta el habla del mapuzungun en la casa a los estudiantes les cuesta ya que al tener que dominar en español y el mapuzungun se les enreda el contenido, esto sucede en un porcentaje muy poco a nivel regional, pero al no ser así es lo mismo que todos los niños y niñas

4) ¿Cuándo usted contextualiza un problema matemático a la cultura mapuche y utiliza la lengua mapuzugun para dar instrucciones y referirse a los números, observa en los estudiantes más atención y mejor comprensión de los problemas que se les plantean? Explique brevemente.

En mi establecimiento y en la mayoría no se habla mapuzungun para explicar las clases, se hacen en español, los estudiantes dominan solo un poco cuando son rurales, pero los urbanos es nulo el habla, a nivel nacional y regional el mapuzungun en el aula es más que nada bilingüismo (traducir palabras) o enseñar a los estudiantes a tener sentido de pertenencia de su propia cultura

5) ¿Considera usted importante iniciar el estudio de los números naturales a partir del conocimiento matemático de la cultura mapuche y luego abordar la matemática escolar establecida en el currículo nacional? Explique brevemente.

Viendo la realidad en los establecimientos y la postura del gobierno en Chile es mejor abordar la matemática escolar establecida en el currículo nacional y luego asociarla al conocimiento matemático de la cultura mapuche

6. Según su experiencia, el aprendizaje del valor posicional de las cifras en el sistema de numeración enseñado en la escuela, ¿supone alguna dificultad especial o ventaja para el niño mapuche que se pueda atribuir al sistema de palabras numéricas de la lengua mapuzugun, y a la manera en que se cuenta y calcula en la cultura Mapuche? Explique. matemático de las culturas originarias de Chile?

No, Ninguno.

3) ¿Qué dificultades observa usted en los estudiantes mapuches al iniciar el aprendizaje de la matemática escolar (tradicional)?

No veo dificultad pues en esta región ( $\left.5^{\mathrm{a}}\right)$ los niños están integrados a la sociedad normal, no estudian ni hablan su lengua.

4) ¿Cuándo usted contextualiza un problema matemático a la cultura mapuche y utiliza la lengua mapuzugun para dar instrucciones y referirse a los números, observa en los estudiantes más atención y mejor comprensión de los problemas que se les plantean? Explique brevemente.

No uso la lengua mapuche.

5) ¿Considera usted importante iniciar el estudio de los números naturales a partir del conocimiento matemático de la cultura mapuche y luego abordar la matemática escolar establecida en el currículo nacional? Explique brevemente.

Considero que sería importante estudiar como parte del programa de lengua mapuche, ahora no se da.

6. Según su experiencia, el aprendizaje del valor posicional de las cifras en el sistema de numeración enseñado en la escuela, ¿supone alguna dificultad especial o ventaja para el niño mapuche que se pueda atribuir al sistema de palabras numéricas de la lengua mapuzugun, y a la manera en que se cuenta y calcula en la cultura Mapuche? Explique. 
No hay dificultad, lo que sirve es la relación con base diez ya que la mayoría de los números en mapuzungun van acompañado con diez ej.: epu mari: 20: dos diez, quechu mari: 50: cinco diez

7. Le agradecemos que incluya cualquier comentario adicional a lo anterior, relacionado con la enseñanza y aprendizaje de las matemáticas en los primeros niveles de enseñanza en el contexto de la cultura Mapuche.

Puedo decir que las matemáticas mapuche se ven cuando el profesor quiere contextualizar los contenidos o la escuela se encuentra inserta en una comunidad mapuche, ya que por curriculum oficial no se solicita hacer este hincapié en la numeración o conocimiento matemático mapuche, se trabaja con lo oficial de los planes y programas.
No lo he observado.

7. Le agradecemos que incluya cualquier comentario adicional a lo anterior, relacionado con la enseñanza y aprendizaje de las matemáticas en los primeros niveles de enseñanza en el contexto de la cultura Mapuche.

Sin comentario.

Como podemos apreciar en las respuestas de las profesoras, existen creencias y concepciones que orientan su actuar en el aula, como es el caso de la frase (...) "sociedad normal". Se abre en este sentido una posible línea de investigación en contextos interculturales y urbanos, con o sin programa de EIB.

$>$ ¿qué creencias y concepciones tienen los profesores de matemáticas sobre el aporte de la matemática a la EIB?

$>$ ¿qué creencias y concepciones tienen los profesores de matemáticas sobre un aula de matemática multicultural?

$>$ ¿qué creencias y concepciones tienen los profesores de matemáticas sobre el conocimiento matemático de las culturas originarias?

A pesar de la diferencia en los años de experiencia profesional de ambas profesoras, lo que hace presumir que su formación profesional se realizó con distintos planes de estudio universitario, ambas concuerdan en que la instrucción en el aula de matemática se imparte en castellano. En este punto podemos apreciar cómo se contradice el paradigma de la interculturalidad y se reafirma lo planteado por Rother (2005) en cuanto a que la cultura mapuche en la escuela es una porción limitada frente al modelo monocultural imperante en la educación en nuestro país. Una nueva línea de investigación amplia se desprende de estas respuestas:

$>$ ¿Cuál es el objetivo socio-político de nuestra Educación Intercultural?,

$>$ ¿Por qué no se incorpora al currículo nacional la EIB?,

$>$ ¿Por qué el currículo de matemática no incorpora el conocimiento matemático mapuche de manera sistemática? 
> ¿Por qué las orientaciones curriculares en matemática para la EIB no está en concordancia con el actual currículo de matemática?

$>$ ¿Qué sentido tiene elaborar orientaciones curriculares de matemática para la EIB que transfiere la responsabilidad del estado al profesor de aula?, si todas las recomendaciones que indica ya se encuentran plasmadas en el Manual para la Buena Enseñanza (MBE).

$>$ ¿Los profesores de matemáticas tienen horas de trabajo cronológicas asignadas para la preparación de la enseñanza de la matemática escolar?, ¿planean la enseñanza en conjunto con el kimche mapuche?

$>$ ¿Cómo se aplican pruebas estandarizadas nacionales (SIMCE) a las escuelas con EIB, si las orientaciones en matemáticas se basan en el marco curricular anterior al introducido con la actual LGE y sus últimas modificaciones?

Éstas y otras preguntas se pueden plantear en una reflexión más amplia e interdisciplinaria.

En relación al conocimiento didáctico-matemático, una plantea no haberlo recibido (profesora 2) y la otra docente (profesora 1) plantea haber recibido formación sobre cómo contextualizar el contenido matemático curricular a las necesidades de los estudiantes y a la ubicación geográfica de la escuela. Al respecto podemos plantear:

$>$ ¿Qué entienden los distintos actores en educación matemática por atención a la diversidad cultural?,

$>$ ¿qué entienden los distintos actores en educación por conocimiento didácticomatemático o por conocimiento matemático para la enseñanza?,

$>$ ¿qué tipo de CDM reciben en la formación inicial y continua los profesores de matemática para la educación básica?,

$>$ El profesor de matemática, ¿tiene conocimiento de las potencialidades del análisis morfo-matemático de los números en mapuzugun?

En este punto aparecen muchas cuestiones que pueden y merecen ser investigadas para avanzar en una democratización (Moreno, 2004) del conocimiento matemático de una nación.

En relación a la pregunta 3), respecto a las dificultades que observan las docentes en los estudiantes mapuches en el aprendizaje de la matemática escolar, ambas concuerdan que el bilingüismo parece ser una dificultad, es decir, mientras se hable sólo el castellano parece más fácil el aprendizaje para el estudiante. Esto contradice el paradigma del bilingüismo, que postula mayor desarrollo cognitivo en los individuos bilingües. A 
nuestro entender el bilingüismo favorece el desarrollo cognitivo, por ello consideramos importante indagar,

$>$ ¿qué saben los sostenedores ${ }^{21}$, directores, profesores y padres sobre el bilingüismo?,

$>$ ¿hay conciencia de las ventajas cognitivas del bilingüismo en la escuela?

$>$ ¿qué entiende el profesor de matemáticas por dificultades de aprendizaje?, ¿reconocen un obstáculo de aprendizaje y de qué tipo es?

Estas interrogantes, también se relacionan con la pregunta 4), ya que ambas profesoras indican que la matemática escolar se trabaja en castellano y la profesora 1 (Araucanía) nos aclara que a nivel regional y nacional el mapunzugun en el aula es sólo para traducir palabras o enseñar a los estudiantes a tener sentido de pertenencia a su cultura de origen. Se refuerza la idea de investigar de manera sistemática sobre este modelo de EIB y sus implicancias en la vida de los ciudadanos de origen indígena, en las aulas, en los profesores y en la sociedad en su conjunto. Más aún cuando la institucionalidad educativa en nuestro país, reconoce formalmente que Chile es un país multicultural y plurilingüe, en el cual convergen una diversidad de culturas y sistemas lingüísticos. Los desafíos que impone un modelo intercultural, requiere de investigación sistemática.

Un aspecto interesante se plantea con la pregunta 5) y hace referencia a que la profesora que se desenvuelve en contexto escolar mapuche, postula abordar la matemática escolar sin considerar los aspectos etnomatemáticos. Explica que una vez aprendida la matemática escolar, luego se asocia al conocimiento de la cultura mapuche; agrega que es la realidad en las escuelas con EIB. En cambio, la profesora que responde que nunca ha trabajado en contextos interculturales, plantea la necesidad de conocer dicho conocimiento a través del estudio de la lengua mapuzugun. Hay que preguntarse en este punto

¿el conocimiento matemático de la cultura mapuche se puede considerar un conocimiento previo del estudiante al ingresar a la escuela?

$>$ ¿qué se entiende, en definitiva, por conocimiento previo desde las dimensiones institucionales y personales?

\footnotetext{
${ }^{21}$ La figura del sostenedor, aunque tiene una relevancia clave en nuestro sistema escolar, se encuentra en un nivel desconocido, ajeno y anónimo para la mayoría de la comunidad educativa y para la opinión pública. A lo más es considerado solamente como un administrador, más cerca de las burocracias financieras que del ámbito educativo (http://www.educarchile.cl/ech/pro/app/detalle?ID=205597).
} 
$>$ Si la EIB promueve el bilingüismo ¿por qué el mapuzugun no está presente de manera interdisciplinar en todas las escuelas con EIB?

$>$ ¿qué creencias y concepciones tienen los profesores de matemáticas sobre la enculturación matemática?

Luego en la pregunta 6) sólo agregamos que falta investigación sobre ¿cómo articular el conocimiento que trae el estudiante desde su cultura de origen y el conocimiento matemático escolar? Una última reflexión sobre la respuesta dada por la profesora 1 a la pregunta 7) es que ésta deja en evidencia el carácter verticalista y centralizado de nuestro currículo monocultural, el que nos hace cuestionarnos sobre estas y otras cuestiones:

¿es posible que los mecanismos de control (Moreno, 2004) del sistema educativo, cercene la intelectualidad del profesor de matemática? y ¿lo convierta en un mero transmisor de valores e ideología de una cultura matemática dominante?

$>$ ¿el currículo de matemáticas promueve en sí un valor democrático o promueve las diferencias en la relación de poder (Valero en Moreno, 2004) a través de las prácticas matemáticas?

> ¿qué valores no declarados por el currículo de matemáticas podemos encontrar en su aplicabilidad en los centros escolares y en el aula de matemática?

\section{SÍNTESIS Y CONCLUSIONES}

El primer análisis realizado en este trabajo reporta nuestras conclusiones sobre los objetivos específicos planteados. Nuestro primer objetivo ha sido logrado, por cuanto hemos realizado una descripción de la estructura morfo-matemática de los números en mapuzugun, para lo cual ha sido fundamental el trabajo de De Bengoechea (2009). Esta descripción nos ha permitido comprender las características del sistema de conteo mapuche, reconocer sus cualidades y potencialidades educativas. Hemos podido establecer la complejidad de aprender la matemática escolar en los primeros niveles de la educación básica y que, necesariamente, están mediados por el habla.

En el segundo objetivo, hemos logrado describir la utilización de la aritmética mapuche en los programas de mapuzugun y el tratamiento didáctico que plantean las orientaciones didácticas en matemática en los primeros niveles de educación básica para la EIB. Una primera conclusión es que la institucionalidad reconoce formalmente la 
existencia de un conocimiento matemático mapuche, que llegan al 70\% de los establecimientos del país, con y sin EIB. Luego, para las escuelas con el programa de EIB (2,43\%), las orientaciones curriculares de matemática plantea este conocimiento matemático como un complemento al currículo de matemática oficial y no como parte de un plan de estudio en escuelas con EIB. Su principal orientación hace alusión a la contextualización de la matemática escolar a la cultura de origen de los estudiantes sin proveer ningún medio para ello (textos, libros de textos, guía didácticas, etc...), delegando una gran responsabilidad en el profesor de matemática. Estas orientaciones didácticas carecen de argumentos pedagógicos y matemáticos que permitan al profesor planear una transposición didáctica en beneficios del aprendizaje de sus estudiantes.

En el tercer objetivo, se describe la aritmética mapuche y algunos principios que subyacen en ella: yuxtaposición de suma y multiplicación, principios para contar correctamente, principio de coordinabilidad, utilización del artefacto kipu o püron. En la estructura morfo-matemática de la numeración en mapuzugun se aprecia claramente la yuxtaposición de la adición y la multiplicación, sin embargo, no tenemos conocimiento empírico de la comprensión de esta yuxtaposición de parte de los estudiantes mapuches. Sobre el objetivo 4, podemos señalar que aún cuando su logro aporta poca información, nos permitió visualizar la complejidad de la problemática global. No obstante, el comprender este escenario nos permite señalar que la numeración mapuche por ser regular en su lógica morfo-matemática puede ser de fácil comprensión, no cambia su estructura sintáctica lo que tal vez facilite los procesos de codificación y descodificación del lenguaje oral y escrito, para luego favorecer su asociación con el lenguaje simbólico matemático. Respecto al artefacto con los que ellos se ayudaban o ayudan en los cálculos; aun cuando son aludidos por documentos oficiales en educación matemática, no hay cabal conocimiento de su uso y como éste ayuda a la abstracción. La historia no es suficiente para atender las necesidades actuales de la educación matemática en la escuela multicultural, pues se hace necesaria la observación sistemática de la cognición del estudiante puesta en juego en la actuación al resolver problemas matemáticos, observando los sistemas de prácticas y la configuración objetos y procesos (Godino y Batanero, 1994; Godino, et al. 2011). Tarea empírica y rigurosa que nos queda para futuras investigaciones, antes que la aculturación matemática logre borrar, por completo, los conocimientos autóctonos de la matemática existente en este pueblo. No obstante, creemos, que estos elementos son suficientes para incentivar la investigación en este campo del conocimiento, para construir mejores argumentos que nos permitan la 
toma de decisiones fundadas en cuanto a la educación matemática a impartir en el aula de la educación obligatoria en el marco de la EIB. También hemos mostrado la necesidad de estudiar la articulación respetuosa entre los conocimientos matemáticos mapuche y escolar. Por último hemos dejado en evidencia el problema de cómo formar a los profesores de matemáticas para que puedan articular ambos conocimientos matemáticos en la escuela.

\subsection{Limitaciones}

Intentar explicar las dificultades de aprendizaje de las matemáticas, su falta de motivación o el comportamiento disruptivos de los estudiantes en las aulas de matemáticas, únicamente en términos cognitivos, supone una posición limitada (Gorgorió et al., 2006) en el mundo actual, globalizado y multicultural. El aprendizaje sociocultural es parte del aprendizaje en la socialización del individuo; pero lejos está esta consideración en la matemática escolar.

Una primera limitación es propia de la investigación en educación matemática, ya que los actuales enfoques teóricos de investigación privilegian estudios sobre, cómo los individuos aprenden la matemática escolar, desde la matemática y la psicología, más escasamente desde lo sociocultural (Valero, 2012). En nuestra investigación en Didáctica de la matemática, abordamos el conocimiento matemático mapuche desde un punto de vista sociocultural y crítico. En este sentido, en nuestro país, la investigación en Didáctica de la matemática es muy incipiente y sin publicación científica. Conscientes de ello creemos que esta limitación puede convertirse en una oportunidad que nos oriente en la construcción de herramientas teóricas que nos permitan dar cuenta de las ventajas de una educación "Etnomatemática Crítica", orientada al rol que la educación matemática debe desempeñar en la formación integral de los estudiantes y su porvenir.

Luego tenemos una limitación propia de este estudio, referida a la parte empírica realizada sobre los posibles conflictos y/o ventajas de aprendizaje de la aritmética escolar de los estudiantes mapuches. Para la aplicación del cuestionario a los niños se realizó a través de sus respectivas profesoras, quienes, además, se aplicaron así mismas el cuestionario al profesor, el contacto fue vía e-mail. No utilizamos otras herramientas de recolección de datos como grabaciones, entrevistas, etc. que nos permitiera el registro de diversos aspectos del proceso. La distancia de los escenarios no permitió la presencia de la investigadora en terreno, la observación directa del proceso y contexto, 
entrevista a otros actores involucrados en el proceso de enseñanza y aprendizaje de las matemáticas, etc. En las actividades de conteo planteadas a los estudiantes, se toman como referentes las actividades propuestas en las orientaciones curriculares de matemáticas y los libros de textos de matemáticas para el nivel. Es decir, seguimos la misma línea de instrucción institucional y sólo incorporamos la lengua mapuzugun en algunos aspectos. En este sentido, creemos que hay que elaborar diseños didácticos que permitan la articulación de ambos conocimientos, tareas que hemos dejado para una futura investigación.

\subsection{Cuestiones abiertas}

En el desarrollo de esta investigación exploratoria descriptiva fueron emergiendo muchas más cuestiones que se relacionan con nuestro fenómeno central, que emerge de esta investigación y que requieren de nuestra atención como investigadores en Didáctica de las matemáticas. En este proceso, logramos identificar algunas de estas cuestiones, lo que no permitió diseñar un nuevo modelo que recoge nuevos puntos de interés de investigación, como mostramos en la imagen 5.1.

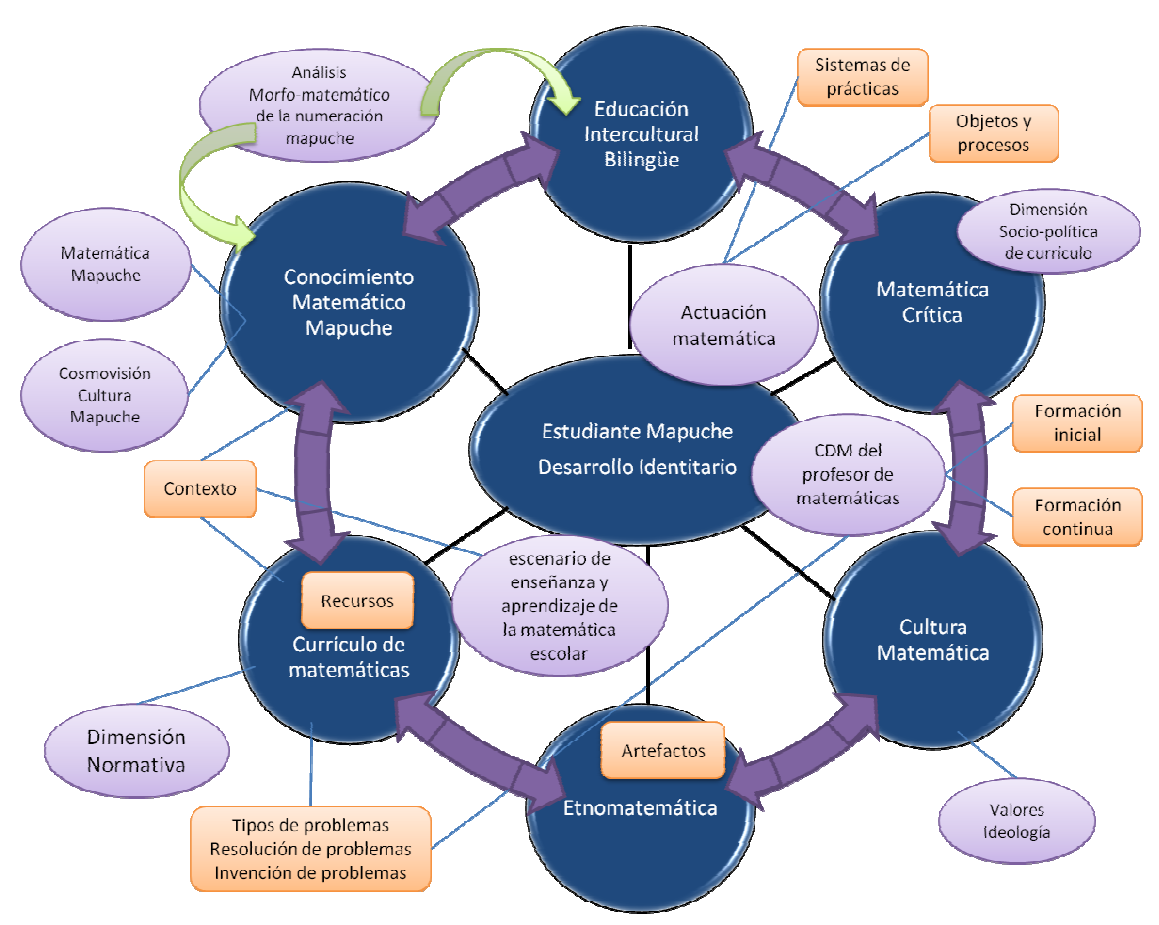

Figura 5.1. Áreas de indagación relacionadas con el aprendizaje matemático del estudiante mapuche

A partir de este nuevo escenario dejamos planteadas algunas preguntas que pueden guiar posibles líneas de investigación: 
P.1. ¿Qué cambios serían necesarios en el estudio de la lengua mapuzugun para mediar en el aprendizaje de la aritmética escolar?

P.2. ¿Cómo debería ser abordado por el currículo y la práctica matemática escolar el conocimiento matemático de origen para facilitar el aprendizaje de los estudiantes?

P.3. ¿Qué conocimiento didáctico-matemático deberían tener los maestros para favorecer el aprendizaje de la matemática escolar a los estudiantes mapuches?

P.4. ¿Qué cambios serían necesarios en el currículo matemático y en la práctica matemática escolar para evitar la autonegación y pérdida identitaria de las raíces culturales del estudiante mapuche?

P.5. ¿Cuáles son las características de la matemática mapuche en los diferentes bloques temáticos y su posible articulación con la matemática escolar?

P.6. ¿En qué medida puede facilitar la comprensión y articulación de la matemática mapuche con la matemática escolar el análisis de dichas matemáticas mediante las herramientas teóricas del Enfoque Ontosemiótico?

P.7. ¿Qué concepciones y creencias de los profesores sobre las matemáticas y su enseñanza pueden suponer un obstáculo para la articulación entre el conocimiento matemático de origen del estudiante y la matemática escolar?

\section{REFERENCIAS}

Ayllón, M.F., (2012). Invención-Resolución de problemas por alumnos de educación primaria. Tesis Doctoral. Universidad de Granada. España

Belloli, L. (2009). Algunos aportes al conocimiento de la numeración Mapuche. Revista electrónica de investigación en educación en ciencias, 4(2), 1-6.

Bishop, A. J. (1999). Enculturación matemática: la educación matemática desde una perspectiva cultural (Vol. 49). Barcelona: Editorial Paidós.

Cid, E., Godino, J. D. y Batanero, C. (2003). Sistemas numéricos y su didáctica para maestros. Universidad de Granada. Disponible en, http://www.ugr.es/local/jgodino/

Corporación Nacional de Desarrollo Indígena (2005). Azümchefe. Hacia la Escritura del Mapuzugun. Teтuco, Chile. Autor.

Consejo Nacional de la Cultura y las Artes (2012). Conociendo la cultura Mapuche. Santiago: Quad/Graphics.

D'Ambrosio, U. (1999). La transferencia del conocimiento matemático a las colonias: factores sociales, políticos y culturales. Llull, 22(44), 347-380. 
D'Ambrosio, U. (2000). Las dimensiones políticas y educacionales de la etnomatemática. Números, (43), 439-444.

D'Amore, B., y Godino, J. D. (2007). El enfoque ontosemiótico como un desarrollo de la teoría antropológica en didáctica de la matemática. Revista latinoamericana de investigación en matemática educativa, 10(2), 191-218.

De Augusta, A. F. J. (1903). Gramática araucana. Valdivia. Impr. Central. Disponible en Memoria Chilena, Biblioteca Nacional http://www.memoriachilena.cl/602/w3-article8186.html

De Bengoechea, N. (2009). Etnomatemáticas, métodos y objetos culturales. Tesis de Máster. Documento no publicado, Universidad de Granada. España.

Gajardo, A. (2012). Caracterización del rendimiento escolar de niños y niñas mapuches: contextualizando la primera infancia. Tesis doctoral. Universidad de Valladolid. España.

Gerdes, P. (1996). Ethnomathematics and mathematics education. In International handbook of mathematics education (pp. 909-943). Springer Netherlands.

Gimeno, S. (2002). Educar y convivir en la cultura global. (2 ed.). Madrid. Morata.

Godino, J. D. (2009). Categorías de análisis de los conocimientos del profesor de matemáticas. UNIÓN, Revista Iberoamericana de Educación Matemática, 20, 13-31.

Godino, J. D., y Batanero, C. (1994). Significado institucional y personal de los objetos matemáticos. Recherches en didactique des Mathématiques, 14(3), 325-355.

Godino, J. D., Font, V., Wilhelmi, M. R., y Lurduy, O. (2011). Why is the learning of elementary arithmetic concepts difficult? Semiotic tools for understanding the nature of mathematical objects. Educational Studies in Mathematics, 77(2-3), 247-265.

Gorgorió, N., Prat, M. y Santesteban, M. (2006). El aula de matemáticas multicultural: distancia, normas y negociación. En Goñi, J., Albertí, M., Burgos, S., Díaz, R., Dominguez, G., Fioriti, et al. (Ed.), Matemática e Interculturalidad. (pp 7-23). Barcelona: Editorial GRAÓ.

Hirmas, C., Hevia, R., Treviño, E. y Marambio, P. (2005). Políticas educativas de atención a la diversidad cultural: Brasil, Chile, Colombia, México y Perú. Santiago. UNESCO.

Ministerio de Educación (2002). Currículum Educación Matemática para la Educación Básica. Santiago, Chile.

Ministerio de Educación (2004). Libro de texto escolar Educación Matemática $7^{o}$ año básico. Santiago. Cal y Canto. 
Ministerio de Educación (2005). Orientaciones para la contextualización de Planes y Programas para la Educación Intercultural Bilingüe. Santiago, Chile.

Ministerio de Educación. (2009). Ley General de Educación. Ley № 20.370. Santiago, Chile.

Ministerio de Educación (2009). Currículum Educación Matemática para la Educación Básica. Santiago, Chile.

Ministerio de Educación (2009). Marco Curricular Lengua Indígena para la Educación Básica. Santiago, Chile.

Ministerio de Educación (2011). Programa de Estudio de Lengua Mapuzugun para $1^{\mathrm{o}}$ y $2^{\mathrm{o}}$ año de educación básica. Santiago, Chile.

Ministerio de Educación (2012). Programa de Estudio de Lengua Mapuzugun para $3^{\text {o }}$ año de educación básica. Santiago, Chile.

Ministerio de Educación (2012). Programa de Estudio de Matemáticas para $3^{\circ}$ año de educación básica. Santiago, Chile.

Ministerio de Educación (2013). Programa de Estudio de Lengua Mapuzugun para $4^{\circ}$ año de educación básica. Santiago, Chile.

Ministerio de Educación y OEI (1993). Sistema Educativo Nacional de Chile. Santiago. Disponible en http://www.oei.es/quipu/chile/\#sis

Ministerio de Planificación y Cooperación (1993). Ley de protección, fomento y desarrollo Indígena. Ley $\mathrm{N}^{\circ}$ 19.253. Santiago, Chile.

Moreno, A. (2004). Ideología y Educación matemática. Barcelona: Editorial Octaedro

Museo Chileno de Arte Precolombino (2009). Chile bajo el Imperio de los Inkas. Santiago. http://www.precolombino.cl/exposiciones/exposiciones-temporales/chile-bajo-el-imperioinka-2009/el-inka-en-las-regiones/quipus/

Nanculef, J. (2001). El origen del txafkintun: el mal llamado trueque. (En línea). La Opiñon. Recuperable en http://www.laopinon.cl/print/16058

Nanculef, J.(2005). La data cultural mapuche y los 12 mil años. (En línea). Revista digital Sepiensa.net. Recuperable en

http://www.sepiensa.net/edicion/index.php?option=content\&task=view\&id=543\&Itemid=0

Oliveras, M. L. (1996). Etnomatemáticas. Formación de profesores e innovación curricular. Granada: Editorial Comares.

Oliveras, M. L. (2006). Etnomatemáticas: de la multiculturalidad al mestizaje. En Goñi, J., Albertí, M., Burgos, S., Díaz, R., Dominguez, G., Fioriti, G., et al. (Ed.), Matemática e Interculturalidad. (pp. 117-149). Barcelona: Editorial GRAÓ. 
Pozo, G. (2007). Rakikan Zugu: un acercamiento sobre el acto y reflexión de contarnumerar. Artículo Red Latinoamericana de Etnomatemática. Disponible en http://www.etnomatematica.org/publica/articulos/RAKIKAN\%20ZUGU.pdf

Quilaqueo, D. y Quintriqueo, S. (2010). Saberes educativos mapuches: un análisis desde la perspectiva de los kimches. Polis, 9(26), 337-360.

Quintriqueo, S., y Maheux, G. (2004). Exploración del conocimiento sobre la relación de parentesco como contenido educativo para un currículum escolar intercultural en comunidades mapuche. Revista de Psicología, 13(1),73-91.

Quintriqueo, S. y McGinity, M. (2009). Implicancias de un modelo curricular monocultural en la construcción de la identidad sociocultural de alumnos/as mapuches de la IX región de La Araucanía, Chile. Estudios pedagógicos, 35(2), 173-188.

Rother, T. (2005). Conflicto intercultural y educación en Chile: Desafíos y problemas de la educación intercultural bilingüe (EIB) para el pueblo mapuche. Revista Austral Ciencias Sociales (9), 71-84.

Salas, A. (1980). El Sistema de numeración en el Mapuche Chileno. Revista la Matemática en el colegio (4), 5-13. Universidad Católica de Chile.

Sampieri, H. R, Fernández, C. y Baptista, M. (2010). Metodología de la investigación. Quinta edición. México: Editorial Mc Graw Hill

Skovsmose, O. (1999). Hacia una filosofía de la educación matemática crítica. Bogotá: Una Empresa Docente.

Skovsmose, O. (2012). Porvenir y política de los obstáculos de aprendizaje. En Valero, P. y Skovsmose, O. (Eds.). Educación matemática crítica. Una visión sociopolítica del aprendizaje y la enseñanza de las matemáticas (pp. 131-147). Bogotá: Una Empresa Docente.

Treviño, E., Donoso, F., Aguirre, E., Fraser, P., Godoy, F., Inostroza, D., et al. (2013). Educación para preservar nuestra diversidad cultural: desafíos de implementación del Sector de Lengua Indígena en Chile. Santiago: Centro de Políticas Comparadas de Educación, Unicef y Mineduc.

Valdivia, L. (1684). Arte y gramática general de la lengua que corre en todo el Reyno de Chile: con un vocabulario, y consessionario. Sevilla. Disponible en Memoria Chilena, Biblioteca Nacional http://www.memoriachilena.cl/602/w3-article-8485.html

Valero, P. (2002). Consideraciones sobre el contexto y la educación matemática para la democracia. Quadrante: Revista Teórica e de Investigação, 33-43. 
Valero, Paola (2012). Perspectivas sociopolíticas en la educación matemática. En Valero, P. y Skovsmose, O. (Eds.), Educación matemática crítica. Una visión sociopolítica del aprendizaje y la enseñanza de las matemáticas. (pp. 195-216). Bogotá: una empresa docente.

Vithal, R., y Skovsmose, O. (1997). The end of innocence: a critique of 'ethnomathematics'. Educational Studies in Mathematics, 34(2), 131-157.

\section{LISTA DE TABLAS Y FIGURAS.}

$\begin{array}{ll}\text { Figura 2.1. Configuración del estudio } & \text { p. } 32\end{array}$

$\begin{array}{ll}\text { Figura 2.2. Esquema de interpretación morfo-matemática. } & \text { p. } 32\end{array}$

Figura 4.1 Actividades Libro de texto 2004 -2005. Editorial Cal y Canto P. 49

Figura 4.2 Quipu o Püron p. 56

Figura 5.1. Áreas de indagación relacionadas con el aprendizaje matemático del $\begin{array}{ll}\text { estudiante mapuche } & \text { p. } 74\end{array}$

Tabla 4.1. Los primeros 20 números en español p. 50

$\begin{array}{ll}\text { Tabla 4.2. Los primeros } 20 \text { números en mapuzugun } & \text { p. } 51\end{array}$

Tabla 4.3. Algunos números y potencias de diez en español p. 52

Tabla 4.4. Algunos números y potencias de diez en mapuzugun p. 53

Tabla 4.5. Respuestas de estudiantes mapuches a cuestiones matemáticas p. 62

$\begin{array}{ll}\text { Tabla 4.6. Respuesta de profesores de estudiantes mapuches } & \text { p. } 65\end{array}$

\section{ANEXOS}

\section{Evolución de la Educación en Chile desde la segunda mitad del Siglo XX}

Tabla 1.1 Evolución histórica de la matrícula escolar en Chile.

Tabla 1.2 Población, matrícula y cobertura del Sistema Educacional Nacional

Tabla 1.3 Cantidad de Establecimientos Educacionales educación Obligatoria

Tabla 1.4 Población Indígena en Chile

Tabla 1.5. Establecimientos que implementan el Programa EIB y qué porcentaje representan del total de establecimientos en la región. 
Tabla 1.6. Resultados SIMCE por región en el año 2012.

Tabla 1.7. Establecimientos según dependencia y zona geográfica

Figura 1.1 Gráfica de la Identidad Indígena en Chile

\section{Programa de estudios de Lengua Mapuzugun. $1^{\circ}$ a $4^{\circ}$ año Básico"}

Figura 2.1. Relato contado a los estudiantes. Programa de Lengua Mapuzugun $3^{\circ}$ Básico.

Figura 2.2. Modelo de invitación presentado a los estudiantes. Programa Lengua Mapuzugun $4^{\circ}$ Básico.

Figura 2.3. Actividad propuesta por el Programa Lengua Mapuzugun para $2^{\circ}$ Básico.

Figura 2.4. Actividad propuesta por el Programa de Lengua Mapuzugun para $2^{\circ}$ Básico.

Figura 2.5. Actividad propuesta por el Programa de Lengua Mapuzugun para $1^{\circ}$ Básico.

Figura 2.6. Actividad propuesta por el Programa de Lengua Mapuzugun para $3^{\circ}$ Básico.

Figura 2. 7. Repertorio sintáctico y mapa semántico para conceptos geométricos.

\section{Orientaciones para contextualizar la educación matemáticas en la EIB}

Tabla 3.1. Actividades propuestas en las Orientaciones del programa de matemáticas para los niveles de $1^{\circ}$ y $2^{\circ}$ año de Educación Básica para la EIB.

\section{Actividades de conteo $2^{\circ}$ básico (caso-tipo)}

Figura 4.1. Araucanía con EIB.

Figura 4.2. Valparaíso sin EIB.

\section{Encuesta profesores de estudiantes mapuches}

Figura 5.1. Profesor Valparaíso sin EIB

Figura 5.2. Profesor Araucanía con EIB 


\title{
ANEXOS TFM
}

\section{ETNOMATEMÁTICA Y MULTICULTURALIDAD EN LA EDUCACIÓN BÁSICA EN CHILE. EL CASO DE LA ARITMÉTICA MAPUCHE}

\author{
SONIA SALAS SALINAS \\ Tesis Fin de Máster \\ Programa de Máster en Didáctica de la Matemática \\ Departamento de Didáctica de la Matemática \\ Universidad de Granada
}

Granada, Septiembre 2014

Índice anexos

Página

1. Evolución de la Educación en Chile desde la segunda mitad del Siglo XX......... 02

2. Programa de estudios de Lengua Mapuzugun. $1^{\circ}$ a $4^{\circ}$ año Básico"................ 13

3. Orientaciones para contextualizar la educación matemáticas en la EIB........... 17

4. Actividad de conteo $2^{\circ}$ Básico (casos-tipos)................................ 28

5. Encuesta profesores de estudiantes mapuches............................... 30 


\section{ANEXO 1 \\ Evolución de la Educación en Chile desde la segunda mitad del Siglo XX}

La educación en Chile ha evolucionado, especialmente, con las leyes que se han promulgado en la segunda mitad del siglo XX y a principios del siglo XXI. A partir de los años 50, centra su atención en la expansión de la cobertura de la educación obligatoria, la diversificación del tipo de instituciones y programas educativos y la sucesión de políticas educativas y reformas en la gestión de ésta, (Ministerio de Educación de Chile \& Organización de Estados Iberoamericanos. 1993); para a finales del mismo siglo e inicios del siglo XXI el enfoque, de las diversas reformas, se orienta hacia la mejora de la Calidad de la Educación y la distribución equitativa del conocimiento.

En la segunda mitad del siglo XX, el sistema educativo sufrió profundo cambios, debido a los drásticos momentos socio-políticos que se vivían en aquella época, la dictadura militar (1973-1990). Ésta se limitó a revisar, cabalmente, los programas de la reforma de 1965, los cuales fueron depurados de todo aspecto "conflictivo" o "político partidista"; re-estableciendo, en ellos, los principios del humanismo cristiano nacionalista y re-legitimando el aspecto tradicional de la educación como disciplina (Ministerio de Educación de Chile \& Organización de Estados Iberoamericanos. 1993).

En este nuevo escenario y fundamentado por una ideología neo-liberal, se inicia la restructuración del sistema educativo, aprobando nuevos programas de estudio. A parir de los años 80, hasta los últimos días de la Dictadura Militar en 1990, se introdujeron varias modificaciones en distintos ámbitos de la educación, entre ellos: se establece un sistema de evaluación nacional del rendimiento escolar PER, que posteriormente en 1988 se denominó como se conoce hasta hoy SIMCE, en los niveles de $4^{\circ}$ y $8^{\circ}$ básico. Se intervienen las universidades, liceo y escuelas para la despolitización y reordenación de las instituciones, ejerciendo un fuerte control en el proceso educativo. Se reestructura la gestión educativa, con el desprendimiento de las escuelas e institutos y liceos de educación básica y media, proceso que culmina en 1986 con el traspaso total de los establecimiento educacionales del país a la administración de corporaciones privadas, creadas por asociaciones gremiales de empresarios privados de la industria, comercio y la agricultura, y un sector de ellos fue traspasado a las municipalidades del país. Se norma la doctrina del "Estado Subsidiario", el que privilegia la "libertad de enseñanza", estimulando la educación privada mediante la subvención escolar; y a finales de este gobierno (10 de marzo de 1990) se promulga la nueva ley de educación LOCE, Ley Orgánica Constitucional de Enseñanza.

El cambio administrativo, en esta época fue muy significativo para lo que es la educación en Chile en la actualidad y su evolución en la matrícula según dependencia de los establecimientos, como se muestra en la Tabla 1.1. 
Tabla 1.1. Evolución histórica de la matrícula escolar en Chile.

\begin{tabular}{|l|l|l|l|l|}
\hline $\begin{array}{l}\text { Total Matrícula Estudiantes } \\
\text { Educación Obligatoria }\end{array}$ & Particular & $\%$ & $\begin{array}{l}\text { Estatal } \\
\text { (Pública) }\end{array}$ & $\%$ \\
\hline $\begin{array}{l}1950 \\
905.504\end{array}$ & 251.394 & 27,8 & 654.110 & 72,2 \\
\hline & Particular & $\%$ & Municipal & $\%$ \\
\hline $\begin{array}{l}1990 \\
3.330 .740\end{array}$ & 1.441 .156 & 43,3 & 1.889 .584 & 56,7 \\
\hline $\begin{array}{l}2012 \\
3.410 .178\end{array}$ & $*$ Particular & $\%$ & Municipal & $\%$ \\
\hline
\end{tabular}

Fuente: Departamento de Estudios y Desarrollo, División de Planificación y Presupuesto, Ministerio de Educación (Ministerio de Educación de Chile y Organización de Estados Iberoamericanos 1993).

* Incluye: Particular Pagado, Particular Subvencionado y Corporaciones.

La evolución de la educación y su expansión no ha sido rectilínea, de acuerdo a los antecedentes señalados y que podemos apreciar en la Tabla 1.2, ésta da cuenta de un período de crecimiento moderado entre 1950 y 1964, una expansión más acelerada entre 1965 y 1973, después de este período y hasta la vuelta de la democracia en 1990, vuelve una expansión moderada (Ministerio de Educación de Chile \& Organización de Estados Iberoamericanos. 1993).

Tabla 1.2. Población, matrícula y cobertura del Sistema Educacional Nacional.

\begin{tabular}{|l|l|l|l|}
\hline Población & Año 1950 & 1981 & 1990 \\
\hline $\begin{array}{l}\text { Población de 0 a 24 años } \\
\text { de edad }\end{array}$ & 3.499 .862 & 5.991 .420 & 6.503 .080 \\
\hline $\begin{array}{l}\text { Matriculados en } \\
\text { educación básica, media } \\
\text { y superior }\end{array}$ & 905.504 & 2.988 .502 & 3.330 .740 \\
\hline $\begin{array}{l}\text { Cobertura del Sistema } \\
\text { Nacional }\end{array}$ & $26,2 \%$ & $49,9 \%$ & $51,2 \%$ \\
\hline
\end{tabular}

Fuente: Informe Ministerio de Educación de Chile y Organización de Estados Iberoamericanos 1993.

Entre 1950 y 1964 se realizó una fuerte inversión en construcciones de establecimientos escolares, equipamiento y formación y capacitación de profesores, además de programas de asistencia escolar, particularmente, de alimentación. En este sub-período la cobertura crece de un 26,2\% hasta un 35,8\%. Para el período siguiente hasta 1973 o 74, para hacer frente al salto expansivo, se recurrió a medidas extraordinarias de aceleración en la formación docente y al empleo de los edificios escolares a doble turno. Con estas medidas la cobertura crece del 35,8\% hasta el 54,8\%. En el período de la dictadura militar hasta 1990, la expansión fue lenta y en algunos niveles se experimento un franco retroceso. Es así como al termino de la dictadura militar se retrocedió en la cobertura a un 51,2\% (Ministerio de Educación de Chile \& Organización de Estados Iberoamericanos. 1993). En relación a estos datos y en términos de crecimiento de la matrícula se tiene: entre 1950 y 1964, se crean 819.798 nuevas plazas; entre 1964 y 1973 o 74, se crean 1.316.985 nuevas matrículas; y entre 1974 y 1990 sólo se ofrecen 
288.455 nuevas matrículas. Sin embargo, al llegar a los años noventa, el problema de la cobertura estaba en gran medida resuelto; pero el modelo educacional "neo-liberal" instalado por la dictadura militar, vigente actualmente, permitió que se continuara con la expansión, ya no de la cobertura, sino de la construcción y habilitación de nuevos establecimiento educacionales para la educación obligatoria. Desde 1990 al 2012 los establecimientos educacionales públicos han disminuido en un $12,3 \%$ y los establecimientos educacionales particulares subvencionados han aumentado en un 121,4\%; como se aprecia en la tabla 1.3, más abajo. Estos datos se condicen con la evolución de la matricula presentado en la Tabla 1.1, es decir han aumentado los establecimientos privados y disminuido los establecimientos públicos, por ende la matrícula en el sector público ha disminuido y en el sector privado ha aumentado.

Tabla 1.3. Cantidad de Establecimientos Educacionales educación Obligatoria

\begin{tabular}{|l|l|l|l|l|l|}
\hline \multirow{2}{*}{ Año } & \multicolumn{4}{|c|}{ Dependencia Administrativa } & \multirow{2}{*}{ Total } \\
\cline { 2 - 5 } & Municipal & $\begin{array}{l}\text { Particular } \\
\text { Subvencionado }\end{array}$ & $\begin{array}{l}\text { Particular } \\
\text { Pagado }\end{array}$ & Corporaciones & \\
\hline 1990 & 6.286 & 2.694 & 758 & 73 & 9.811 \\
\hline 2012 & 5.541 & 5.965 & 625 & 70 & 12.174 \\
\hline $\begin{array}{l}\text { Aumento } \\
\text { disminución }\end{array}$ & $\begin{array}{l}\text { Disminuye } \\
\text { en un 12,3 } \\
\%\end{array}$ & $\begin{array}{l}\text { Aumenta en un } \\
121,4 \%\end{array}$ & $\begin{array}{l}\text { Disminuye } \\
\text { en un 17,5 } \\
\%\end{array}$ & $\begin{array}{l}\text { Disminuye en } \\
\text { un 4,1 \% }\end{array}$ & $\begin{array}{l}\text { Aumenta } \\
\text { en un 24,1 } \\
\%\end{array}$ \\
\hline
\end{tabular}

Fuente: Informe Ministerio de Educación de Chile y Organización de Estados Iberoamericanos 1993.

De acuerdo a la tablas 1.1 y 1.3, se aprecia claramente que la educación pública está en vía de extinción y la educación privada subvencionada por el estado de Chile, se acrecienta cada vez más; incluso absorbiendo lo que era la educación particular privada, en la que el estado no aportaba financiamiento. Muchas de las escuelas y liceos particular pagado, han optado por pasar al régimen de particular subvencionado, bajando así el cobro de colegiaturas a los padres y poder alcanzar una mejor matrícula. Así se instala en nuestro país el modelo educativo neoliberal, capitalista de libre mercado.

En 1990, se inicia un nuevo proceso de transición política, económica y social en Chile, y esto no excluye a la educación, pues se comienzan a realizar estudios que permitan reorientar el Sistema Educativo, sus fines políticos, culturales y sociales. El primer gobierno democrático se instaló el 11 marzo de 1990 y se comprometió a respetar plenamente la Constitución Política de 1980, instaurada por la dictadura militar, y la legislación derivada de ésta, entre ellas la Ley Orgánica Constitucional de Enseñanza (LOCE) aprobada el 10 de marzo de 1990; sin perjuicios de promover cambios si estimase conveniente y ajustados al Estado de Derecho vigente. Las evaluaciones estandarizadas nacionales, de la época, introducidas durante la dictadura militar, hasta hoy vigentes, SIMCE permitió tomar conciencia de la discriminación social existente en el sistema educativo en cuanto a la calidad de la educación, ya que el nivel de aprendizaje en la educación básica eran notoriamente bajos y se distribuían de manera socialmente discriminatoria. Esto es, en sectores de ingreso medios-bajos los estudiantes, atendidos por las escuelas y liceos municipales, aprendían notablemente menos que los estudiantes de los sectores medio-altos o altos que asisten a escuelas y liceos pagados. Realidad educativa que se instala en nuestro país a partir del modelo neoliberal instalado por la dictadura militar. 
Estos antecedentes y otros de aspectos sociales y culturales, fueron recogidos y asumidos por los gobiernos, al regreso de la democracia y desde ahí se inicia una nueva transformación gradual de la educación. Los nuevos principios orientadores de la acción gubernamental, en materia de educación, focaliza, entre otros aspectos: la preocupación por la calidad de la educación; equidad en la distribución del saber, superando las desigualdades sociales y étnicas y la promoción de la creatividad y del acceso masivo a los bienes culturales (Ministerio de Educación de Chile y Organización de Estados Iberoamericanos 1993). Las bases fundamentales de los últimos cambios de la educación se sostienen, principalmente, en la investigación en educación. Las condiciones políticas- culturales que se propician a partir del año 1990, hacen posible una nueva visión investigativa, se enriquecen los enfoques teóricos y se abre la mirada hacia la investigación cualitativa-interpretativa. Son estos estudios los que ponen de manifiesto los puntos críticos por los que atraviesa la educación de vuelta a la democracia, mencionados anteriormente. En materia curricular, la investigación reporta que el desarrollo curricular hasta los años 90, no da cuenta de los requerimientos de la diversidad geográfica y sociocultural de la nación; tampoco marcha de acuerdo al desarrollo del conocimiento ni los requerimientos de la inserción del país en la modernidad ni en la vida contemporánea y su avance hacia el mundo globalizado. Es en este punto de la historia de la educación en nuestro país, cuando se proyecta el rumbo neoliberal y mercantilista de la educación (instalado en dictadura) y que nos conducirá al actual modelo educativo monocultural imperante en el país. En relación a las prácticas educativas, éstas reportan el predominio de estilos de enseñanza que favorecen el aprendizaje dependiente y memorístico, de asimilación pasiva del aprendizaje, tal cual lo reporta a nivel internacional Vithal y Skovsmose, (1997) cuando plantean que hay cuestiones que no andan bien en la enseñanza de la matemática, con instalación de la idea de la modernización. Las prácticas del profesor, capaz de controlar y apaciguar la inquietud de los estudiantes (Skovsmose 1999) comienza a tomar importancia en cuanto a su erradicación, aún cuando hasta hoy encontramos esas prácticas docentes en el aula. Es decir, se enfrenta en esta época de la historia un gran desafío en educación y es de corresponderse con las transformaciones a nivel mundial y con el proyecto nacional de crecimiento económico con equidad.

Con este proyecto nacional, en que está inmerso el sistema educativo, se inicia un proceso de integración internacional, para lo cual una de las acciones que se emprende es participar en las mediciones internacionales estandarizadas a fin de compararse a nivel internacional y procurar tomar medidas que apunten al mejoramiento del sistema educativo, la calidad de la educación y alcanzar los estándares internacionales. Chile ha participado en: Estudio Internacional de Educación Cívica y Formación Ciudadana (ICCS); Estudio Internacional de Alfabetización Computacional y Manejo de Información (ICILS); Tercer Estudio Regional Comparativo y Explicativo (TERCE) del Laboratorio Latinoamericano de Evaluación de la Calidad de la Educación (LLECE), sus aplicaciones han sido el PERCE, el SERCE y se ha participado en los tres; Estudio Internacional de Tendencias en Matemática y Ciencias (TIMSS); Programa para la Evaluación Internacional de Estudiantes (PISA) y el Estudio Internacional del Progreso en Competencia Lectora (PIRLS) que su próxima aplicación será el año 2016, en la que se participará por primera vez.

Es así como la transición política, social y educacional en Chile a partir del regreso de la democracia, en sus inicios mantuvo los principios fundamentales de la educación chilena consagrados en la Constitución Política de la República de 1980 y paulatinamente, con la puesta en marcha de LOCE en 1990, se fueron introduciendo 
modificaciones; sin embargo, los cambios más de fondo vienen en el año 2003 mediante la Ley 19.876 que modifica la Constitución Política y posteriormente con la nueva Ley General de Educación (LGE) el año 2009, la que representa el actual marco institucional para la educación obligatoria en Chile (educación básica y media). Estas medidas y la participación en las distintas evaluaciones internacionales, ha permitido orientar el currículo nacional hacia el logro de las competencias necesarias que cada ciudadano debe alcanzar para desarrollarse plenamente y hacer frente a los desafíos de la sociedad del siglo XXI. Para ello, se introducen modificaciones curriculares en las áreas en que se está midiendo internacionalmente, orientadas al desarrollo de competencias lectoras, competencias matemáticas y competencias en ciencias. En relación a la evolución del marco curricular, se inicia con un proceso de elaboración de nuevos Planes y Programas (Organización didáctica) que establecen los objetivos fundamentales (OF) y los contenidos mínimos obligatorios (CMO) e incorpora los objetivos fundamentales transversales (OFT) y se ponen a disposición de los establecimientos a partir del año 1996 en que se dicta el Decreto Supremo No 40 que aprueba los Planes y Programas que acompañan la Jornada Escolar Completa (JEC).

En el ámbito ciudadano, también se producen cambios a partir de la vuelta a la democracia y una de las principales herramientas ciudadanas que vuelven a emerger fuertemente durante los nuevos gobiernos de la Concertación de Partidos por la democracia, son los movimientos sociales para plantear sus demandas al estado. La manifestación social se empieza a incrementar a partir de los años 2000, entre ellos los estudiantes, el pueblo mapuche, los deudores habitacionales y otros. En el caso de los estudiantes, muchas de sus manifestaciones sociales no fueron atendidas desde la pseudo-democracia ya instalada, sino más bien fueron abordadas con represión e intentos de deslegitimación de sus demandas. El descontento ciudadano en el ámbito educacional comenzó a tomar fuerza y es así como el año 2006, los estudiantes secundarios iniciaron una fuerte movilización social, conocida como la "Revolución Pingüina", que marca un hito importante en el despertar de la sociedad civil en Chile, en cuanto al derecho de participación en las políticas del estado. Luego de haber estado sometidos por 17 años a una dictadura militar, muchas generaciones "hijos de la dictadura militar" estaban adormecido socialmente; pero los estudiantes lideraron y siguen liderando las grandes luchas sociales en Chile. Este movimiento social, que partió con los estudiantes secundarios y que luego fue teniendo más y más adeptos al movimiento, fue realmente notable por su capacidad de organización a nivel nacional, por su carácter rupturista juvenil y por los alcances políticos a nivel nacional. Este fue el primer "terremoto" que ha tenido el modelo educacional neoliberal mercantilista en los últimos 20 años y fue el nido para la concepción de la actual Ley General de Educación (LGE). Si bien, no se logró terminar con el modelo neoliberal de la educación en nuestro país, permitió poner el tema de la "educación" en el centro del debate nacional y promover la organización social en pro de las demandas legítimas de los ciudadanos en Chile.

Junto a estos nuevos procesos que se viven en Chile en torno al modelo educativo y la inserción del país en la dinámica internacional a nivel político, social y cultural. Atendiendo a los Derechos Humanos, los Convenio de la OIT y los Derechos del Niño, los cuales establecen el respeto por el desarrollo autónomo de las minorías étnicas en el mundo y promueven la preservación de su patrimonio cultural en armonía con las naciones independientes a las que pertenecen y principalmente el cultivo de las lenguas originarias, desde un enfoque post-moderno (Hirmas, Hevia, Treviño y Marambio 
2005), que tiene como fin la valoración y trato igualitario de las distintas culturas sin sobreponer un conocimiento sobre otro, se inicia un proceso de reconocimiento de las raíces étnicas de nuestra nación. En 1993 se promulga la Ley $\mathrm{N}^{\circ}$ 19253, que reconoce nueve pueblos indígenas: Mapuche, Aymara, Rapa Nui o Pascuense, Atacameño o Likan Antai, Diaguitas, Quechua, Colla, Kawáshkar o Alacalufe y Yámana o yagán. De esta forma se emprende un proyecto para la valoración de su existencia y el reconocimiento a su integridad y desarrollo, de acuerdo a sus costumbres, valores y cosmovisión. Este reconocimiento se ve reflejado en algunos aspectos en los Planes y Programas educativos introducidos en el año 1996, los que incorporan en algunos sectores (asignaturas) de aprendizaje de la educación general básica, el estudio de los pueblos originarios en América. En educación matemática, también se incorporaron algunos cambios y en $7^{\circ}$ año de educación básica se incorpora la unidad didáctica "Sistemas numéricos en la historia", la que abordaba algunos sistemas numéricos en la historia y la actualidad, se estudiaban los sistemas numéricos mayas, babilónicos, chinos, binario, decimal posicional y el sistema decimal mapuche.

La Ley General de Educación (LGE 2009), representa el actual marco institucional para la educación obligatoria y su principio orientador enmarca a la educación....

(...) "en el respeto y valoración de los derechos humanos y de las libertades fundamentales, de la diversidad multicultural y de la paz y de nuestra identidad nacional”... (Art. 2)

Este nuevo marco curricular para la educación obligatoria reconoce y valora el lenguaje indígena, esencialmente, porque a través de éste la sociedad chilena podrá comprender y valorar su cultura; aprendiendo aspectos fundamentales como la circularidad del tiempo, la relación parte a todo con la naturaleza, la posición y definición de la persona en relación con su entorno, la armonía y otros conocimientos de las culturas originarias. Estos y otros aspectos han sido consagrados en Planes y Programas dictados por Decreto Supremo $\mathrm{N}^{\circ} 40$ de enero de 1996. De alguna forma, estas nuevas medidas aportan al rescate de nuestra cultura, luego del exterminio sistemático y de la aculturación a la que fueron sometidos y son sometidos (Belloli, 2009) nuestros pueblos originarios.

Junto a esta nueva concepción de la educción, el año 2009 se dicta el Decreto Supremo $\mathrm{N}^{\circ} 280$ que incorpora un nuevo Sector de Aprendizaje para la Educación Básica el Sector de Lengua Indígena (SLI), estableciendo así un Programa de Educación Intercultural Bilingüe (EIB). Este decreto se traduce en las actuales Bases Curriculares específicas de la lengua indígena para un nuevo modelo de formación bilingüe. Este nuevo marco legal promueve el respeto por las Culturas Indígenas y para lo cual se establece: "el uso y conservación de los idiomas indígenas, junto al español en las áreas de mayor densidad indígena" (Ministerio de Educación, 2009).

El nuevo sector curricular de lengua indígena, entra en vigencia gradualmente a partir del año 2010 en el primer año de educación básica, de manera obligatoria en aquellos establecimientos con una matrícula indígena igual o superior al $50 \%$ y a partir del año 2014 en los establecimientos con una matrícula igual o superior al 20\%, como lo establece el decreto $\mathrm{N}^{\circ} 280$ del año 2009 (Ministerio de Educación, 2013). Según la base de datos del Ministerio de Educación, en la actualidad, el $70 \%$ de los establecimientos del país poseen matrícula indígena y no puede ser desconocida; por ello en el marco del Programa de Educación Intercultural Bilinguie (EIB), el gobierno propone avanzar en el respeto y valoración de la diversidad, convirtiendo a la escuela en 
un espacio educativo que: asegure a los niños y niñas, el acceso al conocimiento transmitido por su pueblo de origen; invite a los estudiantes a ser actores de su propio proceso educativo, toda vez que su cultura y lengua son el punto de partida para el desarrollo de competencias (habilidades, conocimientos y actitudes); y propicie que la lengua originaria sea un elemento de inicio de una conversación sobre interculturalidad.

Al paso de 4 años de puesta en marcha del Programa de EIB, hemos mirados los datos del Ministerio de Educación en su sección educación intercultural, la que nos dice que en la actualidad 296 establecimientos a lo largo de todo Chile, implementan el sector (asignatura) de aprendizaje de lengua indígena (SLI), como se muestra en la tabla 1.5. En esta tabla podemos ver qué porcentaje representan del total de los establecimientos de la región. De los establecimientos con EIB, la mayor cantidad de escuelas la tiene la región de la Araucanía con 130 establecimientos educacionales. De acuerdo a los datos del censo 2002 (ver tabla 1.4 y Figura 1.1), la población mapuche representa el $87.31 \%$ del total de la población indígena del país, alrededor de 604.349 habitantes; hay algunas discrepancias con los datos preliminares de censo 2012 que apuntan a que la población mapuche ha incrementado sobre el $10 \%$ de la población total del país. La población total de país, según censo 2002, es de 15.116.435 habitantes de los cuales la mayor parte se concentra en la capital, la Región Metropolitana (Santiago de Chile) con 6.045.192 habitantes y de los cuales 180.963 pertenecen a la etnia Mapuche, lo que representa el $30,3 \%$ de la población total mapuche, en la capital. En la región de la Araucanía, al sur de Chile, la población total asciende a 867.351 habitantes, de los cuales 203.221 pertenecen a la etnia mapuche, representando el 33,6\% del total de la población mapuche. Es decir más del $50 \%$ de los habitantes mapuches los encontramos en la Araucanía y Santiago (Capital).

\begin{tabular}{|c|c|c|c|c|c|c|c|c|c|c|c|}
\hline \multirow{2}{*}{$\begin{array}{l}\text { Región de } \\
\text { residencia } \\
\text { habitual } \\
\text { actual }\end{array}$} & \multirow{2}{*}{$\begin{array}{c}\text { Población } \\
\text { Total }\end{array}$} & \multirow{2}{*}{$\begin{array}{c}\text { Población } \\
\text { que } \\
\text { pertenece } \\
\text { a una etria }\end{array}$} & \multirow{2}{*}{ Alacalufe } & \multirow[b]{2}{*}{ Atacameño } & \multicolumn{3}{|c|}{ GRUPO ETNICO } & \multicolumn{3}{|c|}{ Censo 2002} & \multirow{2}{*}{$\begin{array}{l}\text { Ninguno } \\
\text { de los } \\
\text { anteriores }\end{array}$} \\
\hline & & & & & Aimara & Colla & Mapuche & Quechua & Rapanú & Yámana & \\
\hline $\begin{array}{l}\text { País } \\
\text { Porcentaje }\end{array}$ & 15.116 .435 & $\begin{array}{r}692.192 \\
100,0\end{array}$ & $\begin{array}{r}2.622 \\
0,38\end{array}$ & $\begin{array}{r}21.015 \\
3,04\end{array}$ & $\begin{array}{r}48.501 \\
7,01\end{array}$ & $\begin{array}{r}3.198 \\
0,46\end{array}$ & $\begin{array}{r}604.349 \\
87,31\end{array}$ & $\begin{array}{r}6.175 \\
0,89\end{array}$ & $\begin{array}{r}4.647 \\
0,67\end{array}$ & $\begin{array}{r}1.685 \\
0,24\end{array}$ & 14.424 .243 \\
\hline 01 & 424.484 & 48.665 & 66 & 1.061 & 40.700 & 275 & 5.372 & 1.025 & 86 & 80 & 375.819 \\
\hline 02 & 481.931 & 22.808 & 48 & 13.855 & 2.468 & 182 & 4.117 & 2.038 & 42 & 58 & 459.123 \\
\hline 03 & 253.205 & 7.407 & 32 & 3.074 & 380 & 1.738 & 2.057 & 50 & 58 & 18 & 245.798 \\
\hline 04 & 603.133 & 5.177 & 37 & 668 & 467 & 324 & 3.514 & 56 & 63 & 48 & 597.956 \\
\hline 05 & 1.530 .841 & 18.708 & 128 & 419 & 567 & 72 & 14.594 & 144 & 2.671 & 113 & 1.512 .133 \\
\hline 06 & 775.883 & 9.958 & 58 & 97 & 105 & 47 & 9.485 & 57 & 54 & 55 & 765.925 \\
\hline 07 & 905.401 & 8.157 & 56 & 55 & 107 & 15 & 7.756 & 48 & 47 & 73 & 897.244 \\
\hline 08 & 1.859 .546 & 54.078 & 120 & 141 & 211 & 44 & 53.104 & 159 & 126 & 173 & 1.805 .468 \\
\hline 09 & 867.351 & 204.195 & 111 & 61 & 94 & 88 & 203.221 & 456 & 102 & 62 & 663.156 \\
\hline 10 & 1.066 .310 & 101.733 & 434 & 86 & 178 & 62 & 100.327 & 308 & 158 & 180 & 964.577 \\
\hline 11 & 89.986 & 8.063 & 281 & 36 & 44 & 1 & 7.546 & 56 & 27 & 72 & 81.923 \\
\hline 12 & 147.533 & 9.544 & 563 & 25 & 52 & 24 & 8.621 & 45 & 25 & 189 & 137.989 \\
\hline 13 & 6.045 .192 & 191.362 & 669 & 1.379 & 2.743 & 292 & 182.963 & 1.599 & 1.169 & 548 & 5.853 .830 \\
\hline \multicolumn{12}{|l|}{ Extranjeroe } \\
\hline Ignorado & 65.639 & 2.337 & 19 & 58 & 385 & 34 & 1.672 & 134 & 19 & 16 & 63.302 \\
\hline
\end{tabular}

Fuente: INE. Censo 2002. 


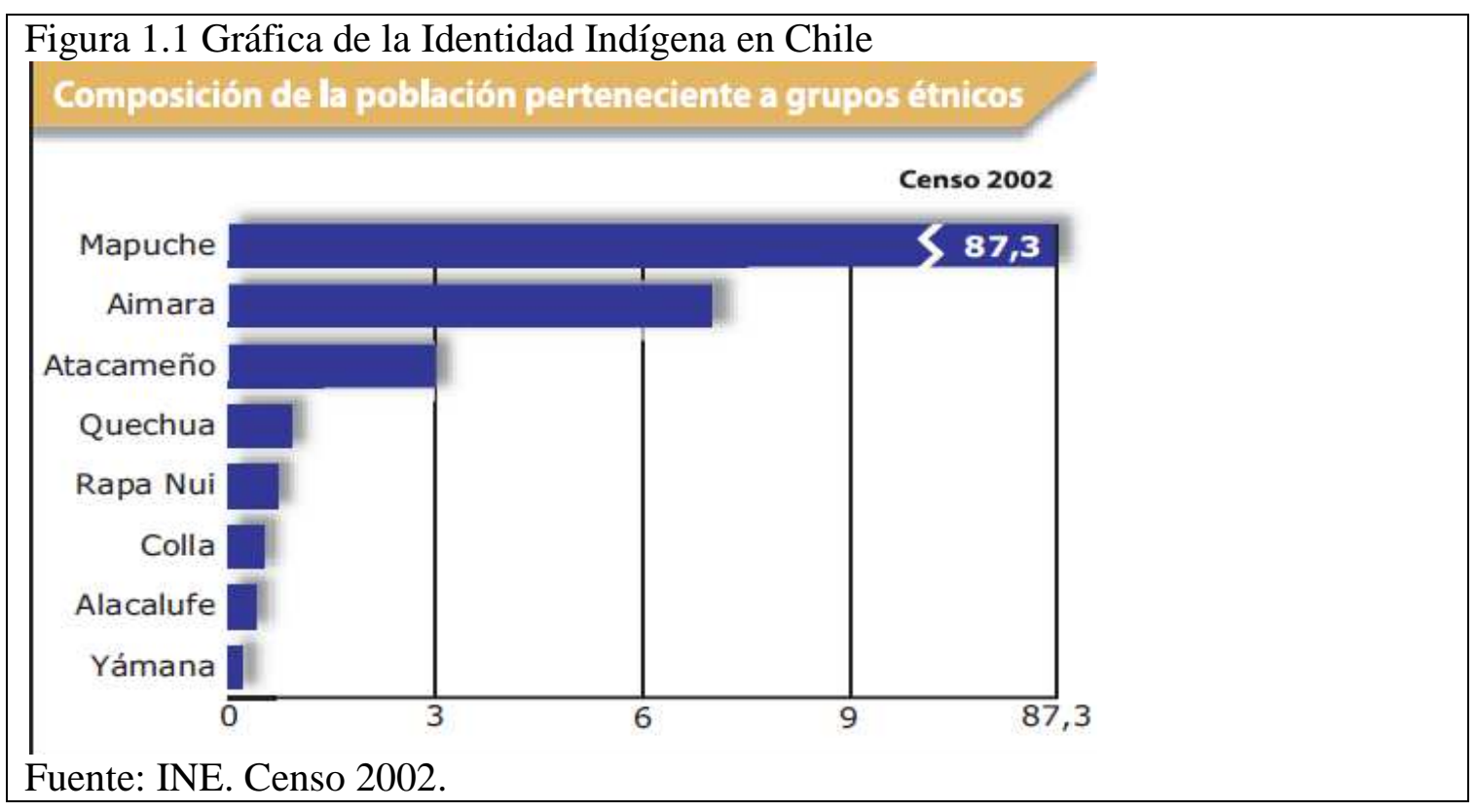

En cuanto a los establecimientos educacionales del país, para atender la educación obligatoria, tenemos un total de 12.174 establecimientos y la mayor cantidad de éstos se encuentra en la capital, Región Metropolitana (Santiago) con 3.063 establecimientos, de los cuales 6 de ellos implementan el programa EIB, es decir u 0,2\%. Luego tenemos en la Araucanía un total de 1.242 establecimientos, de los cuales 130 implementan el programa de EIB, de éstos el $80 \%$ son escuelas municipales (públicas) y representan $10,5 \%$. Del total de establecimientos del país, un 2,43\% implementan el programa de EIB a través del sector de lengua indígena (SLI) establecido por el Ministerio de Educación o con planes y programas propios (PPP), como se muestra en la tabla 1.5.

Tabla 1.5. Establecimientos que implementan el Programa EIB y qué porcentaje representan del total de establecimientos en la región.

\begin{tabular}{|c|c|c|c|c|c|}
\hline $\mathbf{N}^{\mathbf{0}}$ & Región & Total & C/EIB & $\%$ & Observación \\
\hline 15 & Región de Arica y Parinacota & 182 & 25 & 13,7 & SLI \\
\hline 1 & Región de Tarapacá & 227 & 15 & 6,6 & SLI \\
\hline 2 & Región de Antofagasta & 237 & 16 & 6,8 & 1 SLI y 15 PPP \\
\hline 3 & Región de Atacama & 182 & 0 & & \\
\hline 4 & Región de Coquimbo & 794 & 0 & & \\
\hline 5 & Región de Valparaíso & 1.270 & 0 & & \\
\hline 13 & Región Metropolitana & 3.063 & 6 & 0,2 & 4 SLI y 2 PPP \\
\hline 6 & Región del L. G. B. O' Higgins & 701 & 0 & & \\
\hline 7 & Región del Maule & 885 & 0 & & \\
\hline 8 & Región del Biobío & 1.595 & 44 & 2,8 & 40 SLI y 4 PPP \\
\hline 9 & Región de la Araucanía & 1.242 & 130 & 10,5 & SLI \\
\hline 14 & Región de los Ríos & 544 & 33 & 6,1 & SLI \\
\hline 10 & Región de Los Lagos & 1.107 & 27 & 2,4 & SLI \\
\hline 11 & Región de Aisén del G. C. I. del & 84 & 0 & & \\
\hline \multirow[t]{2}{*}{12} & Región de Magallanes y de la & 91 & 0 & & \\
\hline & Total & 12.174 & 296 & 2,43 & \\
\hline
\end{tabular}

Fuente: Ministerio de Educación de Chile (2012). División Educación Intercultural. Centro de Estudios, División de Planificación y Presupuesto. Disponible en 
http://www.peib.mineduc.cl/index2.php?id_portal=28\&id_seccion=3416\&id_contenido $=13947$

Otro aspecto importante a señalar, son los resultados en la medición de aprendizajes en la evaluación nacional (SIMCE) que se aplica cada año al $4^{\circ}$ año de enseñanza básica y alternadamente al $8^{\circ}$ año básico y $2^{\circ}$ año de enseñanza media (secundaria). Un estudio de Quilaqueo y Quintriqueo (2010) hacen mención a la diferencia en los puntajes alcanzados en la evaluación nacional SIMCE el año 2003 por los estudiantes de $2^{\circ}$ año Medio. Señalan que en esa oportunidad el promedio nacional en matemáticas fue de 246 puntos, el promedio regional de la Araucanía, región con mayor población mapuche, fue de 235 puntos y en las escuelas con mayor matrícula mapuche los promedios alcanzaron: Saavedra 192 puntos, Lumaco 203 puntos y Ercilla 202 puntos. Al mirar los resultados el año 2012, luego de transcurridos 10 años, nos encontramos con situaciones similares a las descritas por Quilaqueo y Quintriqueo, el promedio nacional en matemática para $2^{\circ}$ año Medio (secundaria) fue de 265 puntos, en la Araucanía el promedio regional para los $2^{\circ}$ años de enseñanza media fue de 255 puntos y en las comunas señalas por Quilaqueo y Quintriqueo, por su alta densidad mapuche, fueron: Saavedra 206 puntos, Lumaco 225 puntos y Ercilla 198 puntos. Para los $4^{\circ}$ años de educación básica los resultados obtenidos de acuerdo al informe del año 2012 son: el promedio nacional 261 puntos y el de la región de la Araucanía fue de 256 puntos y para las comunas señalas: Saavedra 215 puntos, Lumaco 238 puntos, Ercilla 222 puntos. Estos datos requieren de un profundo análisis y no quedarnos con las cifras, ya que de acuerdo con la connotación de esta evaluación, estas escuelas no son buenas y deberían cerrar.

Un panorama nacional de los últimos resultados del Sistema de Medición de la Calidad de la Educación (SIMCE), lo presentamos en la Tabla 1.6, que refleja la situación interna del país y la distribución democrática del conocimiento. No haremos un análisis del SIMCE, porque es un tema profundo de analizar en cuanto a su trasfondo sociopolítico en un estado que aún mantiene un sistema de educación neoliberal mercantilista del acervo cultural y el derecho a la educación integral de calidad; sin embargo, los presentamos para que el lector pueda mirar las consistencias e inconsistencias de los datos en la tabla 1.1 y 1.3 con los datos de la Tabla 1.5, 1.6 y 1.7. Lo que les puede dar señales sobre el trasfondo sociopolítico de la educación actual con el discurso de inclusión. Cabe mencionar que esta evaluación estandarizada se orienta al logro de las competencias PISA.

Tabla 1.6. Resultados SIMCE por región en el año 2012. (Promedio Nacional 261).

\begin{tabular}{clcc}
$\mathbf{N}^{\mathbf{0}}$ & Región & $\mathrm{N}^{\circ}$ de & Promedio SIMCE \\
\hline $\mathbf{1 5}$ & Región de Arica y Parinacota & 2.843 & 264 \\
$\mathbf{1}$ & Región de Tarapacá & 4.228 & 262 \\
$\mathbf{2}$ & Región de Antofagasta & 8.120 & 260 \\
$\mathbf{3}$ & Región de Atacama & 4.084 & 255 \\
$\mathbf{4}$ & Región de Coquimbo & 9.620 & 260 \\
$\mathbf{5}$ & Región de Valparaíso & 21.721 & 257 \\
$\mathbf{1 3}$ & Región Metropolitana & 84.526 & 264 \\
$\mathbf{6}$ & Región del Libertador General Bernardo O' & 11.850 & 257 \\
$\mathbf{7}$ & Región del Maule & 12.880 & 263 \\
$\mathbf{8}$ & Región del Biobío & 25.750 & 265 \\
$\mathbf{9}$ & Región de la Araucanía & 12.225 & 256 \\
$\mathbf{1 4}$ & Región de los Ríos & 4.765 & 252 \\
\hline
\end{tabular}




\begin{tabular}{llcl}
\hline $\mathbf{1 0}$ & Región de Los Lagos & 11.326 & 260 \\
$\mathbf{1 1}$ & Región de Aisén del General Carlos Ibañez & 1.448 & 261 \\
$\mathbf{1 2}$ & Región de Magallanes y de la Antártica & 2.013 & 259 \\
\hline
\end{tabular}

Es necesario comprender la composición regional de los establecimientos escolares de acuerdo a su dependencia, por otro lado, considerar la cantidad de estudiantes que rinden la evaluación SIMCE por región. Estos y otros elementos que podemos apreciar en los datos estadísticos que nos entrega la institucionalidad, nos muestran que la medición estandarizada de los aprendizajes en el territorio nacional no da cuenta de las diferencias y características propias de cada región y establecimiento. A pesar, de que los criterios de comparación son de acuerdo a los factores comunes entre establecimientos en todos los niveles, según los informes de la institucionalidad.

Lamentablemente, estos resultados quedan en la retina de la ciudadanía y aunque internamente a los establecimientos llegan estos análisis, se insiste en que los resultados obtenidos en estas mediciones describen al establecimiento y el profesor que rindió la prueba. Es decir, malos resultados, establecimientos malos y profesores malos... ¡su hijo no debe asistir a esa escuela!... Esta es la connotación que tiene esta evaluación en la ciudadanía, por cuanto se dice que mide la "calidad de la educación" y sobre esta base se toman medidas año a año, en todos los niveles institucionales. A esta situación le agregamos el sistema de evaluación al docente de la educación pública, cada cuatro años, se aumenta la connotación negativa sobre la educación pública. Para tener un panorama de esta distribución de establecimientos por región, incluimos la tabla 1.7 que muestra dicha conformación y zona geográfica.

Tabla 1.7. Establecimientos según dependencia y zona geográfica.

\begin{tabular}{|c|c|c|c|c|c|c|}
\hline \multirow[b]{2}{*}{ Región } & \multirow[b]{2}{*}{$\begin{array}{c}\text { Área } \\
\text { geográfica }\end{array}$} & \multicolumn{5}{|c|}{ Dependencia administrativa } \\
\hline & & Municipal & $\begin{array}{c}\text { Particular } \\
\text { subvencionado }\end{array}$ & $\begin{array}{l}\text { Particular } \\
\text { pagado }\end{array}$ & $\begin{array}{l}\text { Corporación de } \\
\text { administración } \\
\text { delegada }\end{array}$ & Total \\
\hline \multirow{3}{*}{$\mathbf{I}$} & Urbana & 30 & 136 & 12 & 0 & 178 \\
\hline & Rural & 42 & 6 & 0 & 1 & 49 \\
\hline & Total & 72 & 142 & 12 & 1 & 227 \\
\hline \multirow{3}{*}{ II } & Urbana & 105 & 85 & 28 & 0 & 218 \\
\hline & Rural & 19 & 0 & 0 & 0 & 19 \\
\hline & Total & 124 & 85 & 28 & $\mathbf{0}$ & 237 \\
\hline \multirow{3}{*}{ III } & Urbana & 78 & 53 & 12 & 0 & 143 \\
\hline & Rural & 37 & 2 & 0 & 0 & 39 \\
\hline & Total & 115 & 55 & 12 & $\mathbf{0}$ & 182 \\
\hline \multirow{3}{*}{ IV } & Urbana & 132 & 290 & 25 & 0 & 447 \\
\hline & Rural & 289 & 56 & 1 & 1 & 347 \\
\hline & Total & 421 & 346 & 26 & 1 & 794 \\
\hline \multirow{3}{*}{ V } & Urbana & 292 & 675 & 107 & 6 & 1.080 \\
\hline & Rural & 174 & 16 & 0 & 0 & 190 \\
\hline & Total & 466 & 691 & 107 & 6 & 1.270 \\
\hline \multirow{3}{*}{ VI } & Urbana & 150 & 244 & 23 & 5 & 422 \\
\hline & Rural & 264 & 12 & 2 & 1 & 279 \\
\hline & Total & 414 & 256 & 25 & 6 & 701 \\
\hline \multirow{3}{*}{ VII } & Urbana & 171 & 256 & 13 & 2 & 442 \\
\hline & Rural & 413 & 27 & 0 & 3 & 443 \\
\hline & Total & 584 & 283 & 13 & 5 & 885 \\
\hline
\end{tabular}




\begin{tabular}{|c|c|c|c|c|c|c|}
\hline \multirow{3}{*}{ VIII } & Urbana & 383 & 533 & 36 & 10 & 962 \\
\hline & Rural & 560 & 71 & 0 & 2 & 633 \\
\hline & Total & 943 & 604 & 36 & 12 & 1.595 \\
\hline \multirow{3}{*}{ IX } & Urbana & 185 & 289 & 13 & 4 & 491 \\
\hline & Rural & 353 & 398 & 0 & 0 & 751 \\
\hline & Total & 538 & 687 & 13 & 4 & 1.242 \\
\hline \multirow{3}{*}{$\mathbf{X}$} & Urbana & 152 & 269 & 31 & 1 & 453 \\
\hline & Rural & 520 & 134 & 0 & 0 & 654 \\
\hline & Total & 672 & 403 & 31 & 1 & 1.107 \\
\hline \multirow{3}{*}{ XI } & Urbana & 24 & 27 & 0 & 1 & 52 \\
\hline & Rural & 30 & 2 & 0 & 0 & 32 \\
\hline & Total & 54 & 29 & 0 & 1 & 84 \\
\hline \multirow{3}{*}{ XII } & Urbana & 38 & 32 & 5 & 0 & 75 \\
\hline & Rural & 16 & 0 & 0 & 0 & 16 \\
\hline & Total & 54 & 32 & 5 & $\mathbf{0}$ & 91 \\
\hline \multirow{3}{*}{$\begin{array}{l}\text { R.M. } \\
\text { XIII }\end{array}$} & Urbana & 619 & 1.964 & 296 & 33 & 2.912 \\
\hline & Rural & 116 & 27 & 8 & 0 & 151 \\
\hline & Total & 735 & 1.991 & 304 & 33 & 3.063 \\
\hline \multirow{3}{*}{ XIV } & Urbana & 72 & 118 & 8 & 0 & 198 \\
\hline & Rural & 185 & 160 & 1 & 0 & 346 \\
\hline & Total & 257 & 278 & 9 & 0 & 544 \\
\hline \multirow{3}{*}{$\mathbf{X V}$} & Urbana & 30 & 80 & 4 & 0 & 114 \\
\hline & Rural & 35 & 3 & 0 & 0 & 38 \\
\hline & Total & 65 & 83 & 4 & 0 & 152 \\
\hline \multirow{3}{*}{ Total } & Urbana & 2.461 & 5.051 & 613 & 62 & 8.187 \\
\hline & Rural & 3.053 & 914 & 12 & 8 & 3.987 \\
\hline & Total & 5.514 & 5.965 & 625 & 70 & $\begin{array}{r}12.17 \\
4\end{array}$ \\
\hline
\end{tabular}

Fuente: Centro de Estudios, División de Planificación y Presupuesto, Ministerio de Educación (2012).

Dejamos al lector las distintas interpretaciones que se pueden obtener de los datos entregados por la institucionalidad, nosotros por lo pronto y considerando que este estudio no pretende analizar los resultados SIMCE y cómo este incide en la inclusión social en la escuela y cómo afecta a la democratización del conocimiento, consideramos pertinente mostrar estos resultados en la evolución histórica de la educación en nuestro país, ya que en los inicios de la vuelta de la democracia, se perpetuó la proyección del modelo educacional neoliberal, basado en la comercialización de la educación por sobre el "Derecho a la Educación". Respecto de estos antecedentes y con la experiencia de la tesista como docente de aula en escuelas públicas, queremos señalar que las características de cada establecimiento son muy distintas, aún cuando la institucionalidad diga que son similares de acuerdo a indicadores definidos (Nivel socioeconómico, ubicación geográfica, etc) y encuestas que se aplican. Nos referimos con esto a que una familia de nivel socioeconómico bajo de la primera región es distintas a una familia de nivel socioeconómico bajo de la región metropolitana y diferente a otra de nivel socioeconómico bajo de la décima región; sin embargo, para la institucionalidad las tres pertenecen al mismo nivel socioeconómico por cuanto son comparables. Creemos, que junto con los avances en otras materias en el país, también hay que avanzar en el tema de la evaluación de la educación, ya que este modelo no 
representa los actuales desafíos de la educación en nuestro país, frente a las demandas de la sociedad civil en esta materia.

\section{ANEXO 2}

\section{Programa de estudios de Lengua Mapuzugun. $1^{\circ}$ a $4^{\circ}$ año Básico"}

Las siguientes figuras muestran algunas actividades didácticas propuestas por los Programas de Lengua Mapunzuzgun para los niveles de $1^{\circ}$ a $4^{\circ}$ año de Educación Básica del Ministerio de Educación Chile, en las que podemos apreciar el uso del conocimiento matemático..

\section{Actividades propuesta para $3^{\circ}$ año Básico}

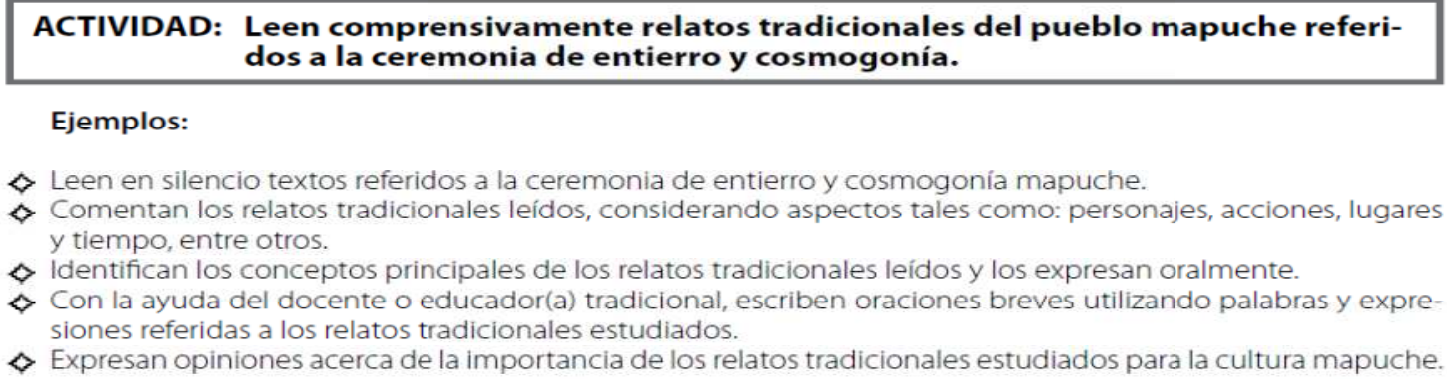

$\diamond$ Leen en silencio textos referidos a la ceremonia de entierro y cosmogonía mapuche.

$\diamond$ Comentan los relatos tradicionales leídos, considerando aspectos tales como: personajes, acciones, lugares y tiempo, entre otros.

$\Leftrightarrow$ Identifican los conceptos principales de los relatos tradicionales leídos y los expresan oralmente.

$\Leftrightarrow$ Con la ayuda del docente o educador(a) tradicional, escriben oraciones breves utilizando palabras y expre. siones referidas a los relatos tradicionales estudiados.

$\diamond$ Expresan opiniones acerca de la importancia de los relatos tradicionales estudiados para la cultura mapuche.

\section{Txem mawiza}

Fütxa kuyfi afi mapu, tamu epu waragka txipantu femi zewma. Feychi kuyfimu kine machi pewtuwi pewma mew, günemapun feypifi, kiñe weya zugu mülealu, afalu mapu ko mu fütxa lhafkengetuay mapu, pigerki. Feypiaymi tami pu che pürayaimün tiechi mawiza mu txem mawiza pigelu Porvenir pituy wigka fewla. Feychi mawiza mu puwülaymün tamün pu kullin, awka kullin kom.

Ti machi txawuli ñi pu che ka feypifi afalu mapu ko mu, pürayaymün mawiza mu, puwülaymün tamün awka kullin egu.

Akuyti anthü meli mari anthü mawi

Puwi anthü kümegetual fey ka zuguli taiñ pu che ti machi, amutuaiñ chew mülekefuiñ, fill anthü gillatulekeain kom che, montulu iñchiñ, rupalu weyake zugu kiñe anthü montuigeymün.

Akutulu egün chew mülekefuygün, gewetulay chem no rume kom apümi ko.

\section{La montaña que crece}

Hace mucho tiempo, hará como dos mil años, se acabó la tierra. Esa vez una machi a través de un sueño supo, que la tierra sería terminada por el agua. Los poderes de la tierra le dijeron que todo se convertiría en un gran mar. También le dijeron que avisara a toda su gente, que subiera a la montaña que crece, hoy llamada por los no mapuche: "Porvenir". Además, le dijeron que tenían que traer a esta montaña sus animales, incluyendo animales salvajes.

Se supo la noticia por esta machi quien juntó a su gente y avisó la mala noticia.

Llegó el día anunciado, llegó la lluvia, llovió durante cuarenta días y cuarenta noches. Se oscureció, el día se volvió noche, la lluvia no paró en ningún momento. La gente llegó con dificultad al cerro.

Llegado el día indicado para terminar la lluvia, la machi nuevamente habló a su gente y dijo:

Regresaremos donde siempre hemos estado, todos los días deberemos rogar y dar las gracias, porque nos salvamos.

Cuando regresaron, llegaron donde siempre estuvieron. No quedaba nada, todo se lo había llevado la lluvia.

Figura 2.1. Relato contado a los estudiantes. Programa de Lengua Mapuzugun $3^{\circ}$ Básico, p.57-58 


\section{Actividades propuesta para $4^{0}$ año Básico}

\section{Mageluwün}

23 konchi anthü, marzu küyenh mew, 2008

Poyefal lamgen Maria:

Epuwechi anthï niean kiñe once ñi ruka mew, puwïltxipantulean Rume ayiafun eymi mi witxantumeal tiufa mew.

Recreo mew feypiaen tami amual.

Pewkallal, pewmagele küme feleaymi.

Tami lamgen,

Gilberto

\section{Invitación}

23 de marzo, 2009

Pasado mañana tendré una once en mi casa. Será mi cumpleaños. Estaré muy contenta con tu visita.

Avísame en el recreo si puedes ir.

Hasta pronto hermana, que estés bien.

Tu hermano,

Giberto'.

Figura 2.2. Modelo de invitación presentado a los estudiantes. Programa Lengua

Mapuzugun $4^{\circ}$ Básico, p. 122-123

\section{Actividad para $2^{\circ}$ año Básico}

ACTIVIDAD: Comparan la forma de ubicarse en el tiempo en la cultura mapuche tradicional y no tradicional.

Ejemplos:

Establecen semejanzas y diferencias entre la concepción de tiempo entre la cultura mapuche y no mapuchè. (Ver orientácionés à docèntè).

* Observan un reloj y una figura que muestra tiempo en mapuzugun (identifican las partes del día).

* Leen y comentan la pregunta: ¿Tunten pürapay anthü? ("¿Cuánto ha subido el sol?)

* Responden a la pregunta según la hora que deseen decir.

* Las respuestas pueden ser:

Puliwenhi, Pürapay anthü, ragianthüy, naqanthüy, konanthüy, punhi.

* Aprenden a preguntar la hora: ¿Chunten pürapay antü?'¿Qué hora es?'

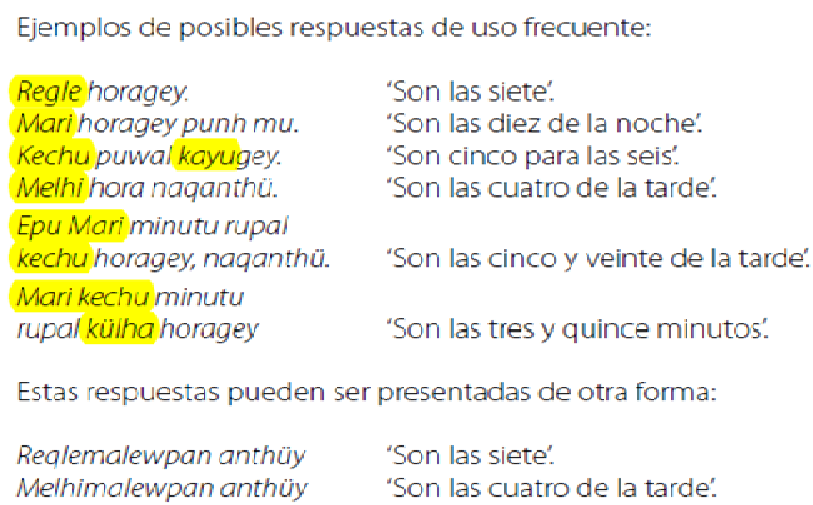

Figura 2.3. Actividad propuesta por el Programa Lengua Mapuzugun para $2^{\circ}$ Básico, $p$. 72. 


\section{Actividad para $2^{\circ}$ año Básico}

ACTIVIDAD: Ejercitan un diálogo en mapuzugun.

Ejemplos:

* Reportan una información empleando interacciones breves en el que una persona da un mensaje y la otra recibe la información, por ejemplo:

De madre a hijo:

Nuke: yemege kayu kuram.

'Madre: anda a buscar seis huevos'

Pichiwentxu: ñi ñuke yemege kayu kuram pienew.

'Niño: mi madre me dijo anda a buscar seis huevos'.

De padre a hija

Chaw: gillamege kin̄e kilu kofke.

'Padre: anda a comprar un kilo de pan'

Pichi malhen: ñi chaw gillamege kiñe kilu kofke pienew.

'Niña, mi padre me dijo que compre un kilo de pan'.

\section{De profesor a estudiante:}

Kimeltuchefe: kintuge mari nemel mapuzugun mew.

'Profesora: busca diez palabras en mapuzugun'.

Chillkatufe: ñi kimeltuchefe mari nemel mapuzugun kintuge pienew.

'Estudiantes: mi profesora me dijo que buscara diez palabras en mapuzugun.

* Aprenden y reproducen las oraciones ejercitando la pronunciación de las palabras.

- En parejas toman el rol de los personajes, uno da el mensaje y el otro lo recibe.

* Con ayuda del educador(a) tradicional, crean nuevos mensajes y los comparten con el resto del curso.

Figura 2.4. Actividad propuesta por el Programa de Lengua Mapuzugun para $2^{\circ}$ Básico, p. 83 .

\section{Actividad para $1^{0}$ año Básico}

EJEMPLOS DE ACTIVIDADES:

ACTIVIDAD: Preguntan en sus hogares o comunidades pichike txoy zugu versos tradicionales, o ketxokantun zugu.

Ejemplos:

+. Preguntan en sus hogares o comunidad algunos pichike txoy zugu'versos cortos'y ketxokantun zugu'trabalenguas', como por ejemplo:

Melhiantü thalu mogeltukefin, kaz kaz, kaz kaz, kaz kaz.

"Revivo a los que mueren después de cuatro dias, kaz kaz kaz'.

Kine pichi achawall epe kurami kosh kich kach piyawi.

Una pollita está casi por poner, anda diciendo kosh kich kach:

Figura 2.5. Actividad propuesta por el Programa de Lengua Mapuzugun para $1^{\circ}$ Básico, p. 50. 


\section{Actividades propuesta para $3^{\circ}$ año Básico}

\section{ACTIVIDAD: Describen el entorno empleando cantidades numéricas y adverbios de}

cantidad.

Ejemplos:

\& Responden a la pregunta ¿Chem müley chlllkatupeyüm katxüntuku mew?

$\Leftrightarrow$ Escriben las descripciones en sus cuadernos empleando cantidades numericas y adverbios de cantidad y las corrigen en el pizarrón.

En grupo describen un paisaje de su entorno natural. Incorporan un listado de verbos y sustantivos relacionados con el entorno natural, dados por el docente o educador(a) tradicional para construir sus textos.

$\&$ Presentan sus descripciones a sus compañeros. Corrigen escritura en el pizarrón.

\section{ORIENTACIONES AL DOCENTE / EDUCADOR(A) TRADICIONAL}

Al tratarse de entornos urbanos, se sugiere al docente o educador(a) tradicional ensenar vocablos para describr laciudad.

Por otro lado también debe enseñar los números. Para ella será necesario enseñarios del uno al diezy luego de diez en diez hasta el cien.

Figura 2.6. Actividad propuesta por el Programa de Lengua Mapuzugun para $3^{\circ}$ Básico, p. 131.

Conceptos trabajados en actividades propuesta para $3^{\circ}$ año Básico en p. 131

Descripción de la sala de clases:

Ni chılkatupeyüm welliñwe mew müley epu Marı kechu pichikeche, ka nlen kiñe kimeltuchefe ka kiñe kimche mapuzugukelu.

En mi sala de clases hay 25 niñas y niños, un profesor(a), y un educador o educadora tradicional que habla mapuzugun.

Ni chillkatupeyüm wellıñwe mew müley fentxen lıfüru ka fentxen wirıkantuwe, cuaderno pigelu.

En mi sala de clases hay muchos libros y muchos cuadernos.

Figuras geométricas*:

$\begin{array}{ll}\text { Mell nor az: } & \text { Cuadrado } \\ \text { Küla nor az: } & \text { Triángulo } \\ \text { Fenxen nor az: } & \text { Polígonos } \\ \text { Monkol: } & \text { Esferas } \\ \text { Chünkü: } & \text { Clrculos } \\ \text { Epu küf az: } & \text { Angulo } \\ \text { Wechun: } & \text { Esquina } \\ \text { Monkol: } & \text { Esfera redonda }\end{array}$

- Los conceptos geométricos propuestos fueron creados en un Taller de Renovaciốn Lexical del Mapuzugun, realizado con profesores mapuche de la Fundación Magisterio de la Araucania. Mayo 03, 1995.

MAPA SEMANTICO

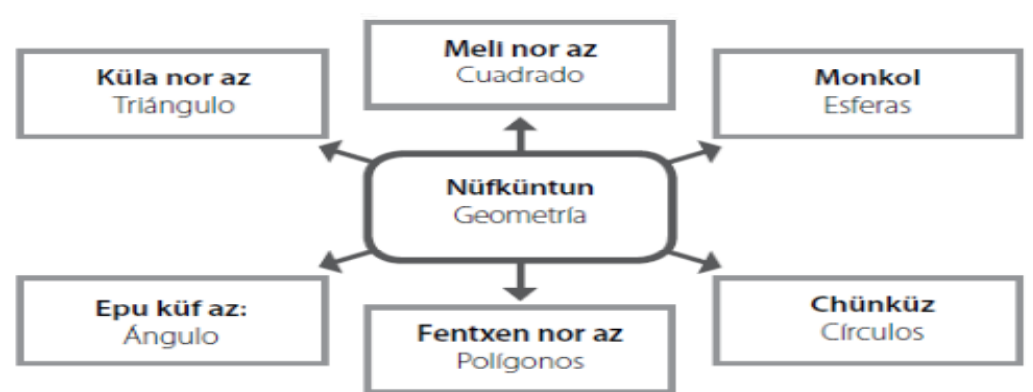

Figura 2. 7. Repertorio sintáctico y mapa semántico para conceptos geométricos 


\begin{abstract}
ANEXO 3
“Orientaciones para contextualizar la educación matemáticas en la EIB”

Orientaciones para la Contextualización de Planes y Programas para la Educación Intercultural Bilingüe NB1.

Ministerio de Educación, República de Chile/ Unidad EIB de la CONADI. Edición 2005
\end{abstract}

En la tabla 3.1., hemos transcrito, textualmente, las actividades que proponen las orientaciones curriculares para la enseñanza y aprendizaje de la matemática en el primer semestre de $1^{\circ}$ básico y el primer semestre de $2^{\circ}$ básico para la Educación Intercultural Bilingüe, a fin de identificar la etnomatemática presente en ellas y que son parte de nuestro estudio.

Tabla 3.1. Actividades propuestas en las Orientaciones del programa de matemáticas para los niveles de $1^{\circ}$ y $2^{\circ}$ año de Educación Básica para la EIB.

\title{
Eje temático Números para $1^{0}$ año básico
}

\section{Actividad Genérica 1 (página 139)}

Ejercitan la secuencia de uno en uno en forma oral, (en ambas lenguas) de los números en el ámbito del 0 al 30, tanto en forma ascendente como descendente y reconocen algunas de sus características

\section{Ejemplos de Actividades Interculturales Sugeridas}

Se ubican las niñas y niños en una disposición espacial circular o media luna.

Se presenta cada niño y niña en la forma tradicional, propia de su cultura, indicando quiénes son sus padres y abuelos.

El profesor pide a los niños que nombren a coro las partes de su cuerpo, en ambas lenguas (una cabeza, dos orejas, cinco dedos etc.)

Utilizando los pronombres personales, propios de la cultura, junto a la enumeración de las partes del cuerpo, van ampliando el ámbito numérico. (Dos cabezas, cuatro orejas 20 dedos etc,. hasta llegar a 30).

El profesor agrupa a los niños y niñas de a tres y les nombra algún número, en ambas lenguas. Lo escribe en la pizarra, pidiéndole que lo representen con los dedos de sus manos. Si pedimos un número menor que 3 , uno o dos niños no aportan dedo, con lo que expresamos la idea de que un niño no aporta nada, introduciendo el concepto de cero, sustentado sobre algo concreto.

El profesor puede anotar el resultado en la pizarra de cada grupo, con el fin de premiar al grupo con mayor cantidad de aciertos (los números señalados por el profesor deben permitir a los niños contar sus dedos hasta llegar a 30)

Cantan canciones en castellano y de la cultura indígena que incorporan conceptos numéricos. El profesor les pide a los alumnos que digan, en ambas lenguas, secuencias de números del 0 al 30 a coro, acompañándolas de ritmos como aplausos, zapateos, golpes de algún instrumento u otros, tanto en forma ascendente como descendente.

Repiten la actividad anterior, pero el profesor no nombra el número; los niños lo reconocen por el sonido hecho con palmas o algún instrumento $\mathrm{y}$, a partir de tal reconocimiento, dicen la secuencia ascendente o descendente, según señales acordadas 
previamente. Pueden variar la actividad nombrando uno, dos y hasta tres sucesores o antecesores en ambas lenguas, según señal convenida con los niños, dando énfasis a los sucesores y antecesores de 10 y 20.

\section{Observaciones al docente}

Es necesario que, antes de desarrollar la actividad, el profesor haga un proceso de exploración para determinar lo que los alumnos manejan sobre las secuencias numéricas; identificando, muy bien, a los niños y niñas hablantes de lengua indígena. Lo anterior, para poder trabajar en equipo con los niños que presentan problemas de lenguaje y con los que no manejan secuencias numéricas. De acuerdo a estos antecedentes, podrá diversificar las actividades e introducir en el proceso de aprendizaje nuevos puntos de vista.

Es importante para el profesor observar con detalle las respuestas que darán los alumnos a la pregunta ¿qué otros nombres pueden tener los números once, doce, trece, catorce y quince? Se esperaran respuestas tales como: "dieciuno", "diecidos". Lo anterior, indica que los niños están entendiendo la estructura de formación de números de dos cifras y están incorporando el nuevo conocimiento.

Nota:

Se hace necesario que el docente, si no es hablante de lengua indígena, al menos se interiorice de la cosmovisión del pueblo de origen, preocupándose de conocer la forma de nombrar, contar y comprender el mundo. Tal vez, uno de los aspectos más profundos especialmente de la cultura mapuche, aymara y lican antai, es la articulación de lo comunitario como forma de relación social. Por esta razón, el profesor debe sustituir, la tan arraigada noción de individualidad, por la de comunidad.

Las lenguas aymara y mapuche no cuentan con una voz especial para el cero; no se puede decir: "tengo cero animales", pero sí existen voces para indicar que algo no existe y para denotar el conjunto vacío: en mapuzugun son ñielay y afí respectivamente, afí: se usa cuando hubo algo y ya no existe.

Ejemplos:

* No hay animales......... ñielay kulliñ

* Se terminó la carne.......... afí ilo

En el caso aymara:

* No tengo animales......... jani uywanitwa

* Se terminó la carne.......... aycha nha tukusi tawa

Actividad Genérica 2 (página 140)

Realizan variadas actividades de conteo y sacan conclusiones respecto del significado y de la utilidad de contar

\section{Ejemplos de Actividades Interculturales Sugeridas}

Se sugiere desarrollar la actividad jugando con el püron (nudo) como inicio para el pueblo mapuche y jugando con el quipu (nudo) para el mundo andino. Así, comienzan contando con objetos concretos y, además, guiados por preguntas al docente, pueden sacar conclusiones respecto de las características del conteo.

Emplean el conteo para verificar su capacidad de anticipar o estimar cantidades. Por ejemplo, cantidad de semillas que hay en una bolsa, número de brazadas de paja para llenar un saco, etc. Verifican sus respuestas a través del conteo. A partir de un hecho ya comprobado, como la cantidad de lápices necesaria para llenar una caja, estiman 
cuántos lápices contiene la caja, si está llena aproximadamente hasta la mitad, si tiene una cantidad de lápices claramente mayor que la mitad o claramente menor que la mitad, etc.

\section{Observaciones al docente}

Que el niño incorpore la idea de que el último número de una secuencia indica la cardinalidad del conjunto que sé esta numerando. Definimos cardinalidad como: número que abarca la totalidad de elementos del conjunto.

El orden al contar no altera la cardinalidad, sólo el agregar o quitar elementos altera la cardinalidad.

El profesor debe recordar siempre que contar es establecer una relación entre la cantidad de objetos y el número abstracto que los conjuga.

Cabe hacer notar que el proceso de escritura de los números es de lenta incorporación y que el profesor debe marcar los números que los niños van a escribir con línea segmentada. Así, ellos sólo delinearán encima, ejercitando la caligrafía numérica. El profesor debe construir un muestrario de nudos con la finalidad de crear un set de elementos que puedan ser asociados a los números.

El püron (cultura mapuche) y el quipu (cultura andina) son elementos de gran fertilidad en el proceso de aprendizaje del acto de contar.

\section{Actividad Genérica 3 (página 141)}

Leen números, al menos hasta 30 , en objetos portadores de información numérica presentes en su entorno y comentan acerca del uso y utilidad de los números.

\section{Ejemplos de Actividades Interculturales Sugeridas}

El profesor, con la ayuda de los apoderados, puede organizar una visita a la escuela de alguna ilustre personalidad de la comunidad, anciano u otro. Uno de los objetivos de este evento es la interacción de profesores y alumnos con un personaje que cuente la experiencia ancestral respecto de la cosmovisión numérica indígena.

Preparar una salida a terreno a un lugar que posibilite el ejercicio de la cuantificación. Es importante que la visita se haga en el marco de las costumbres de la cultura en la cual se trabaja.

En el subsector de educación matemática debe preparar la pauta de visita como:

- Contar las estacas de los cercos las marcas del camino u otros.

- Estimar el número de estacas del cerco de una hectárea, el número de aves en el gallinero, animales en el potrero, etc. Y comprobarlo contando.

- Cantan canciones y aplausos matemáticos durante el trayecto.

- Cuentan y estiman diversos elementos ubicados en el camino.

- Emplean el conteo para verificar su capacidad de estimar y anticipar cantidades.

- Cantan canciones ül, mapuzugun; jayma, aymara. Juegan durante el trayecto con aplausos, saltos u otras situaciones en las que tengan que contar y estimar.

- Valorizan a los números como elementos importantes de la vida cotidiana de cada alumno.

De vuelta en el colegio, se "textualiza" la visita pegando en el diario mural una lámina con los números. Por ejemplo, durante y después de la visita el profesor debe insistir en los diferentes usos de los números tales como:

- Cuantificadores (cantidad de): 10 árboles, 10 estacas u otros.

- Ordenadores (ubicación en secuencia o esquema): la posición que tiene cada alumno en la lista o en algún grupo, la posición de alguna estaca según el orden que le demos, 
etc.

- Identificadores: el número de una parcela, hijuela, potrero u otro, número de microbús, de camiseta de algún futbolista, etc.

De la actividad anterior el profesor comenta situaciones significativas que entreguen información, de tipo numérico, escribiendo esos números.

Después de estas actividades, debemos reforzar con los otros subsectores el uso de los números y su escritura.

\section{Observaciones al docente}

El profesor debe prepararse y recorrer el camino hasta el lugar donde se desarrollará la visita, planificando cuidadosamente qué van a observar los niños. De esta forma incentiva tanto la observación atenta, como la actitud analítica y contemplativa. La idea es que cada niño pueda reconocer para qué sirven los números, sin siempre tener que categorizarlos. La idea es diversificar la experiencia que tengan los niños con los números, asumiendo que cumplen diferentes funciones, sin importar de qué pueblo y qué lengua hablen.

El profesor debe construir una pauta de trabajo para el desarrollo de la visita. No solamente en el subsector de educación matemática, sino también para los otros subsectores.

Sin lugar a dudas, el manejo fluido de la secuencia numérica es un conocimiento necesario e imprescindible para contar, pero ello no agota el contar. Contar implica establecer una relación entre una cantidad y un número que la representa.

Si hay alumnos que no saben contar, se sugiere comenzar con una cantidad pequeña de objetos pero no menos de 6 ya que un número menor a éste, provoca un reconocimiento visual inmediato de la cantidad, lo que no implica que sepan contar; luego se puede ir aumentando.

Las actividades relacionadas con estimaciones y su verificación a través del conteo, tienen como propósito que los niños y niñas vayan desarrollando paulatinamente su sentido de cantidad, es decir, tengan una idea aproximada de qué número podría representar una cierta cantidad. Ello exige que la práctica de la estimación evolucione hacia un mayor grado de aproximación a la cantidad estimada.

\section{Consideraciones culturales:}

Una de las cosas que marca la diferencia entre las culturas, con respecto a las matemáticas, es la cosmovisión particular de cada pueblo con respecto al sentido de los números. En el caso de los mapuches, se da la importancia a la dualidad y paridad como perfección y de la imparidad como imperfección.

Cuando el profesor haga la pauta debe considerar:

Que los alumnos valoren mucho más la cultura propia y su identidad, que comprendan la idea de "par" e "impar" según la cosmovisión de su cultura.

Que en los procesos de observación se incentive una actitud "reflexiva", al igual que la tuvieron los ancestros de los niños frente a la naturaleza, azkintün, mapuzugun, uñaqaña, aymara.

\section{Actividad Genérica 4 (página 142)}

Escriben números, al menos hasta 30 y los utilizan para registrar información numérica que obtienen por conteo

o mediante exploración de su entorno. 


\section{Ejemplos de Actividades Interculturales Sugeridas}

Realizan actividades para reconocer y trazar los números. Para facilitar este proceso, el docente puede presentar los números agrupados de acuerdo a su forma. Por ejemplo, en cuatro categorías: 1 - 7 - 4, 0 - 8 - 3, 5 - 2, 6 - 9 .

Recorren, con el dedo índice, números escritos en tamaño grande y de preferencia sobre relieve.

Trazan grandes números "en el aire", siguiendo el modelo del movimiento hecho por el profesor.

Juegan en parejas a adivinar el número que cada uno de ellos traza en la espalda del otro.

Escriben los números dígitos, guiados por una secuencia de puntos, siguiéndola en un orden determinado.

En su hogar, buscan objetos con números y registran algunos de ellos. Por ejemplo, los números presentes en los envases de alimentos, en algún aparato electrónico, etc. Realizan inventarios, tales como: número de ampolletas, de puertas, de ventanas, etc. Escriben los números que recogen en sus indagaciones y los comunican en la clase.

En relación al proceso de ubicación espacio-temporal, cuentan los meses del año, las horas del día, la cantidad de pasos de un lugar a otro, etc.

En el aula, hacen inventarios de materiales empleados habitualmente, efectuando los conteos correspondientes (lápices, libros, hojas de trabajo, etc.).

Colocan etiquetas para recordar la cantidad de objetos de cierta clase guardados en un lugar determinado; también puede inventariar el número de libros de la biblioteca de aula, el número de libros leídos por cada alumno, etc.

\section{Observaciones al docente}

Una vez que los alumnos aprenden a escribir los dígitos, es conveniente pedirles que anticipen cómo creen que se escribirá. Por ejemplo, "veintiséis" para darles oportunidad de poner en juego sus hipótesis. Estas pueden ser correctas o erróneas; un alumno podría escribir "veintiséis" como 206. A través del cuestionamiento y reformulación de sus ideas, se aproximarán progresivamente a la comprensión de las reglas de la escritura convencional. Por ejemplo, si dices que veintiséis es menor que treinta. ¿Por qué escribiste el primero con tres cifras (206) y el segundo sólo con dos (30)?

El profesor debe tener presente que está nombrando números en dos lenguas pero que la escritura es una sola y que debe hacer el proceso de enseñanza aprendizaje gradualmente, tomando en cuenta los ritmos de avance distintos en cada niña y niño.

\section{Actividad Genérica 5 (página 143)}

Realizan actividades para ordenar números y comparar cantidades y establecen relaciones de mayor, menor o igual entre ellas.

\section{Ejemplos de Actividades Interculturales Sugeridas}

Usando el proceso de observar, propio de la cultura, determinan qué grupos de elementos tienen mayor, menor o igual cantidad de unidades de la siguiente manera:

- El profesor forma grupos de 2 ó 3 niños y les entrega dos conjuntos de elementos. Estos conjuntos de elementos (semillas), separados en tres bolsas trasparentes etiquetadas, A, B y C, con distinta cantidad de elementos (porotos), 8, 12 y 7 y (habas), 9,12 у 6 . 
Se les pide que estimen y comprueben contando.

Se hace hincapié en las ideas de mayor, menor o igual en ambas lenguas.

Separados en grupos de trabajo, observan diversos conjuntos de elementos (paquetes de hojas de árbol, grupos de piedras, puntos o hilos de un tejido, elementos de una joya, instrumentos, o animales del exterior).

Escriben el número tentativo.

Contando, comprueban y determinan si la cantidad estimada fue mayor, menor o igual a la cantidad exacta. Dentro de los elementos a estimar, el profesor puede dibujar conjuntos de puntos desordenados y después establecer estrategias para contar.

Desarrollan juegos propios de su cultura, awar kuzen, mapuche; palama, aymara. El profesor debe establecer un sistema para llevar una estadística de las puntuaciones, estableciendo los grupos que sacaron un puntaje mayor, menor o igual.

Es importante destacar que, por ahora, no es necesario que los alumnos manejen los signos < (menor que) o > (mayor que), cuya diferenciación agrega una dificultad adicional al reconocimiento del orden de los números. La actividad de efectuar estimaciones, tiene como finalidad ir desarrollando o fortaleciendo el sentido de la cantidad.

\section{Observaciones al docente}

Notas:

El profesor debe familiarizarse con la concepción de "semejante" de las culturas indígenas, muy distinta a la idea occidental. En mapuzugun, el concepto de "semejante" es un sinónimo de igualdad total, lo que difiere de la concepción occidental que considera dicho término como un "compartir características", sin llegar a la igualdad o identidad.

\section{Actividad Genérica 6 (página 144)}

Componen y descomponen números en forma aditiva, apoyándose en asociaciones con conjuntos de objetos o cantidades de dinero

\section{Ejemplos de Actividades Interculturales Sugeridas}

Parten haciendo agrupaciones de elementos cercanos, como semillas. Por ejemplo, Juanito tiene 10 semillas de porotos y María 8, entre ambos tienen 18, usan elementos de la lengua para estas asociaciones.

Reparten una cantidad determinada de pequeños objetos (fichas, palitos, etc.) en dos cajas.

Pueden repartir, por ejemplo, 9 fichas, poniendo 4 en una caja y 5 en la otra o bien 8 en una caja y 1 en la otra. Responden preguntas como las siguientes:

¿Pueden repartir las fichas de manera que quede la misma cantidad en cada caja?

Pongan 3 fichas en una caja y las restantes en la otra:

¿Pueden saber cuántas fichas hacen la segunda caja, sin contarlas?

Cuenten cuántas fichas tienen en cada caja. Saquen una ficha de la primera caja y pónganla en la segunda:

¿Pueden saber cuántas fichas hay ahora en cada caja, sin contarlas?

Pongan las 9 fichas en una caja:

¿Qué número sirve para decir cuántas fichas hay en la otra caja?

Guiados por el docente, concluyen que un número puede expresarse como la suma de otros dos.

\section{Observaciones al docente}


Es importante que los alumnos y alumnas aprecien los dos sentidos del camino que recorren: de las partes al total, en la composición o "formación" y del total a las partes, en la descomposición. En consonancia con el trabajo en el eje de "operaciones aritméticas", aquí se recomienda enfatizar la actividad manual, el razonamiento y la expresión oral de las conclusiones, sin apurar su formalización a nivel escrito. El profesor debe tener en claro que, si bien el dominio de la composición y descomposición canónica es un objetivo, el cómo se alcance debe ser de manera flexible y creativa, exponiendo a los alumnos a variadas formas de descomposición y composición.

\section{Nota:}

El profesor debe investigar, según la cosmovisión indígena pertinente, si existen conceptos duales, básicos para el entendimiento matemático, tales como: agregar/ quitar, juntar/separar. Por ejemplo, en los pueblos mapuche, aymara y lican antai, no se concibe el concepto de sustracción como operación binaria, aunque, en forma concreta, utilizan los conceptos: de sacar "algo" de un total, separar por tamaño, cortar, etc.

\section{Actividad Genérica 7 (página 145)}

Abordan problemas que pueden resolver poniendo en juego lo que saben sobre números. En cada caso, dramatizan o relatan los problemas que han resuelto, destacando cuál fue el camino qué siguieron para resolverlo y a qué solución llegaron.

\section{Ejemplos de Actividades Interculturales Sugeridas}

Resuelven problemas tales como:

Si un alumno sabe el nombre de los números hasta 30 y puede seguir avanzando, se recomienda el aumento gradual de la formación de los números en la lengua de la cultura pertinente, formados por combinación de dos dígitos.

Abordan problemas de comparación de cantidades como el siguiente:

Sonia ha averiguado sobre la cantidad de horas que duermen al día algunos animales, encontrando lo siguiente: el león (16 horas), el murciélago (20 horas), la ardilla (14 horas), la jirafa (4 horas), la tortuga (16 horas). ¿Qué animales duermen menos que la tortuga?

\section{Observaciones al docente}

La resolución de problemas puede llegar a constituir una herramienta muy útil para profundizar y resignificar conocimientos ya adquiridos. Al mismo tiempo, el contexto en el que tales problemas se presentan, posibilita rescatar y revalorizar las culturas indígenas de las que son parte los niños.

Una vez resueltos los problemas, se sugiere conversar acerca de qué hicieron para resolverlos y comentar sobre las respuestas obtenidas. Muchas veces los alumnos resuelven un problema, pero, como no tienen claro qué es lo que buscan, no se dan cuenta que llegaron a la respuesta. Es necesario que el problema propuesto esté bien entendido y que los alumnos puedan reflexionar respecto de la coherencia entre la respuesta encontrada y la pregunta planteada. De esta manera, se impulsa el desarrollo del pensamiento reflexivo y metódico. 


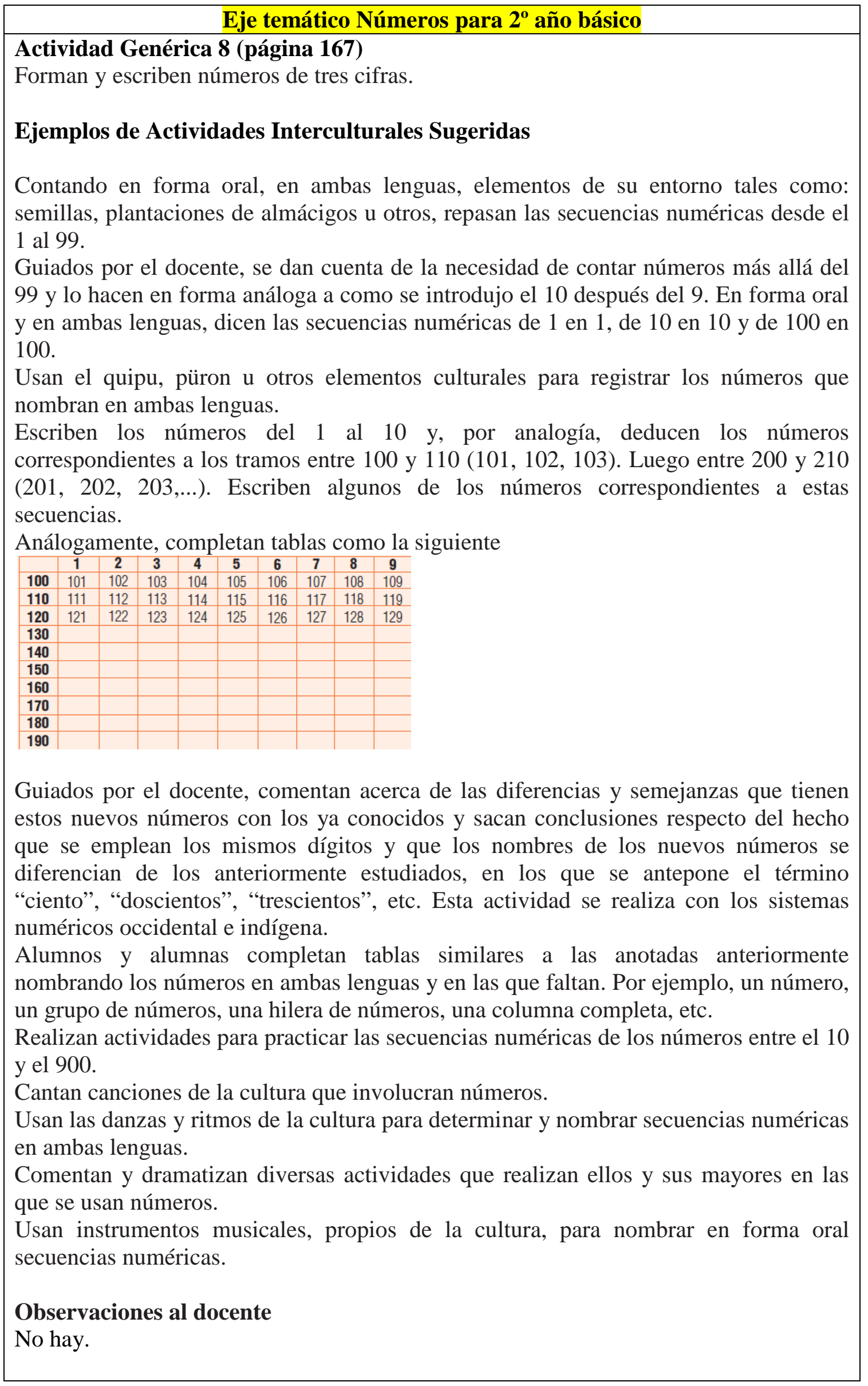


Actividad Genérica 9 (página 168)

Interpretan, registran y comunican información numérica presente en el entorno.

\section{Ejemplos de Actividades Interculturales Sugeridas}

En parejas o grupos, cuentan, en ambas lenguas, elementos que conforman tejidos, pulseras, collares, artesanías, joyas y otros. Dicen hasta dónde o qué elementos son mayores que 100, cuáles menores y escriben los números.

Buscan números de tres cifras en libros, envases, avisos, catálogos de precios u otros. Leen los números encontrados, en ambas lenguas y comentan con sus compañeros la información que ellos entregan. Reconocen números de tres cifras del ámbito estudiado, que han podido observar al recorrer su entorno, ya sea en excursiones o en el camino a su hogar. Por ejemplo, en envases de alimentos, en micros, en letreros camineros, etc. Los anotan en su cuaderno, los leen y comentan con sus compañeros la información que entregan.

Trabajando en grupos, realizan mediciones usando las formas de medir de las culturas indígenas pertinentes, como las partes del cuerpo u otras. Por ejemplo, estatura, distancias, cantidad de objetos, número de pulsaciones luego de realizar una actividad física; posteriormente, registran los resultados obtenidos y los comunican a sus compañeros. Usan el quipu, püron u otros para registrar la información de las medidas. Utilizan los números conocidos cada vez que necesiten escribir fechas, elaborar invitaciones, hacer afiches, etc.

\section{Observaciones al docente}

No hay

\section{Actividad Genérica 10 (página 168)}

Realizan actividades de conteo en las que es necesario recurrir a agrupaciones en decenas y centenas y efectúan estimaciones de cantidades antes de contar.

\section{Ejemplos de Actividades Interculturales Sugeridas}

Trabajando en grupos, el docente entrega bolsas de semillas u otras cosas propias del entorno de los niños y niñas con más de 100 elementos y, sin contar, estiman la cantidad de objetos que hay en la bolsa. Hacen una tabla en la que anotan cada una de las estimaciones de cada integrante del grupo:

El docente hace preguntas en torno al por qué estimaron ese número y comentan entre los grupos las estimaciones hechas.

Comprueban su estimación contando en ambas lenguas.

Comentan en qué forma podrían contar más rápido; el docente guía la discusión para determinar agrupaciones de 10 en 10 (decenas), 100 en 100 (centenas) para contar más rápidamente.

Forman grupos con los mismos objetos anteriores y determinan cuál es el que tiene más objetos, cuál tiene menos o cuáles pueden ser iguales. Determinan qué grupo estuvo más cerca en su estimación.

Sacan una cantidad determinada de objetos, haciendo una estimación "a ojo". Por ejemplo, sacar de la bolsa de semillas (500 semillas en total) alrededor de 200 . Se reparten la tarea de contar en ambas lenguas y comprobar sus estimaciones usando los términos adecuados.

Organizados en grupos, reciben del docente una cierta cantidad de fichas que 
representan monedas de $\$ 1, \$ 10$ y $\$ 100$. Clasifican las monedas recibidas de acuerdo al valor que representan y cuentan la cantidad de dinero que corresponde a cada tipo de monedas.

Determinan cuánto dinero recibieron en total y comparan los resultados obtenidos. Verifican sus conteos, si es que hay diferencias, comentan cómo llamaban al dinero los mayores y lo que este representaba.

\section{Observaciones al docente}

En esta actividad se espera que los alumnos comprendan el concepto de centena y puedan transferir sus aprendizajes respecto del conteo con decenas al conteo con centenas.

Es importante destacar que, al trabajar con monedas de 1, 10 y 100 pesos, los niños y niñas se van familiarizando con el manejo del dinero y simultáneamente están realizando actividades de composición de números. Por ejemplo, 5 monedas de $\$ 100$ y 7 , monedas de $\$ 1$ forman $\$ 507$; contenido que se reforzará más adelante

\section{Actividad Genérica 11 (página 169)}

Ordenan números de hasta tres dígitos y comparan cantidades de objetos y medidas para ampliar sus conocimientos del entorno.

\section{Ejemplos de Actividades Interculturales Sugeridas}

Efectúan comparaciones de números de tres dígitos, a través de actividades como las siguientes:

Guiados por el docente y por analogía con lo que saben respecto del orden en números de dos cifras, deducen relaciones de orden en números de tres cifras que tienen el mismo número en el lugar de las centenas. Por ejemplo, responden preguntas formuladas por el docente, tales como: si 20 es mayor que 10. ¿Cuál será mayor, 110 ó 120?, ¿cuál es mayor 369 ó 371?, ¿por qué?, etc. Comentan acerca del procedimiento seguido.

Concluyen que si dos números tienen el mismo dígito en el lugar de las centenas, para saber cuál es mayor o menor, basta comparar los dígitos que ocupan el lugar de las decenas.

Guiados por el docente analizan las actividades realizadas y concluyen que para saber sí un número de tres cifras es mayor que otro, hay que comparar primero los dígitos que se ubican en el lugar de las centenas (es mayor, el que tiene el dígito mayor); si estos son iguales, hay que comparar los dígitos que ocupan el lugar de las decenas (es mayor el que tiene el dígito mayor) y si estos son iguales, hay que comparar los dígitos que ocupan el lugar de las unidades (es mayor el que tiene el dígito mayor).

Se miden y pesan y anotan en su cuaderno: la fecha en la que hicieron la medición, los datos de su estatura, medida en $\mathrm{cm}$ y su peso, medido en $\mathrm{Kg}$.

Comparan sus estaturas y pesos y determinan cuál es más alto y cuál es más pesado o más liviano.

Guiados por el docente, conversan acerca de la importancia de mantener estas relaciones y de qué es lo que se puede hacer en caso de estar muy lejos de ellas.

Orientados por el docente, miden la sombra que proyectan colocados siempre en un lugar determinado a distintas horas del día y registran en su cuaderno: la hora y el tamaño de la sombra medida en centímetros.

Conversan acerca de la información obtenida y sacan conclusiones respecto de cómo 
varía el tamaño de la sombra a medida que transcurre el día.

\section{Observaciones al docente}

En esta actividad se espera que los alumnos comprendan que el procedimiento utilizado para comparar números de dos cifras se pueden extender a este nuevo rango numérico. Al igual que en semestres anteriores, se parte de los conocimientos que los alumnos y alumnas ya manejan, tratándose de que puedan ser transferidos a nuevas situaciones.

Es conveniente que las mediciones que se incorporan en esta actividad les proporcione información relevante respecto de sí mismos y de su entorno.

Se recomienda aprovechar actividades como las propuestas para que los niños y niñas ejerciten la habilidad de expresar y comunicar sus ideas, conjeturas y conclusiones respecto al tema en estudio, reconociendo que el diálogo y el intercambio de ideas generan una buena convivencia y permite aproximarse a la verdad.

\section{Actividad Genérica 12 (página 170)}

Abordan problemas y los resuelven poniendo en juego lo que saben sobre los números. En cada caso, comparten los procedimientos empleados, los comparan y concluyen respecto de sus ventajas o desventajas relativas.

\section{Ejemplos de Actividades Interculturales Sugeridas}

Resuelven problemas tales como:

Con tarjetas con los números 0,1 y 2 forman números de tres cifras y los nombran en ambas lenguas. Comentan los resultados obtenidos por cada uno, en especial lo que respecta a la ubicación que puede tener el 0 y en qué situaciones se pueden utilizar números cuya primera cifra es cero y en cuáles no. Por ejemplo, en números para identificar objetos se puede emplear el cero al inicio: direcciones, números de boletas, etc. En el caso de utilizar números para cuantificar, el cero al comienzo no tiene sentido y comentan que antiguamente no tenían signos para los números y una voz especial para el cero, pero sí voces para indicar que no había objetos o se habían terminado.

¿Cuántos números hay entre 10 y 20? Nombrándolos en ambas lenguas, ¿hay la misma cantidad que entre 100 y 200?, ¿por qué? ¿Cuántos números pares hay entre 100 y 120?, ¿hay la misma cantidad de impares? y ¿los nombran en ambas lenguas? ¿Qué características tendrá que tener un número de tres cifras que sea mayor que 299 en ambos sistemas numéricos (occidental e indígena)?

\section{Observaciones al docente}

En la resolución de los problemas propuestos, es fundamental que los alumnos y alumnas tengan la posibilidad de utilizar estrategias propias, recurriendo a los conocimientos que han ido adquiriendo en torno a los números. 


\section{ANEXO 4.}

\section{Actividades de conteo $2^{\circ}$ básico (casos-tipos)}

Figura 4.1. Estudiante Araucanía con EIB

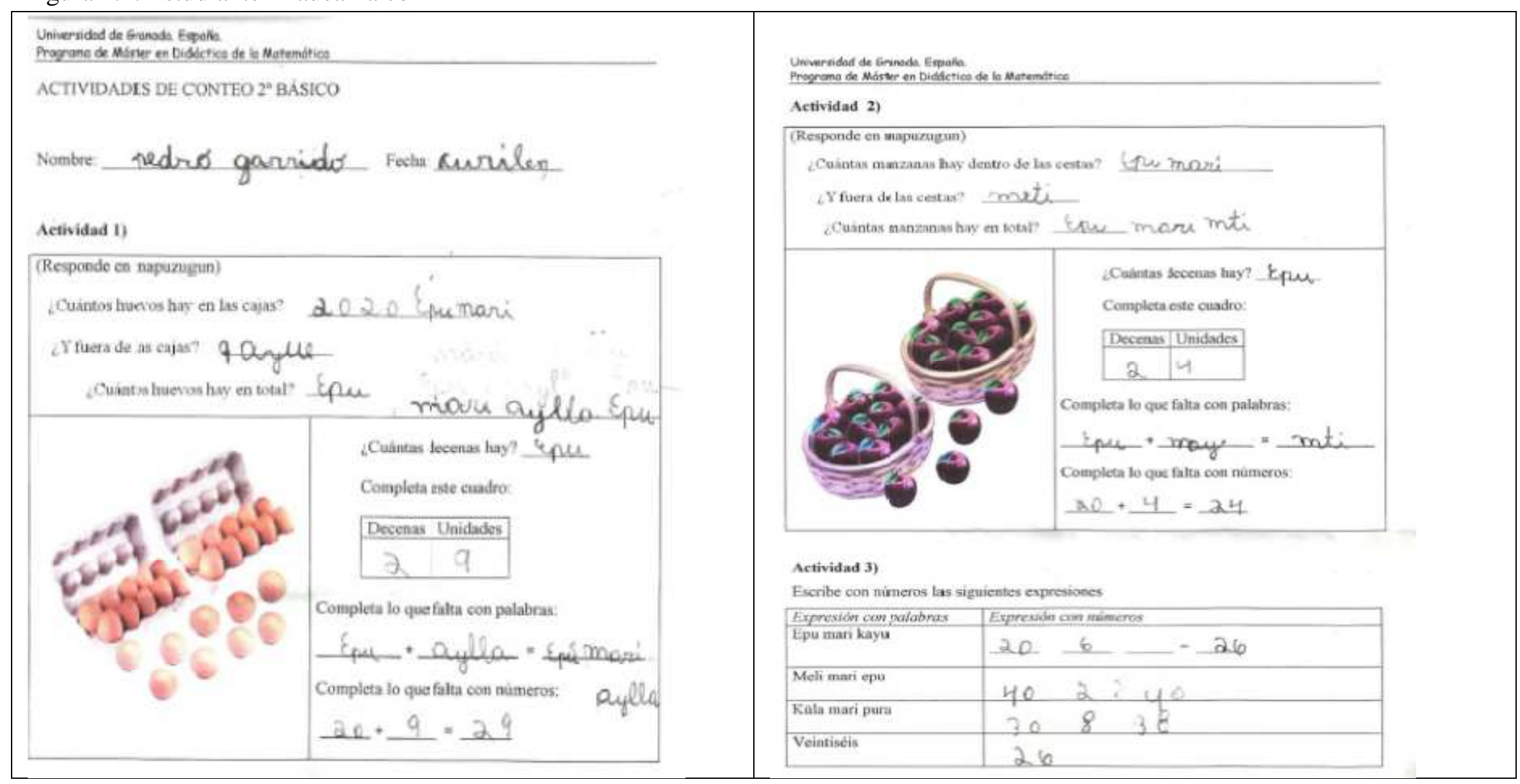


Figura 4.2. Estudiante Valparaíso sin EIB.

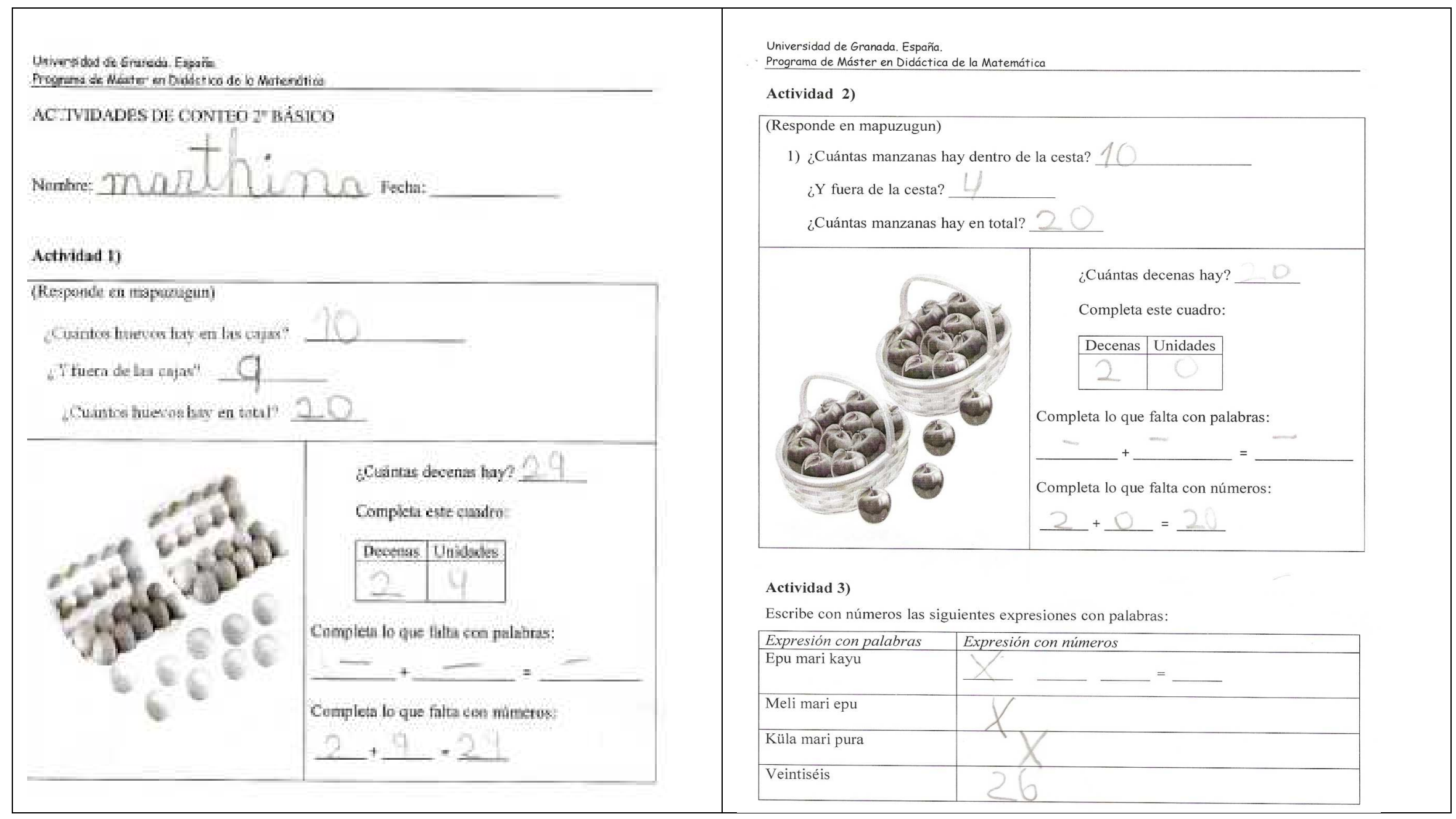




\section{ANEXO 5.}

\section{Encuesta a profesores de estudiantes mapuches.}

Figura 5.1. Profesor Valparaíso sin EIB

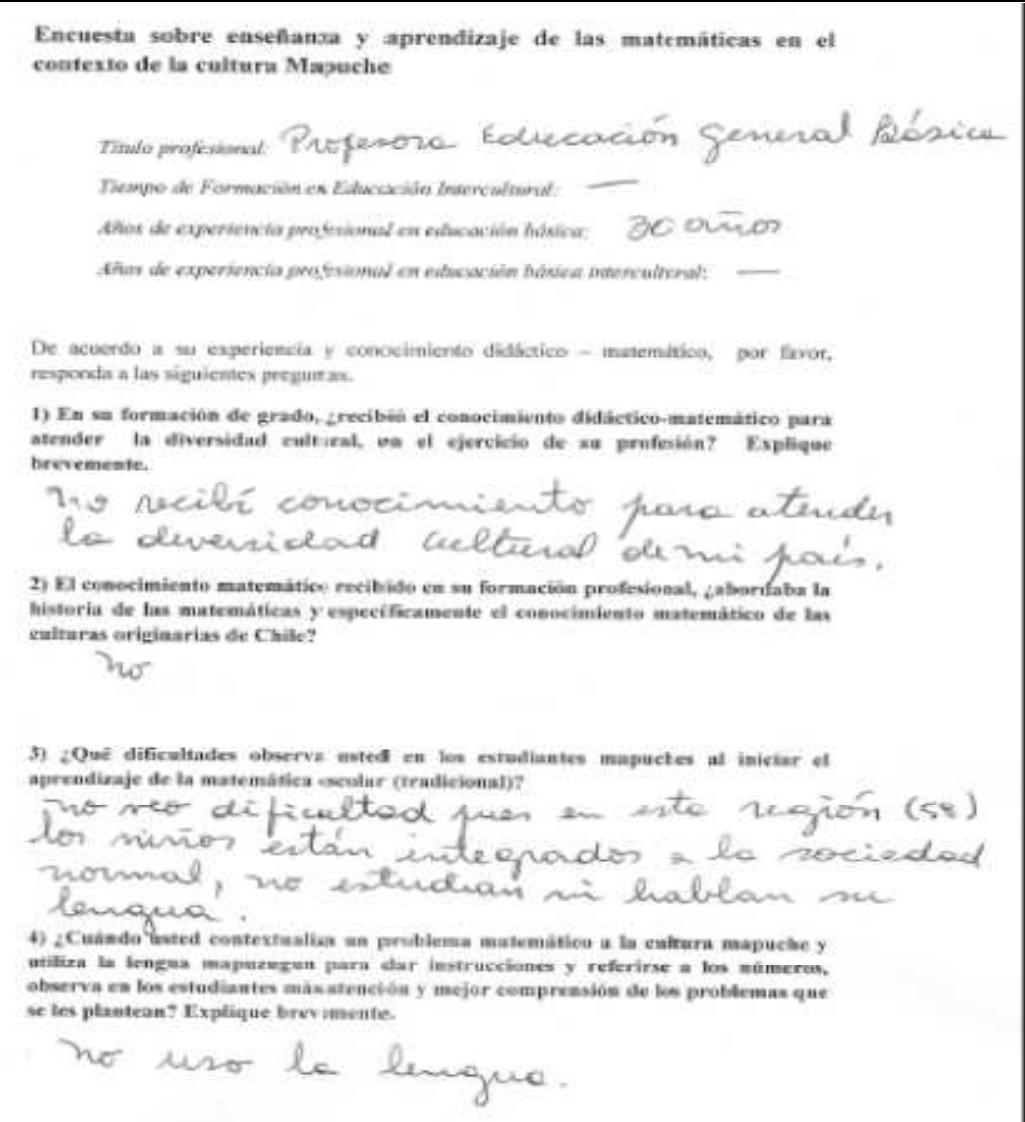

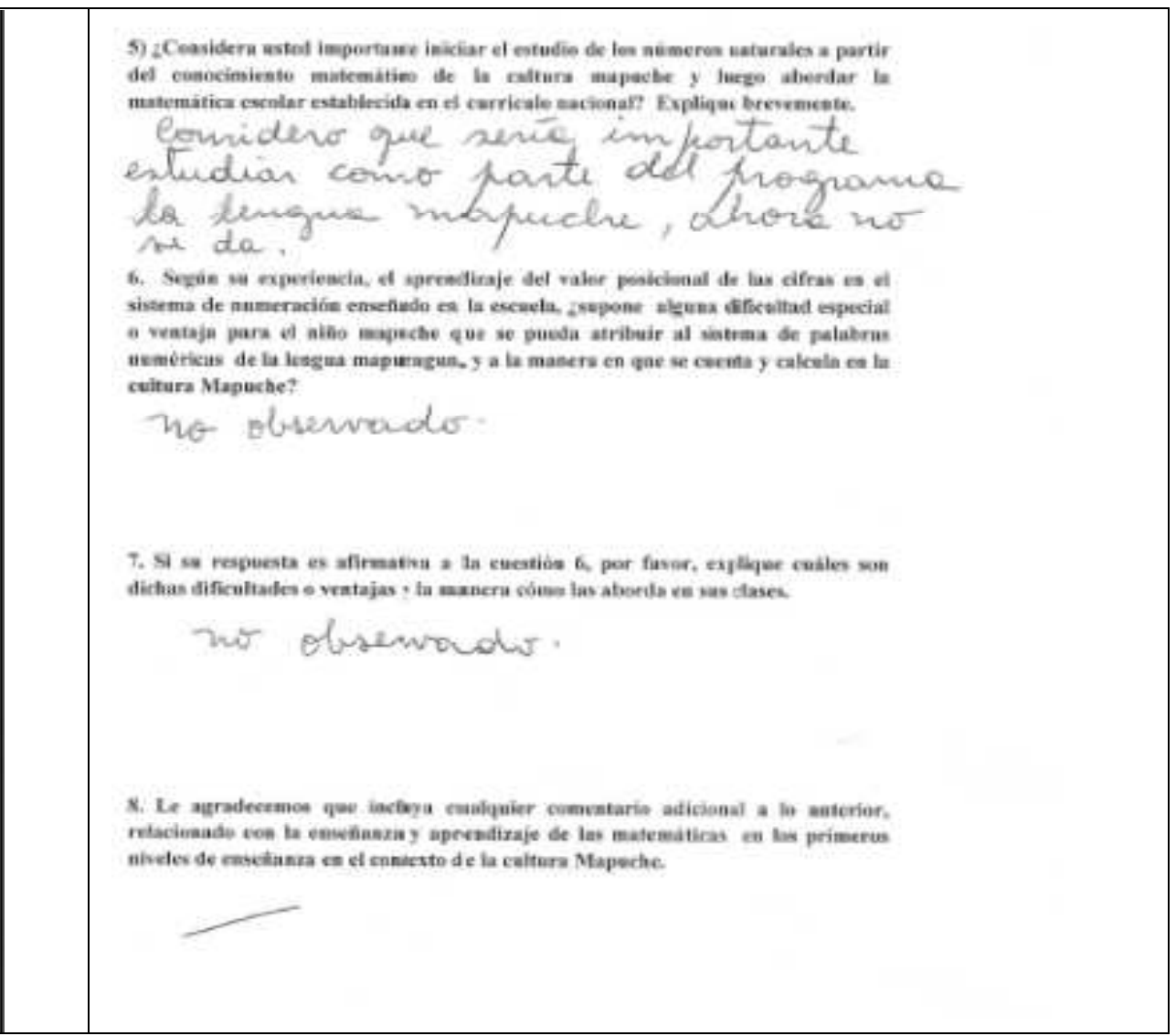


Figura 5.2. Profesor Araucanía con EIB

Encuesta sobre ensetianza $y$ aprendizaje de las matemíticas en el contexto de la cultura Mapucbe

Titulo preferional: Profecera de Educacion General Basica con Especialiaction en Edicaction Pntercainural

Tiempo de Fonnacioin en Educacion Invecularal 4 años

Linor de experiencia profecional en educacion bática: 9 añor

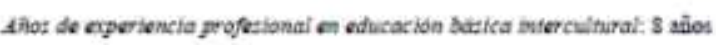

De acuerdo a su experiescia y conocimiento didictico - mareanitico, par favor. respenda a las siguientes preguntas

1) En su formacióe de grado, jrecibió el conocimiento didáctico-matemático para atender la diversidad caltural, en el ejercicio de su profesióe? Explique brevemente.

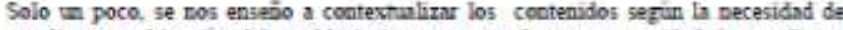
estudiante o abicacion del establecimeato, ya que ha mayc cartidad de estudiante mapuche se encueratan en las ronas nurales

2) El conocimiento matemitico recibido en se formación profecional, abordaba b bistoria de las matemaiticas y especificamente el cobocimiento matemitico de los culturas origisarias de Chile?

Aborda bistoria de mateminica pero des a culnurai orignesias en ch investipación a parte

3) ZQué dificultades observa wsted en los estudiantes mapaches al iniciar el sprendizaje de la matemitica escolar (tradicional)?

Caando la familin fomente el habla del mapurangm en la casa a los estudientes la

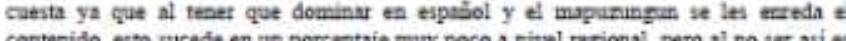

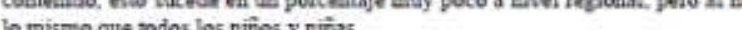

4. Cuindo wsted conterinaliza ma problema matemaitico a la caltura mapoche y uthiliza la lesgua maporagun para dar introcciobes y referise a los números,

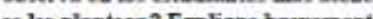

En mi esabtecimiento y en la mayoria no se habla mapurungua para explicar las clases, se hacen en espaciol. los estudiantes dominan solo un poco cuando son nuales pero los

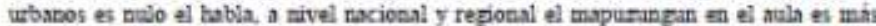
que rada bilingiliumo (traducir palabtrai) o ensebiar a los estudiantes a tener sentido de pertenencia de sa propia culnura

5) .Considera usted importante injicis el estodio de los aúmeros anturales a partir del conocimiento matemitico de la cultura mapache $y$ luego abordar la matemitica escolar establecida en el curriculo nacionaln Explique bretemente

Viendo la realidad a les eatablecieierton y la pertua del gobiemo en Chile es mejor abordar la matemitica escolur establecidn en el curriculo nacional y heap asocinth al

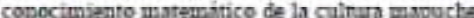

6. Segua sa expentencia, el aprebdizaje del valor posicional de las cifras ell el tistema de numeracion easenado en la escueb, jupoue alguba dificaltad especial o vestaja para el anio mapuche que 20 poeda atribeir al sitema de palabra:

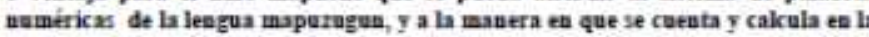
cultura Mapuche?

No hay dificalnd, to gae sirve es la relacion con base diez ya qua la mayoria de los

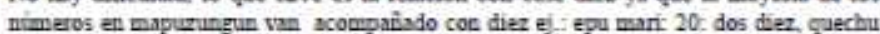
mari 50 . cinco diez

7. Si su respuesta es afirmativa a la coestión 6, por favor, explique cailes sou dichas dificultades o ventajas y la manera cómo las aborda en sus clases.

8. Le agradecemos que incluya cualqueier comentario adicional a lo anterior, relacionado con la enseinanza y aprendizaje de las matemiticas eb los primeros niveles de easeáanza ea el conterto de la coltora Mapache.

Puedo decir que las matemiticas mapache se veu cuando el profesor quiere contertualizar los contenidos o la escueh se encuestra iuserta en ubs comaoidad mapecter, ya que por corricelum oficial no se solicita hacer ete tincapie en th planes y programas. 